\title{
TEACHER BELIEFS, KNOWLEDGE, AND REPORTED PRACTICES REGARDING NUMERACY OUTCOMES IN THE SOLOMON ISLANDS
}

A thesis submitted in partial fulfilment of the requirements for the degree of Master of Education at the Victoria University of Wellington, New Zealand 2010

Prepared by

Adrian Alamu 
The low level of basic numeracy achievement in the Solomon Islands education system is a growing concern to key stakeholders. Apart from monitoring numeracy standards, no attempt has been made to explore how Solomon Islands teachers structure mathematics teaching and learning, or the quality and effectiveness of teaching and learning in schools. It has been widely recognised that teachers' beliefs, knowledge, and practices are major influences in teaching and learning mathematics in classroom situations. Therefore, the purpose of this study is to explore Solomon Islands primary school teachers' beliefs, knowledge, reported practices, and professional learning experiences that enhance numeracy outcomes. The review of literature thus focuses on teacher beliefs about mathematics, its teaching, and learning; teacher pedagogical content knowledge; and professional development. Sixteen mainly urban based primary school teachers were interviewed to explore teachers' beliefs, pedagogical content knowledge, and professional learning experiences.

A phenomenological approach to qualitative methodology was adopted to explore the phenomenon. A methodological triangulation of data collection was used involving a Belief Cards exercise and a semi-structured interview protocol. The combination of these methods helped to provide a coherent picture of teacher beliefs, knowledge, and practices. The results were analysed using interpretative phenomenological analysis.

The findings of the Belief Cards exercise showed that individual teachers held disparate and inconsistent views and beliefs about mathematics, its teaching, and learning. Although the majority of the teachers agreed with beliefs about the nature of mathematics as problem solving and favoured pupil-centred approaches, when it came to specific beliefs representing pedagogic strategies about teaching and learning of mathematics, teachers held differing views about linking mathematics to real life situations; mathematics as teacher-centred and transmitted, and pupils as passive listeners; and teachers' enthusiasm about doing mathematics. The study also 
indicates most study teachers displayed a combination of traditional-transmission and contemporary-constructivist beliefs and views about mathematics, its teaching, and its learning. Further findings based on the interview protocol included that almost 50 per cent of the teachers claimed to have insufficient knowledge about mathematical content and theoretical perspectives about learning, inadequate specific mathematics teaching resources, and 75 per cent claimed a lack of ongoing professional development support in mathematics. Some constructivist mathematical practices were reported; however, the teaching described by some teachers tended to reflect the traditional-transmission approach to teaching and learning of mathematics. The overall results showed a disparity between teacher beliefs and practices exists. 


\section{ACKNOWLEDGEMENTS}

I wish to acknowledge a number of people who have one way or the other have rendered support to the successful accomplishment of this thesis.

I am indebted to my primary and co supervisors, Dr. Robin Averill and Roger Harvey for their systematic supervision role, the invaluable advice and critical evaluations provided.

I also thank Ruth Davidson-Toumu'a (Learning Advisor, Pasifika) and Elizabeth O’Connor from the Student Learning Support Services, Victoria University of Wellington, for their services and support.

I would like to thank the nineteen participants (both pilot and main study) as well for their time, effort and discussions during interviews; not forgetting the headmasters/headmistresses and education secretaries in allowing their schools and teachers to participate.

I am grateful to the Solomon Islands Government through the Ministries of Education and Public Service in allowing me to undertake this study. Also to the New Zealand Government through the New Zealand Development Scholarships in granting me this opportunity, and the Victoria University of Wellington, Faculty of Education for my placement.

Last, I am thankful to my wife Pamela and younger son Adrian (Jnr) for their prayers and encouragement from a distance. I am equally grateful to my elder son Lindsay who has accompanied me for this study for his patience and understanding.

I dedicate this thesis to my dear mum, Joyce Alamu who had called to rest on the $30^{\text {th }}$ July, 2008 while undertaking this study. 
ABSTRACT

ACKNOWLEDGEMENTS iv

LIST OF TABLES, FIGURES, and BOXES viii

$\begin{array}{lc}\text { ABBREVIATIONS ix } & \text { ix }\end{array}$

GLOSSARY

$\begin{array}{lr}\text { CHAPTER 1: INTRODUCTION } & 1\end{array}$

1.1 Background context of the study 2

1.1.1 Geographical and demographical features 3

1.1.2 Education in Solomon Islands 4

1.1.3 Numeracy in Solomon Islands $\quad 7$

1.1.4 Primary teachers in Solomon Islands 11

$\begin{array}{lll}1.2 & \text { Rationale for the study } & 13\end{array}$

$\begin{array}{lll}1.3 & \text { Research questions } & 14\end{array}$

$\begin{array}{lll}1.4 & \text { Summary } & 15\end{array}$

CHAPTER 2: LITERATURE REVIEW 16

2.1 Teachers' beliefs 17

2.1.1 Relationships between beliefs and teaching and learning 19

2.2 Pedagogical content knowledge 24

2.2.1 Knowledge of teaching 25

Theoretical perspectives about learning 27

Melanesian perspectives about learning 30

2.3 Teachers’ professional development (PD) 34

2.4 Implications for Solomon Islands classroom practices 35

$\begin{array}{lll}2.5 & \text { Summary } & 38\end{array}$

CHAPTER 3: METHODOLOGY 39

3.1 The study approach 39

3.2 Research design 41

3.2.1 Ethical procedure 42

3.2.2 The interview protocol 42 
3.2.3 Preliminary stages: Informal visit, pre-trial interview, and the Pilot run

3.2.4 Selection of participants 45

3.2.5 Treatment of data collection procedure 48

3.3 Ensuring validity and reliability 50

$\begin{array}{lll}3.4 & \text { Summary } & 51\end{array}$

CHAPTER 4: FINDINGS

4.1 Interview data: Descriptive analysis 52

4.2 Thematic analysis $\quad 53$

4.2.1 Teacher beliefs 53

Teachers' feelings towards mathematics $\quad 59$

4.2.2 Teachers' practice 61

Teachers' primary role in teaching and learning mathematics 61

Monitoring pupils' learning progress 62

4.2.3 Teacher pedagogical content knowledge 63

Knowledge of content 63

Knowledge of curriculum $\quad 67$

Knowledge of teaching $\quad 70$

$\begin{array}{lll}\text { 4.2.4 Professional development (PD) } & 80\end{array}$

Teachers with some PD support $\quad 80$

Teachers without PD support 81

Professional support for mathematics teachers 82

$\begin{array}{lll}4.2 .5 & \text { Open question } & 83\end{array}$

$\begin{array}{lll}\text { 4.2.6 Summary } & 84\end{array}$

4.3 Interpretive analysis 86

$\begin{array}{llr}4.4 & \text { Summary } & 100\end{array}$

$\begin{array}{ll}\text { CHAPTER 5: CONCLUSION } & 101\end{array}$

5.1 Summary of the main findings 102

5.2 Limitations of the study 104

5.3 Implications 106

5.2.1 Implications for teachers 107

5.2.2 Implications for teacher education 108

5.2.3 Implications for Ministry of Education 109

5.4 Recommendations 111

5.5 Summary 112 
REFERENCES

APPENDICES

Appendix 1: Ethics Approval

Appendix 2: Research Permit

Appendix 3: Participants' Consent Letter

Appendix 4: Participants' Consent Form

Appendix 5: The Belief Cards

Appendix 6: Interview Protocol 


\section{LIST OF TABLES, FIGURES, AND BOXES}

\section{TABLES}

1.1 Year 6 National Numeracy baseline data

2.1 The three relationships of beliefs about mathematics, teaching, and learning 20

3.1 Participants' background information

4.1 Number of teachers who responded to each Belief Card

4.2 Teachers individual results of the Belief Cards statements

4.3 Teacher's primary role as reported by participants

\section{FIGURES}

1.1 Year 4 overall numeracy achievements

1.2 The overall mean level by strands for Honiara schools

3.1 The design framework

4.1 Types of PD experienced by teachers

\section{BOXES}

4.1 Teachers’ perceptions on pupils’ areas of difficulties 66

$\begin{array}{lll}4.2 & \text { Teachers' best lessons } & 71\end{array}$

$\begin{array}{lll}4.3 & \text { Reported teaching styles and strategies } & 74\end{array}$ 


\section{ABBREVIATIONS}

AISQ: $\quad$ Association of Independent School of Queensland

APS: $\quad$ Average-Performing Schools (defined for the purposes of this study, Section 3.2.4)

BELS: $\quad$ Basic Education for Life Skills

EFA: $\quad$ Education for All

ESIRP: $\quad$ Education Sector Investment and Reform Programme

HBJ: $\quad$ Harcourt Brace Jovanovich

HPS: $\quad$ High-Performing Schools (defined for the purposes of this study, Section 3.2.4)

IPA: $\quad$ Interpretative Phenomenological Analysis

Lc: $\quad$ Critical Level

LPS: $\quad$ Low-Performing Schools (defined for the purposes of this study, Section 3.2.4)

MDG: $\quad$ Millennium Development Goals

MEHRD: Ministry of Education and Human Resources Development

NCTM: National Council of Teachers of Mathematics

PCK: $\quad$ Pedagogical Content Knowledge

PD: $\quad$ Professional Development

PIC: $\quad$ Pacific Island Countries

PILL: $\quad$ Pacific Islands Literacy Levels

QCEC: Queensland Catholic Education Commission

S.I: $\quad$ Solomon Islands

SISTA: Solomon Islands Standardised Test of Achievement

ZPD: $\quad$ Zone of Proximal Development 


\section{GLOSSARY}

Beliefs: The term 'beliefs' has no universal agreed definition in the education literature (Pajares, 1992). However, in this study 'beliefs' are taken to be part of knowledge and consistent with the definition used by Ajzen and Foshbein (1980):'beliefs’ will be interpreted as anything regarded as true by 'individuals'.

Solomon Islands Standardised Test of Achievement [SISTA] (SISTA 1 Report, 2006): The SISTA is a strategy for monitoring the standard of basic literacy and numeracy in the Solomon Islands. The SISTA numeracy analysis includes operations $(+,-, \mathrm{x}, \div)$, working with numbers, measurement, shape and space, time, graphs and money. The SISTA instrument is based on the key learning behavioral objectives of the Solomon Islands Mathematics syllabus at Years 4 and 6. It measures pupils' performance against five achievement levels: level 5 indicates a full/complete mastery of key learning behavioural objectives; level 0-1 is referred to as a critical level (Lc) and is exemplified by no attempts or pupils struggling with the outcomes. Level 3+ performances are deemed by the Ministry of Education as satisfactory or better.

Numeracy: The Solomon Islands have adopted a definition of 'numeracy' consistent with Withers (1992) definition which is the "confident, appropriate and accurate use of number and the language of mathematics for the wide variety of personal and public uses demanded by the society in which the user lives” (p. 13). This definition is featured in the official Solomon Islands Ministry of Education SISTA Report 1 (2006). 'Numeracy' is used interchangeably with 'mathematics' and in this study it is regarded as the concepts, skills, and processes in mathematics (Willis, 1998).

Pedagogical Content Knowledge (PCK): The definition and framework adopted in this study is based on that of An, Kulm and Wu (2004). That is, PCK is about effective teaching: having knowledge about the subject matter (content), the curriculum (selection/choice of teaching materials), and teaching (knowing your pupils). In general the term refers to knowing the teaching content and knowing how to deliver it. 


\section{CHAPTER 1 - INTRODUCTION}

Education is what remains after one has forgotten everything he learned in school ${ }^{1}$

- Albert Einstein

Puamau (2007, p. xiv) states:

A literate and numerate society with citizens well versed in the ins and outs of their indigenous/local cultures and languages, as well as the required life skills to function effectively, at home, at school, in the community, nationally and in a rapidly globalising world-- this is the ideal picture that Pacific governments and community leaders envisage, for their country. And yet, sadly, the reality indicates that levels of literacy and numeracy are under threat in Pacific Island Countries (PICs), contributing to significant numbers of Pacific students underachieving in English and mathematics.

The above quote reflects the current situation of low basic numeracy achievement in the Solomon Islands. Many Solomon Islanders believe that the country is faced with a literacy and numeracy crisis (Marau, 2007). Past and current numeracy results have raised concerns about the quality and effectiveness of teaching and learning in Solomon Islands schools. The current Solomon Islands education sector reform (Ministry of Education and Human Resources Development [MEHRD], 2007) is designed to address the deficiencies of pupils’ numeracy standards. Despite these concerns, no attempt has yet been made to investigate or explore the issue of numeracy teaching and learning in the Solomon Islands. Therefore this study is aimed at exploring Solomon Islands primary school teachers' beliefs, knowledge, practices, and professional learning experiences that they believe enhance numeracy outcomes. It is hoped that exploring these dimensions with teachers in the Solomon Islands will provide valuable information for future improvement of

\footnotetext{
${ }^{1}$ Retrieved October 16, 2008, from http://rescomp.stanford.edu/ cheshire/EinsteinQuotes.html
} 
education policies and planning for appropriate professional development to enhance numeracy outcomes.

This introductory chapter describes: the background context of the study; the rationale for undertaking the study; the research questions; and gives an overview of the remaining thesis chapters.

\subsection{Background context of the study}

The quality of life and learning of our future generation lies with our current pupils (Phillips, 2007). We live in a world where educational accountability from teachers and school administrators is high, putting more pressure on pupils to perform well (Cummings, 2005). The Dakar Education for All (EFA) goals and the Millennium Development Goals (MDG) (EFA Global Monitoring Report, 2006) related to education have put pressure on many developing countries to develop educational intervention strategies to meet the targets and goals. The third key dimension of the EFA target is improvement in learning achievement (Vine \& Ordonez, 2000). In order to achieve the EFA goal of 50 per cent improvement in adult literacy by 2015 (EFA Global Monitoring Report, 2006), member countries are challenged to put a range of interventions in place. It is to be hoped that improving primary numeracy will later impact on adult numeracy proficiency.

My interest in numeracy began as an assessment education officer in the MEHRD and as part of the team that developed the Solomon Islands Standardised Test of Achievement (SISTA) instrument and administered the tests. The SISTA outcomes generated discussion amongst Solomon Islands educators about the quality and effectiveness of teaching and 
learning in schools. Monitoring alone will not improve pupils’ numeracy achievement, unless appropriate remedial strategies are also in place. My keen interest is that the MEHRD addresses issues identified by the tests by identifying ways to improve pupils' numeracy achievement. I believe pupils enter the classroom with differing abilities and prior knowledge, and monitoring their learning progress is crucial for teachers, and at the same time can be a daunting task if not managed well.

This section provides a brief overview of: Solomon Islands (S.I) geographical and demographical features; education in Solomon Islands; numeracy in Solomon Islands; and Solomon Islands primary teachers.

\subsubsection{Geographical and demographical features}

The Solomon Islands is the second largest country in the Pacific rim in terms of area, with a current population of over half a million (est., from 1999 Census, Solomon Islands National Statistics Office, 2006). It lies close to the eastern part of Papua New Guinea and northeast Australia, close to the equatorial zone, and is characterised by a warm and humid climate. The Solomon Islands is an archipelago of about one thousand islands (six main islands) divided into nine provinces with overall more than a hundred different indigenous languages. English is the stated official language of instruction at school, although the Pidgin (lingua franca) is the commonly used medium of communication.

The Solomon Islands is a multicultural, multiethnic society that gained independence on

the $7^{\text {th }}$ July 1978 from the British Protectorate. Melanesian is the predominant race (over 90 per cent of the population), with less than five per cent being Polynesians, 
Micronesians, and Others (Asians, Europeans, and other races). About 80 per cent of the population live in rural areas or villages and engage in a subsistence style of living.

\subsubsection{Education in Solomon Islands}

This section describes events, issues, concerns, and constraints that have shaped education in the Solomon Islands.

After the advent of colonisation and the Christian Missions, the early formal education system espoused a 'Eurocentric curriculum' that focused on European/Western content, resources, language, perspectives, and development. The education system is managed and administered under the Education Act of 1978 (Education Act, 1978, S.I).

Because of the geographical spread of schools in the provinces (which affect communication and transportation), much of the implementation and administration of the education system is delegated to the Provincial and Private Education Authorities (Sikua, 2002). Schools operate under different Education Authorities (ownership \& management), namely, the private schools (churches, individuals or Associations) and public schools (Town Council \& Provinces). Although operated by different authorities, the government provides support in terms of teachers' salaries and school grants.

During the late 1990s, stakeholders began to question the outcomes of the Solomon Islands education system. Stakeholders have partly blamed the Solomon Islands Education system for the failure to produce young people with a purpose in life and a commitment to their own society (Treadaway, 2003). For example, the public at large, including parents and 
teachers, have grave concerns about the current education system which is heavily driven by high-stakes selective examinations (Elley, 2001). There are four national external examinations (exit points) that filter pupils as they pass through the school system, since there are not enough secondary places available for all. On average only 12 per cent of the cohort who enter primary school reach Year 12 (National Examination \& Standards Unit, 2007).

The Solomon Islands Education System continues to be confronted with specific and broad issues such as: the population growth rate (2.8 per cent per annum) will require more space in schools; current access to schools is less than 100 per cent for primary aged children; insufficient access to teaching and learning facilities; lack of professional development programmes for teachers; services to schools are costly and inefficient because of isolation and distance; inadequate access to schools for secondary age students; school leavers possess very few life long skills (e.g., hands on skills or communication skills), and little focus on vocational education exists (MEHRD, 2007). The education system since independence has so far gradually undergone very small changes to take into account the aspirations and needs of the country.

Because of these issues, the Solomon Islands government felt a wider sector education reform that will be driven by all stakeholders input. This has led to a current education reform called the ‘Education Sector Investment and Reform Programme’ (ESIRP) which started in 2003 through a Sector Wide Approach. The ESIRP is linked to regional and international development strategies such as EFA in Dakar 2000, the Millennium Development Goal (MDG) for 2015, and the Pacific Education Forum (MEHRD, 2007). Thus the ESRIP has three main long-term strategic goals: 
1) to provide equitable access to quality basic education for all children,

2) to provide access to community, technical, vocational, and tertiary education that will meet individual, regional and national needs for a knowledgeable, skilled, competent and complete people, and

3) to manage resources in an efficient, effective and transparent manner.

(MEHRD, 2007, p. 11)

The ESRIP has identified key outcomes regarding access and equity, quality, and management. One notable achievement in terms of access is the expansion of basic education $^{2}$ for all children from six year olds to 15 year olds as it is envisaged that by 2015 there should be universal access to basic education. To further cement this move, the government has introduced a policy of free basic education by eliminating school fees (known to be one of the key factors affecting access to education).

The quality aspects of education identified by ESRIP include having high quality learning achievement through curriculum reform, sound literacy and numeracy standards, a skilled and qualified teaching force, and professional development of teachers (MEHRD, 2007). The current curriculum reform under the ESRIP faces challenges in terms of content, resources, capacity, and approach. It is also challenged to reflect the 'Re-thinking Education Initiatives’ in the Pacific ${ }^{3}$ (Sanga \& Thaman, 2009), that states that curriculum embedded with sound principles of cultural values and indigenous processes and frameworks are crucial for a better society in the midst of multiethnic groupings.

\footnotetext{
${ }^{2}$ (ie., from preparatory year/age six to Year 9/Form 3)

${ }^{3}$ An initiative born out of a meeting held in 2001, University of the South Pacific (USP) by Pacific Island researchers \& scholars about addressing educational crisis in the PICs.
} 
However, very little is known about quality teaching and learning that enhances numeracy outcomes at the primary school level in the Solomon Islands. The Solomon Islands Ministry of Education has set a minimum standard for Year 4 pupils of greater than 60 per cent for numeracy in SISTA (Catherwood, 2007). The minimum standard has not yet been met (Section 1.1.3).

\subsubsection{Numeracy in Solomon Islands}

Numeracy teaching and learning in the Solomon Islands is based on the national primary mathematics curriculum, called the $\mathrm{Nguzu}^{\mathrm{Nguzu} \text { mathematics curriculum }}{ }^{4}$ (Ministry of Education, S.I, 2001) The Nguzu Nguzu curriculum came into effect in the late 1990s and replaced the Harcourt Brace Jovanovich (HBJ) series of texts (Barry, Booker, Perry, \& Siemon, n.d.) from Australia with local materials. A national baseline data for numeracy achievement was established since then, based on the Nguzu Nguzu mathematics primary curriculum.

The Curriculum Development Centre has written and produced teaching aids (such as cards, charts, posters or games) that include Nguzu Nguzu Mathematics Teacher's Guide and a Pupil’s activity book for schools. The Nguzu Nguzu Mathematics Teacher’s Guides have highlighted the primary importance of specific mathematics and teaching methods that teachers can adopt. It also highlights the importance of using teaching aids and local materials in order to teach the curriculum successfully. Some of the primary aims of mathematics education in the Solomon Islands include: experience mathematics in real situations through practical activities or games; contextualise mathematics; and encourage problem solving, exploration, investigation, and discussion about mathematical activities

\footnotetext{
${ }^{4}$ The Nguzu Nguzu curriculum quoted once here and subsequently used frequently.
} 
(Curriculum Development Centre, 2005). The Nguzu Nguzu Mathematics Teacher’s Guide emphasises using both teacher-led activities and child-centred practical activities. For example, the Nguzu Nguzu Teacher's Guide has highlighted the advantages of using group work, for it encourages both independent learning and allowing pupils to talk to each other. The Guide provides information which allows teachers to read and understand the reasons for using such approaches. There have been Nguzu Nguzu in-service trainings for primary teachers between 1997 and 2006, organised by the Curriculum Development Centre (L. Puia, personal communication, October 16, 2009) ${ }^{5}$.

The SISTA, a national instrument, is used to monitor Years 4 and 6 pupils' numeracy achievement. It is based on the Nguzu Nguzu mathematics curriculum. The SISTA was first administered in years 2004-05 for Year 4 and 2005-06 for Year 6. The development of the SISTA was in response to the termination of the Basic Education for Life Skills (BELS) pilot project in 1998, and the lack of continuation of the Pacific Islands Literacy Levels (PILL) tests for Basic English literacy and numeracy skills (SISTA 1 Report, 2006).

As a yardstick of achievement, the SISTA results revealed significantly varying levels of attainment at Years 4 and 6. Almost half of the pupils were at a 'critical level' (Lc) or 'at risk’ in mastering basic numeracy skills (Figure 1.1).

\footnotetext{
${ }^{5}$ Linda Puia, current Director acting, Curriculum Development Centre, MEHRD, S.I.
} 


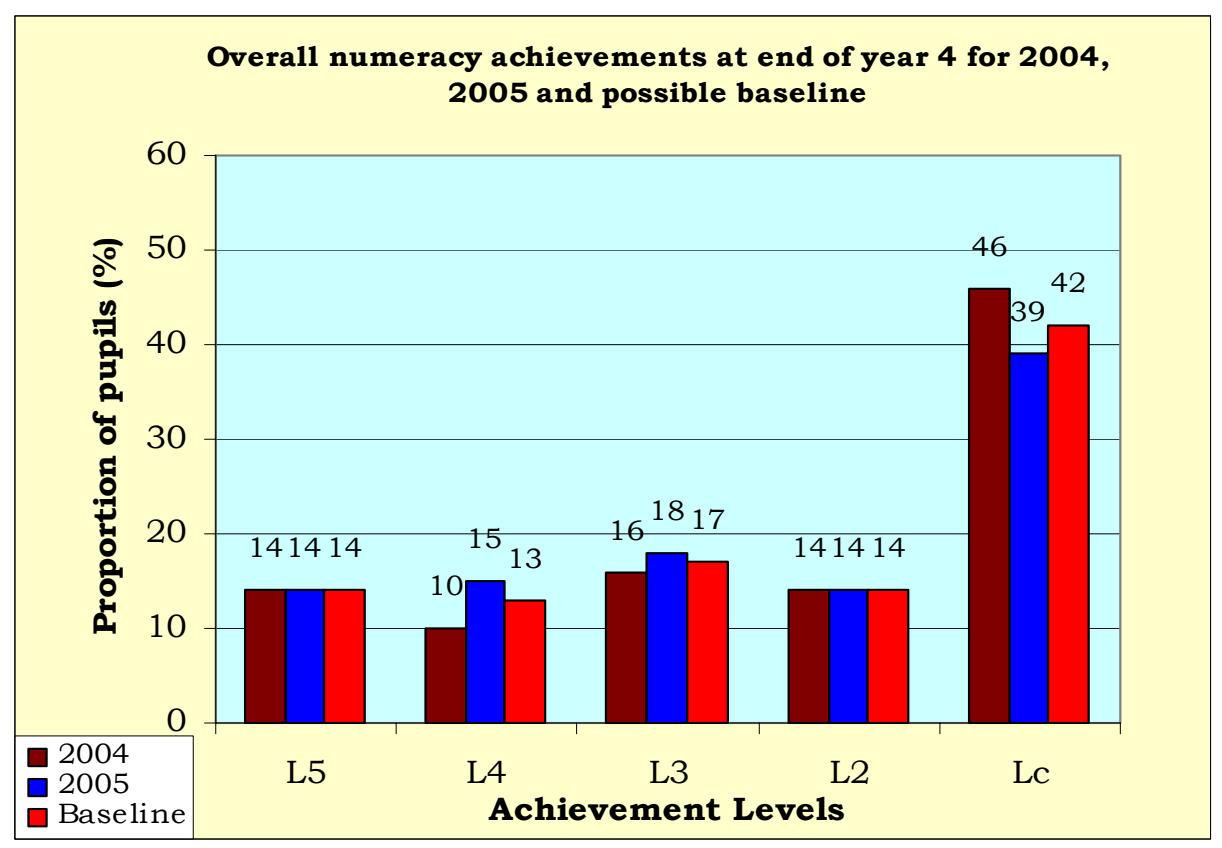

Figure 1.1: Year 4 overall numeracy achievements The SISTA 1 Report (2006, Figure 2, p. 2) ${ }^{6}$.

Note: Baseline data was gathered to allow monitoring changes to levels of numeracy over time (SISTA 1 Report, 2006).

One in every three pupils achieved below the expected level for Year 4, which means they are still struggling to achieve the intended learning outcomes at Year 4 (SISTA 1 Report, 2006).

At Year 6, there is a greater proportion of pupils still at the critical level, with one in every two pupils underachieving in relation to the MEHRD goals (Table 1.1).

\footnotetext{
${ }^{6}$ Permission is granted for the use of SISTA results as background information from the Permanent Secretary, MEHRD.
} 
Table 1.1: Year 6 National Numeracy baseline data

\begin{tabular}{|c|l|}
\hline Achievement level & Baselines (\%) \\
\hline L5 & 12 \\
\hline L4 & 15 \\
\hline L3 & 13 \\
\hline L2 & 12 \\
\hline L3+ & $\mathbf{4 1}$ \\
\hline Lc & $\mathbf{4 7}$ \\
\hline
\end{tabular}

The SISTA 2 Report (2007, Table 9, p. 5)

Across mathematics, there are different levels of achievement. For example, the overall SISTA 1 mean level of achievement by strand for Honiara schools (Figure 1.2) shows basic arithmetic operations have higher mean level than the other topics. In other words, schools or pupils performed better in addition, subtraction, division, and multiplication, compared with strands such as measurement or fractions.

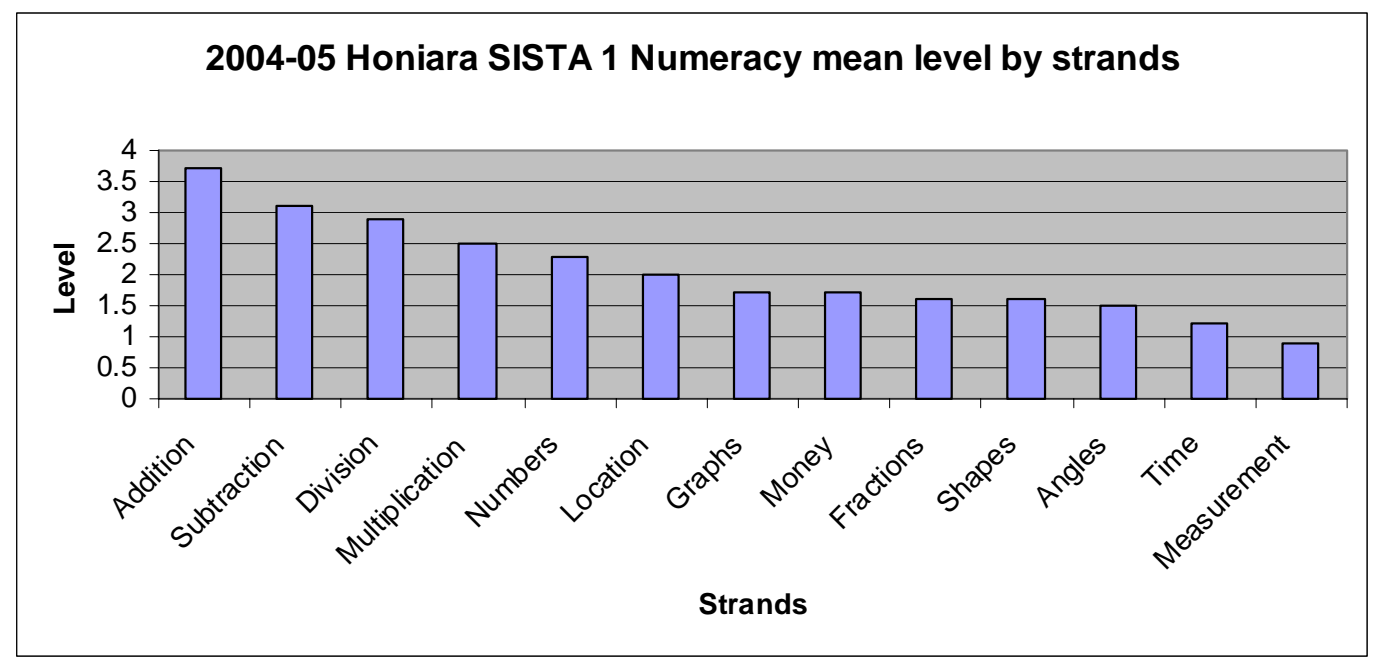

Figure 1.2: The overall mean level by strands for Honiara schools.

The SISTA 1 and 2 reports also revealed similar trends across provinces (Fig. 1.2).

The data gained from standardised testing has created challenges regarding what teachers and education officials should do to improve the situation. While it is imperative to 
continue monitoring educational standards, it is equally important to utilise available data to investigate achievement gaps. In order to facilitate teachers’ work and pupils’ numeracy outcomes, policy (decision making) is needed. Such policy creation and implementation requires quality evidence-based information.

While developed countries like the United Kingdom, Australia, and New Zealand have developed national numeracy strategies; most developing Pacific Island Countries (PIC) have yet to do so. The Solomon Islands has less than five years before 2015 (The EFA target date) and is still undecided on how best to improve pupils’ numeracy skills.

\subsubsection{Primary teachers in Solomon Islands}

Teaching in the Solomon Islands, although seen as a noble profession, provides poor salary and conditions for teachers compared to developed countries. The unfavourable conditions are not attractive for qualified and experienced teachers (Malasa, 2007). Primary teaching is one of the lowest paid jobs in the country. In public schools, on average primary teachers earn SB500 per fortnight (equivalent to NZ\$100). A primary teacher is expected to teach all subjects. Most urban schools experience overcrowding. Other issues confronting primary education include: poor teacher retention; low qualifications (e.g., certificate level); high numbers of untrained teachers (those without any formal qualification $^{7}$, ghost teachers (those who are paid but do not teach); and lack of ongoing professional learning and teacher development activities.

\footnotetext{
${ }^{7} 67 \%$ of primary teachers are regarded as qualified (Solomon Islands Government, MEHRD, 2005)
} 
One of the policy issues regarding teachers in the Education Strategic Framework 2007 2015 (MEHRD, 2007) is:

How the Solomon Islands can secure an adequate supply of well trained and qualified teachers to meet the educational needs of a rapidly expanding school population. It is also an issue whether current national teacher development plans will deliver the required number of teachers of appropriate quality, and whether existing teachers have access to appropriate professional development. (p. 38)

The MEHRD (2007) policy signals two important aspects: teacher quality and access to professional development. Teacher quality is related to teacher effectiveness and to ongoing professional development, which further supports effective teaching and learning. In general, the stakeholders in the Solomon Islands often question how effective teachers are in instruction delivery, and how they know whether or not their pupils are achieving the expected learning outcomes. Effective delivery also encompasses many other factors including effective use of learning materials and being able to improvise in a learning environment with few resources. It is against this background that teachers were selected as the subjects of this study, in order to gather their reflections on their beliefs, knowledge, and practices regarding their role in numeracy learning.

Professional development in the Solomon Islands context is still a remote concept to a certain extent. The in-service training currently experienced by Solomon Islands primary school teachers is when they undergo long term training for qualifications and the Nguzu Nguzu induction training workshops (Section 1.1.3). In-service training for higher qualifications allows teachers to move on to the secondary school level or seek other jobs once their qualification has been acquired. The terms and conditions for primary teaching are likely to be a contributing factor to such decision-making in light of the current 
financial difficulties. The other training provided for as mentioned (Section 1.1.3) is when the Nguzu Nguzu national curriculum came into effect. Other than the trainings described above, there is not very much known about primary teachers' mathematics PD experiences. Hence, one of the aims of this study is to explore teachers' beliefs about PD.

\subsection{Rationale for the study}

The study is based on the following factors. First, it is a policy issue within the Solomon Islands Ministry of Education's long term $\operatorname{plan}^{8}$ (MEHRD, 2007) to determine "how best to address the weaknesses in standards ... of numeracy as revealed in the results of the SISTA” (MEHRD, 2007, p. 30). The SISTA results have indicated in general where the weaknesses and strengths are. However, the results alone cannot determine how the results came to be the way they are. At this stage, very little has been done to ascertain strategies to address this policy issue. Secondly, the significant number of untrained teachers in the primary sector, coupled with a lack of proper and effective professional learning programs is a threat to fulfilling the policy goal of having "well trained and qualified teachers" and “have access to appropriate professional development” (MEHRD, 2007, p. 38). Thirdly, there is little information regarding how teachers in the Solomon Islands structure their numeracy teaching.

\footnotetext{
${ }^{8}$ The long term plan is called the 'Education Strategic Framework 2007-2015 (ESP), under the ESRIP.
} 
The results of this study are planned to begin to inform strategies to ascertain how best to:

- address weaknesses in current numeracy teaching in the Solomon Islands,

- $\quad$ work towards professional learning programmes to better equip Solomon Islands primary mathematics teachers to teach numeracy, and to

- $\quad$ inform the literature on numeracy teaching in the Solomon Islands.

\subsection{Research questions}

The study explores: 1) teachers’ beliefs about mathematics, its teaching, and learning, 2) teachers' knowledge and practices through investigating teachers' pedagogical content knowledge (content, curriculum and teaching, and reported practices) and 3) teachers' experiences of numeracy/mathematics professional development.

The primary question is:

What are teachers' beliefs, knowledge and practices regarding enhancing basic numeracy outcomes in the Solomon Islands?

The sub questions:

1) What beliefs do teachers hold about the nature of mathematics, its teaching and its learning?

2) What are teachers' beliefs about their pedagogical content knowledge and how it links to numeracy outcomes?

3) To what extent have teachers experienced numeracy professional learning and development? And what are teachers' views on professional development in numeracy teaching? 


\subsection{Summary}

This study is timely and appropriate with regards to the SISTA developments, the ongoing education sector reform, and the direction in relation to education policy and numeracy standards. The study will both inform local practice and add a valuable dimension to international literature regarding teacher beliefs and practices, and that of teachers in a developing nation.

Chapter 2 reviews relevant literature important to provide a theoretical basis for the study. Chapter 3 presents the methodology and the design processes used. The results, findings, and discussion are presented in Chapter 4 and the conclusions are outlined in Chapter 5. 


\section{CHAPTER 2 - LITERATURE REVIEW}

Not only has the world changed; the students have changed, and our philosophical questions and answers must reflect these changes - $\quad$ Wink \& Putney, 2002, p. 9

Reviewing the literature is important as it shows how new research relates to the field of study and complements what others have contributed (Anderson \& Arsenault, 2002). This chapter describes literature relevant to the study. The following broad elements of literature, derived from the research questions, include: teacher beliefs, pedagogical content knowledge, and professional development experiences. These elements provide a backdrop to frame the study findings (Chapter 4).

Much of the literature described in this chapter is from developed countries as there are few empirical studies concerning teaching and learning of numeracy in the Solomon Islands and similar developing nations. Firstly, the review will examine the teachers' beliefs about mathematics; its teaching; and its learning. Secondly, the review discusses teacher pedagogical content knowledge including knowledge of teaching, theoretical perspectives about learning, and Melanesian perspectives about learning. Thirdly, literature regarding teacher professional development will be presented. Through an evaluation and synthesis of the literature, the implications for Solomon Islands classroom practices are then provided and are followed by a brief summary. 


\subsection{Teachers' beliefs}

Research into the affective domain of mathematics education is gaining in popularity (Boz, 2008). Exploring people’s beliefs qualitatively provides rich and valuable descriptions of the realities of belief constructs. Most work about understanding teacher beliefs has been conducted in western countries involving western researchers; however, lately there are cross-cultural studies comparing teacher beliefs across East/Western countries, for example, between China, Hong Kong and Australia, U.S.A (Cai, Perry, Wong, \& Wang, 2009). This study will add to the literature regarding teacher beliefs.

Teachers' beliefs are critical to any mathematics education reform (Cooney \& Shealy, 1997; Ernest, 1989) and affect teaching and learning (Ernest, 1989; Fang, 1996). There can be inconsistencies and disparities between beliefs and practices (e.g., Cooney, 1985; Ernest, 1989; Shield, 1999), and debate regarding the extent to which beliefs shape teachers’ practices (e.g., Barkatsas-Tasos \& Malone, 2005; Hoyles, 1992; Putnam, 1992) or classroom practices shape teachers’ beliefs (Barkatsas-Tasos \& Malone, 2005; Clarke, 1994, as cited in Nisbet \& Warren, 2000).

This section examines the nature of beliefs and belief systems, and synthesises the relationships that have been described between beliefs about the nature of mathematics, about mathematics teaching, and about mathematics learning.

Researchers have conceptualised beliefs in many ways. For example, beliefs are regarded as part of subjective or tacit knowledge linked to learning and teaching (Pehkonen \& Pietila, 2003), as a component of affect (McLeod, 1992, as cited in Pehkonen \& Pietila, 
2003) or conceptions (Thompson, 1992). Beliefs can be masked by attitudes, values, judgements, axioms, opinions, ideology, perceptions, conceptions, or perspectives (Pajares, 1992). The term beliefs has no commonly accepted or agreed definition in education (Pajares, 1992), (see Glossary, p. x).

There are a number of dimensions of belief systems (Green, 1971). Beswick’s (2006) study of secondary mathematics teachers' beliefs has highlighted three in particular: the notions of 'centrality’ (strength and connections to other beliefs), 'clustering' (i.e., beliefs held in isolation and in groups), and the 'basis on which they are held' (could be nonevidentially held). Centrally-held beliefs and non-evidentially held beliefs can be resistant to change, whereas evidentially-held beliefs can undergo change based on evidence (Beswick, 2006).

The distinction between beliefs and knowledge sometimes causes confusion. Some studies have made a distinction between beliefs and knowledge, whereas others broadly combine the two terms. Pajares (1992) points out, that "distinguishing knowledge from belief is a daunting undertaking” (p. 309). Ernest (1989) made a point that knowledge alone is insufficient to account for teachers' differences in practice, because two teachers may have similar knowledge but may have different belief orientations about teaching.

Teachers' beliefs and classroom practices can influence each other and are dynamic (Barkatsas-Tasos \& Malone, 2005; McDonough \& Clarke, 2003; Nickson, 2004; Nisbet \& Warren, 2000). A numeracy project based on detailed case studies of 18 teachers carried out in the United Kingdom found that highly effective numeracy teachers (based on pupils’ gain in numeracy) have a coherent set of beliefs and knowledge about their teaching 
(Askew, Brown, Rhodes, Wiliam, \& Johnson, 1997a). These beliefs are associated with the teachers' understanding of what being numerate requires, the relationship between teaching and pupils' learning, and the effectiveness of presentation and intervention strategies (Askew et al., 1997a).

Some explanation of the causes of disparity between beliefs and practices include effects of past experiences whether in schools, classroom practices, personal character, or teaching norms (Barkatsa-Tasos \& Malone, 2005; Raymond, 1997). Likewise, Ernest (1989) has highlighted two factors that can affect mathematical teaching practices: the social context and a teacher's level of thought. However, sometimes beliefs are strongly held and we often practise what we sometimes do not believe (Edward \& Mercer, 1987), and this often leads to a demonstrated resistance to change (Barkatsas-Tasos \& Malone, 2005; Beswick, 2006; Rokeach, 1968, as cited in Pajares, 1992).

\subsubsection{Relationships between beliefs and teaching and learning}

Cai et al. (2009) state that “a teacher's conception of the nature of mathematics can be viewed as that teacher's conscious or subconscious beliefs, concepts, meanings, rules, mental images, and preferences” (p. 3). Since this study first explores teachers' beliefs about mathematics, its teaching and learning, relevant theoretical constructs were used based on Ernest’s (1989) conceptions about mathematics, Barkatsas-Tasos and Malone’s (2005) belief orientations about mathematics, and Kuhs and Ball's (1986) views on teaching mathematics. These theoretical constructs (belief orientations) have been selected because of their theoretical relationships and connections to practices, shown by studies such as Beswick (2005) and Cai et al. (2009). It is assumed that Solomon Islands primary 
school teachers will exhibit characteristics that reflect various positions on these belief constructs about mathematics, its teaching, and learning.

Ernest's (1989) conceptions about mathematics, its teaching, and learning are shown in Table 2.1 below. It shows the characteristics of these relationships, for example, going down the columns shows belief categories or levels which can be regarded as describing sections of belief continua, and each of these levels consistently reflects belief characteristics indicated across the table.

Table 2.1: The three relationships of beliefs about mathematics, teaching, and learning (Ernest, 1989)

\begin{tabular}{|c|c|c|}
\hline $\begin{array}{l}\text { Beliefs about the nature } \\
\text { of mathematics }\end{array}$ & $\begin{array}{l}\text { Beliefs about mathematics } \\
\text { teaching }\end{array}$ & Beliefs about mathematics learning \\
\hline i) Instrumentalist view & i) instructor model & $\begin{array}{l}\text { i) skill mastery, passive reception } \\
\text { of knowledge }\end{array}$ \\
\hline ii) Platonist view & ii) explainer model & $\begin{array}{l}\text { ii) active construction of } \\
\text { understanding }\end{array}$ \\
\hline iii) Problem-solving view & iii) facilitator model & $\begin{array}{l}\text { iii) autonomous exploration of } \\
\text { own interests }\end{array}$ \\
\hline
\end{tabular}

In terms of beliefs about the nature of mathematics, Ernest (1989) describes three conceptions: an Instrumentalist view, a Platonist view, and the Problem solving view. In terms of beliefs about mathematics teaching, Ernest (1989) offers three models: the instructor model based on mastery of skills and facts; the explainer model based on the conceptual understanding; and the facilitator model as problem solving. In terms of beliefs about mathematics learning, Ernest (1989) explains that the mastery of skills and passive reception corresponds to instrumentalist view of mathematics and the instructor model of teaching mathematics. The active construction of understanding, corresponds to the Platonist view about mathematics and the explainer model of teaching. The autonomous 
exploration reflects problem-solving view of mathematics and the facilitator model of teaching. Teachers are believed to have one or combinations of these belief orientations.

Similar relationship categories to those in Table 2.1 were used in Beswick's (2005) study of 25 secondary mathematics teachers in the Australian State of Tasmania. Beswick (2005) used a belief survey of 26 belief statements. She found that majority of the participant teachers agreed on the belief statements consistent with problem solving and pupil-centred views of mathematics teaching and learning. However, although the majority of the teacherparticipants held problem solving and pupil-centred beliefs, many were unsure about related teaching strategies and implementation. The inconsistencies between teachers' views and apparent knowledge may due to the teachers' beliefs about teaching and learning (Green, 1971), and effects of aspects of the teaching context on their beliefs and practices (Beswick, 2005).

Similarly, Barkatsas-Tasos and Malone (2005) discuss beliefs about the nature of mathematics as a 'traditional-transmission orientation' and a 'contemporary-constructivist orientation' or 'child-centredness' view. Teaching of mathematics can be classified as a transmission approach and a constructivist approach (Burton, 1993). It can be further classified into four models of teaching mathematics as: content-focused (emphasis on performance), content-focused (emphasis on understanding), classroom-focused (focus on content using classroom tasks/activities), and learner-focused (focus on individual's construction of knowledge) (Kuhs \& Ball, 1986). 
Basically, the distinction is between traditional models of understanding mathematics and constructivist views or the inquiry model for learning mathematics, although different terms are used by different authors. Those with traditional approaches view mathematics a bag of tools for accumulation of basic knowledge, rules, and facts (Ernest, 1989), whereas constructivists view mathematics as making connections, meanings, interpretations and applications (Bartatsas-Tasos \& Malone, 2005), and value learning by discovery (Askew, Brown, Rhodes, Wiliam, \& Johnson, 1997b).

Those with conventional beliefs about mathematics view teachers as transmitters of static knowledge, rules, or right answers (Stipek, Givvin, Salmon, \& MacGyvers, 2001). Walls’s (2003) longitudinal case study research into sociomathematics in the middle primary years in New Zealand found four traditional teaching and learning approaches in which learners were regarded as passive rather than active participants:

- emphasis of speed in mathematics teaching and learning;

- identification and differentiation based on socially constructed perceptions of mathematical 'ability';

- establishment of 'doing maths' as solo written work;

- presentation of mathematics as consisting of 'correct' and non-negotiable facts and procedures. (p. iii)

Walls (2003) found that these practices negatively affected pupils through alienation, marginalisation, and impoverished learning. She concluded that, in order to realise the full potential of a learner, the traditional views of teaching and learning of mathematics must be changed. Matang's (1998) research into the role of ethnomathematics by Papua New Guinean mathematics teachers also supports this view. Matang suggests that teachers need to change from being transmitters of knowledge to facilitators of learning. 
However, Ernest (1989) strongly emphasised that any changes in mathematics teaching approaches, for example a change towards a problem-solving approach, require deep changes that depend on a number of factors. These include institutional reform which would involve, for example, changes to mathematics curriculum, assessment system, individual teacher approaches, and teachers' systems of beliefs. In addition, the actual teaching of mathematics also depends on a number of factors: the teacher's knowledge of mathematics (which includes the teachers' system of beliefs about mathematics, its teaching, and learning); the social situation or context (i.e., the challenges/constraints and opportunities available); and the teacher's capability in terms of thought processes (Ernest, 1989). For example, one factor strongly influencing teachers' beliefs and practices in the Solomon Islands education system is national examinations (Elley, 2001; Walani, 2009). The education system is examination driven and this has very much influenced teaching and learning in the classrooms.

Thus overall, the need for more debate within the Solomon Islands context on how teachers' beliefs about the nature of numeracy outcomes are implicitly or explicitly linked to the approaches they use and vice versa. To explore this in this study, Ernest (1989), Bartatsas-Tasos and Malone (2005), Burton (1993), and Kuhs and Balls (1986) belief orientations about the nature of mathematics, its teaching, and learning will be used to explore primary teachers' systems of belief. The next section discusses teacher pedagogical content knowledge which can be influenced by the nature of beliefs towards mathematics, its teaching, and learning. 


\subsection{Pedagogical content knowledge}

Sound pedagogical content knowledge is important in shaping teachers' beliefs about teaching mathematics effectively (An, Kulm, Wu, Ma, \& Wang, 2002). This section provides a brief overview of pedagogical content knowledge (PCK), examines PCK in terms of knowledge of teaching, and discusses theoretical perspectives about learning including Melanesian perspectives about learning.

Pedagogical content knowledge involves mathematics teaching and understanding how pupils think, taking into consideration the cultural background, pupils' preferential teaching methods, and appropriate learning styles (An, Kulm, \& Wu, 2004). It is about teachers having sound knowledge (Elbaz, 1983; Shulman, 1985), their ability to transform content, about knowing the learners and their characters, and values (Shulman, 1987). In terms of primary teachers' mathematics PCK in the Solomon Islands, very little is known, which is partly why this study explores this area.

Pedagogical content knowledge has been defined (Glossary, p. x) as knowledge of content, knowledge of curriculum, and knowledge of teaching (An et al., 2004). Knowledge of content includes broad and specific mathematics content knowledge. Knowledge of curriculum involves identifying suitable curriculum materials and understanding the text or curricula (National Council of Teaching of Mathematics [NCTM], cited in An et al., 2004), and knowledge of teaching includes knowing the pupils, preparing, and delivering instruction (An et al., 2004). An et al. (2004) emphasise that the knowledge of teaching is the key component of the pedagogical content knowledge, hence it is the focus of the next section. 


\subsubsection{Knowledge of teaching}

Although the knowledge of teaching is the key component of PCK, the knowledge of content and curriculum is important as well (An et al., 2004). This section highlights the importance of teachers having both the knowledge of teaching and knowledge of content.

Teachers and their methods of teaching have often been scrutinised to understand effective practices and intervention strategies that can enhance pupil performance. Teachers' lack of content knowledge and suitable teaching practices are two factors negatively affecting children’s basic numeracy skills (Groves, Mosley, \& Forgasz, 2004; Kyriacou, 2005; McDonough \& Clarke, 2003; Son, 2006; Stylianides \& Stylianides, 2006; The Profiling High Numeracy Achievement Project Team, 2004). Similarly, a lack of confidence in teaching mathematics can limit teachers' mathematical ability in engaging children in learning activities (Bliss, Askew, \& Macrae, 1996; Education Queensland, Queensland Catholic Education Commission [QCEC] \& Association of Independent School of Queensland [AISQ], 2004).

Even and Tirosh's (1995) study based on more than hundred prospective secondary mathematics teachers in the USA and more than 30 Israeli secondary mathematics teachers revealed that teachers' decisions to respond to students' answers is limited by their content knowledge, and can hinder students' construction of knowledge. How teachers ask questions and explain mathematical ideas reflects their own subject knowledge (Askew et al., 1997a). Anthony and Walshaw (2007) agree that teachers must know how to teach or deliver the content knowledge they have. The inquiry-oriented (constructivist) teaching 
approach requires teachers have a sound knowledge of mathematics in order to respond to pupils through diagnosis, problem-solving strategies, and scaffolding (Stipek et al., 2001). Bakalevu (2009), a teacher educator in Fiji, when working with primary teachers over many years, found that the majority of them lacked sound mathematical background. This may also be the case for the PIC including the Solomon Islands.

Even and Tirosh (1995) claim that teachers' roles have changed from delivering an 'expert made curriculum' in the 1960s and 1970s to promoting learning in 1980s, and this still applies today. This new role places high emphasis on subject-matter knowledge in order to help pupils understand concepts using a variety of learning strategies (Ball, Thames, \& Phelps, 2008; Even \& Tirosh, 1995). Shulman (1986) points out that there are two types of understanding required within teachers' subject-matter, that is, knowing that and knowing why. 'Knowing that' is the subject-matter basic knowledge, for example, rules, procedures, or concepts; for 'knowing why' on the other hand, it is important to understand the meaning of why and how things are as supported by Even and Tirosh (1995).

The ideas above relate to what An et al. (2004) describe as divergent and convergent processes in teaching. A divergent process is defined as content and curriculum knowledge based but lacking consideration for pupils’ mathematical thinking. A convergent process, however, focuses on pupils' thinking and includes four aspects: “building on pupils' mathematical ideas, addressing pupils’ misconceptions, engaging students in mathematics learning, and promoting students’ thinking mathematically” (p. 148). A divergent teaching process reflects learning as knowing and the convergent process associates learning as understanding (An et al., 2004). It is important to link teaching to learning. Teaching is to 
help pupils learn, and learning and teaching should be always together (Fosnot \& Dolk, 2005).

Therefore, the follow up discussions explore theoretical perspectives about learning, and incorporating cultural perspectives that may affect pedagogic strategies, since PCK also involves understanding pupils’ learning styles and cultural backgrounds.

\subsubsection{Theoretical perspectives about learning}

The theoretical perspectives of this study are derived from the broad notion of constructivism that includes the constructivist views and the socio-cultural (Cobb, 2005; McChesney, 2009) theories of learning. The socio-cultural teaching and learning has been described by many different terms such as: socially grounded learning, social-culturalpolitical, historical learning, social constructivist, social constructionist, and sociocognitive perspectives (Wink \& Putney, 2002).

There is a belief that these theoretical perspectives of learning and development help guide classroom teaching and learning. The perspectives are relevant to mathematics teachers because of their contribution to teachers' understanding of children's development as interacting with the environment, and the role of social influence or socio-culture to cognitive development. There has been little literature probing the difficulties and challenges teachers face in their constructivist classroom endeavours (Windschitl, 2002).

Constructivism "is a theory about knowledge and learning; it describes both what knowing is and how one come to know" (Fosnot, 2005, p. ix). Dougiamas (1998) described constructivism as having many faces, such as radical constructivism by Von Glaserfeld, 
social constructivism by Vygotsky, cultural constructivism, critical constructivism, and constructionism. The key notion about constructivism "is that learning is an active process in which learners construct new ideas or concepts based upon their current and prior knowledge” (Haylock \& Thangata, 2007, p. 35). Constructivism is about pupils’ learning and thus it is important that teachers clearly understand how their pupils learn in order to be effective (Haylock \& Thangata, 2007).

Nickson (2004) believes contemporary teaching and learning is shifting in style from behaviourist to constructivist approaches. The shift in perspectives has an impact on teachers' beliefs about the nature of mathematics, its teaching, and learning. Implementing instruction that is constructivist in nature can be difficult for teachers, as they have different levels of understanding of the concepts behind constructivism (Windschitl, 2002). Walani's (2009) case study found that secondary teachers in the Solomon Islands need to understand various theoretical perspectives such as social constructivism to become effective mediators of learning. If secondary teachers are faced with this challenge then it seems safe to assume that primary teachers in the Solomon Islands have also been faced with these conceptual challenges that influence classroom teaching and learning. One challenge facing teachers in creating a constructivist learning environment is that constructivism is a learning theory rather then a teaching description (Fosnot \& Perry, 2005). Thus, teachers' conceptualisation of learning theories is important to help them understand the learning process (Reid, 2005) and their roles. However, in any classroom teachers also create their own personal learning theories (McChesney, 2009; Sylva \& Lunt, 1992) and it is vitally important for teachers to understand how pupils learn. 
The constructivist model, pioneered by Piaget (Liebeck, 1990) considers adaptation as the significant feature of learning which occurs through assimilation and accommodation. The recognition of the role of social interaction in learning saw the inception of social constructivism, led by Vygotsky (Ackermann, 1996; Wink \& Putney, 2002) and Bruner (Liebeck, 1990). Vygotsky found two fundamental themes in his framework regarding cognitive development. That is, the influence of social interaction and the recognition of the 'zone of proximal development' (ZPD) which can be attended to through 'scaffolding' (Haylock \& Thangata, 2007). Consideration of Vygotsky’s ZPD is an important condition that can enhance learning, including the environment, mood, self-esteem, motivation, teaching style, learning style, task/task expectations, materials, and support (Reid, 2005).

Windschitl (2002) in his theoretical analysis of constructivism practices identifies four dilemmas that concern teachers in creating a constructivist classroom. These include: conceptual (understanding of constructivism), pedagogical (approaches and design demands of constructivism), cultural (between teachers and pupils collaborations), and political (resistance). Therefore, teaching in a constructivist environment is a demanding job, requiring teachers to understand their pupils and to structure their teaching (Cooney \& Shealy, 1997). The creation of an ideal constructivist classroom teaching and learning depends very much on the teacher. As Earl (2007) points out, "teachers are the ones who work directly with students, who translate and shape curricular goals and theoretical ideas into classroom practices and who shape the environment for learning” (p. vii). Teachers can make a difference in enhancing pupil achievement (Hattie, 2002). The study on constructivism characterises some classroom activities for teachers and students that include: teachers to build on pupils' ideas and experiences; pupils to engage in problembased tasks; teachers provide pupils variety of resources; pupils collaborating, teachers 
encourage pupils' reflection; and teachers use wide range of assessment strategies to monitor pupils’ progress and to provide feedback (Windschitl, 2002). The teacher will also depend on other players to help him/her establish an ideal classroom. Thus any teacher's dilemmas and concerns in creating an ideal constructivist classroom could be addressed through appropriate professional support.

The three major implications of a constructivist approach to effective learning of mathematics are: i) children construct knowledge and not necessarily the receiver, ii) children to mathematise, experience real mathematics, and iii) it is important to acknowledge and consider children's contribution in mathematics (Nickson, 2004, p. 5).

To summarise, the two major features of a constructivist-based education are: pupils construct their own knowledge or ways of knowing; and the emphasis on socio-cultural perspectives. That the combined effects of these two theoretical perspectives are critical to create a full constructivist learning environment (Fosnot \& Perry, 2005; Windschitl, 2002) is acknowledged in the preparation of this study.

\subsubsection{Melanesian cultural perspectives about learning}

It is important to explore Melanesian education-related perspectives because of their own pedagogical implications. Recognition of cultural methods of learning or learning styles/preferences should have a place in a predominantly western style of teaching and learning expectations. As Thaman (1992) reminds us, some of the answers to our questions regarding teaching and learning could come from our own cultures. 
There is a dearth of literature that specifically highlights the Melanesian cultural/traditional ways/styles of learning, particularly in the Solomon Islands. This is further complicated by the cultural diversity of Melanesian societies. One factor which affects learning is the language of instruction. This was first espoused in Vygotsky's sociocultural perspective that language plays a very important role in all initial learning and is achieved through our cultural heritage and interaction (Wink \& Putney, 2002). In the Solomon Islands, the English language has become the official medium of instruction in schools. However, for the majority of pupils it is their third or fourth language. Interpretation of the language of instruction can be a barrier to conceptual understanding and contextual reality. Bakalevu (1999) states that learning the English of mathematics (called Mathematical English) causes cognitive problems for many Pacific Islanders. In Papua New Guinea learning difficulties in mathematics are commonly attributed to English language instruction (Clarkson, 1998). Thaman (2009) generally concurs that the current curriculum in most PIC is culturally undemocratic since it fails to consider learners’ cultures, notably in the areas of language, teaching and learning.

In developing countries like S.I, I have observed the traditional or cultural ways of learning are in some ways seen as detrimental to formal learning. There is ongoing debate over beliefs about the nature of mathematics, which by some is perceived as culture-free (Banks, 2001; Nickson, 1989) and by others as culture-bound (Nickson, 1989). The culture-free mathematics proponents believe that it cannot be adapted to follow individual culture, whereas culture-bound theorists support mathematics as a social activity involving human interaction (Nickson, 1989). Mathematicians from the Melanesian countries or the Pacific region often regard cultural mathematics as of less standing than the formal/dominant mathematics (Bakalevu, 2009). In my recollection of primary school 
days, cultural mathematics was seen as detrimental to learning and teachers were struggling to cope with the dominant mathematics curriculum. A teacher's role at that time was regarded as being an agent of change towards western practices. Parents have high expectations of teachers to follow the dominant (Eurocentric) curriculum. Some parents have high monetary investment in their children's education or expect them to be able to read and write like the expatriates (Sanders, 1989).

Thaman (2002) and Bakalevu (2009) argue that there is no such thing as universalism or culture-free knowledge. However, Nickson (1989) has highlighted an important point for consideration, that rather than exploring cultural differences either at the societal or individual levels, what is more imperative is how pupils' cultural perspectives affect their mathematical thoughts.

According to some Melanesian societies, "knowledge is not something which results from an individual's own experiences, but is a commodity which is passed on from one individual to another” (Ninnes, 1992, p. 41). Thus, teachers are seen as transmitting knowledge, rather than individuals constructing knowledge (Matang, 1998; Ninnes, 1992). This is an apparent tension for Melanesian classroom teachers when moving from the orthodox approach of transmitting mathematical knowledge to the adoption of knowledge construction by individual pupils. In other ways, learning in Melanesian culture is different to learning expectations in formal schools. Teachers have been trained under the conventional Western ways of teaching as teacher-led or teacher-directed and this in some ways suits the learning styles of Melanesia. Most Melanesian pupils tend to listen and respect the teacher, believing that whatever the teacher says is always true and is not to be questioned. This reflects the cultural ways of learning, including observation or imitation. 
For instance, the Kamasu people of East Sepik Province, Papua New Guinea, treat verbal instruction as of secondary importance to actual showing - the training model (Sanders, 1989). Learning through observation and imitation is believed to be highly effective. This may enable and encourage teachers to continue functioning as a transmitter of knowledge in a teacher-dominant situation.

Consideration of cultural values and perspectives to help pupils to understand better and motivate them to learn is important (Averill, Anderson, Easton, Te Maro, Smith \& Hynds 2009; Averill, Te Maro, Taiwhati \& Anderson, 2009). An example of this is a consideration of cultural practices and thinking, for example, the Ausae pedagogy ${ }^{9}$ advocated by Sanga (2009). According to Ausae traditional fishing pedagogy, knowledge is an interactive process in various phases (Sanga, 2009). Sanga's exemplar of the cultural Ausae pedagogy offers an alternative re-thinking to curriculum developers and educators in seeking how one comes to understand knowledge as a cultural process. This is important where knowledge and beliefs shape our cultural values and perspectives, especially in cases of conflict with knowledge, beliefs, and practices in the Eurocentric curriculum. These cultural metaphors and analogies can be subsumed into pedagogical ideologies, especially in mathematising learning (Bakalevu, 2009). Success in schooling is viewed with a holistic approach (both inside and outside classroom) in the Solomon Islands, which emphasises cooperation and interdependence (Ninnes, 1992).

\footnotetext{
${ }^{9}$ A traditional fishing metaphor practised in Malaita province, Solomon Islands, that can represent teaching and learning.
} 


\subsection{Teachers’ Professional development (PD)}

Teachers are central to any classroom teaching and learning, hence professional learning and development is important in developing teachers to improve teaching and learning in schools (Earl, 2007). This section defines PD, briefly highlights the importance of PD in general, provides a typical scenario of teachers’ PD in the Solomon Islands and explores suitable strategies from the literature for enhancing PD practices.

The terms professional learning and professional development are often used interchangeably but these two terms could imply different purposes. Timperley, Wilson, Barrar and Fung (2007) quote Guskey’s definition of professional development as “those processes and activities designed to enhance the professional knowledge, skills, and attitudes of educators so that they might, in turn, improve the learning of students” (p. 3). Professional development implies delivery of information to teachers, whereas professional learning is "an internal process through which individuals create professional knowledge” (Hannay, Mahony, \& MacFarlane, cited in Timperley et al., 2007, p. 3).

It is important to identify teachers’ professional learning needs (Timperley et al., 2007), since professional development is becoming a vehicle for change (Smith, 2001). Staff development programmes are devised to bring about change in classroom practices, beliefs and attitudes, and pupils’ learning outcomes (Guskey, 1986). Because of the complex nature of teachers' beliefs and practices, it is important that professional learning programmes are there to help address any mismatches between these (Wilson \& Cooney, 2002). Borko and Putman (1996) claim close relationships exist between teacher beliefs, classroom practices, and effective professional development. 
A number of strategies for professional development activities exist. The most suitable PD to undertake depends on the kinds of needs or learning gaps that exist and other factors, such as resources, feasibility, and teacher motivation. The characteristics of effective professional learning programmes include PD being driven by pupils’ performance, based on teachers' needs or based on shared concerns (Hawley \& Valli, 1999) should suit any initial undertaking of PD support. More specifically for mathematics, Clarke (1994, as cited in QCEC \& AISQ, 2004) offers ten principles for effective PD. Similar to Hawley and Valli (1999), Clarke proposed that teachers identify their issues/concerns and help address any hindrance to their work. However, any form of professional support should aim at continuous professional development rather than short term PD as found in the detailed case studies by Askew et al. (1997b). This claim shows that any plan PD programmes should minimise short term events such as one off workshops or visits and include programmes that emphasise continuity.

In summary, all teachers should be entitled to benefit from the ability to refresh and upgrade their pedagogical content knowledge, and mathematical beliefs by attending PD support pertaining to their needs.

\subsection{Implications for Solomon Islands classroom practices}

The literature discussed so far described salient ideas towards effective classroom practices. In brief, this section further evaluates the implications of teaching approaches and models discussed in the context of Solomon Islands classroom practices. 
Important themes have emerged from the review of relevant Western and Pacific literature, which include the relationship between teacher beliefs about the nature of mathematics, teaching, and learning; the importance of teacher's pedagogical content knowledge; the recognition of cultural responsiveness and theoretical perspectives about teaching and learning of mathematics; and the importance of professional development. We learnt from the literature that any changes to educational reform or the adoption of mathematics approaches to teaching require changes in teachers' deeply held beliefs about mathematics, its teaching, and learning (Ernest, 1989). Theoretically, these beliefs have been categorised into a hierarchy of levels (Table 2.1). Presumably these hierarchies of belief orientations reflect the Solomon Islands teacher practices in mathematics. Either to transform or change these belief orientations into actual practice is dynamic, and depends on a number of factors including teacher pedagogical content knowledge and the social context, and teachers’ systems of belief (Ernest, 1989). In the Solomon Islands context these factors could be crucial in influencing teacher beliefs and practices.

Based on the belief orientations, the main argument derived from the literature is that the approaches/models espoused by teachers concerning the nature of mathematics, its teaching, and learning, influence their pedagogical knowledge and practices. What are the implications of these approaches or models for an ideal Solomon Islands classroom teaching and learning situation that aims to enhance better numeracy outcomes? The Nguzu Nguzu Teacher's Guide emphasises the importance of pupils achieving numeracy understanding. I believe one of the major challenges to teachers is how to transfer the Teacher Guide content into practice. Implementation perhaps depends on the teacher's level of intuitiveness and on what Ernest (1989) believed as the teacher's level of consciousness of their own beliefs and self reflection on practices. 
In addition, the implications of the constructivist approach and socio-cultural perspectives to teaching and learning are that they demand teachers have strong pedagogical content knowledge and an appreciation of a learner growing up and interacting with the environment and socio-cultural forces. It is presumed that teachers face challenges linking theory and practice, for example, there is a likely chance that teachers' practices may reflect certain principles of various theoretical perspectives without realising that there is a connection between theory and practice. McChesney (2009) mentions that "although [teachers] may not consciously think about theories of student learning, these are implicit in the choices and decisions we make before, during, and after teaching” (p. 67). For Solomon Islands primary school teachers, this is a challenge that will be explored in this study.

A number of studies still point to traditional types of teaching and learning adopted by teachers as opposed to learner-focused or child-centred approach (constructivist in nature). It is thus imperative that research of this nature should produce results that will illustrate consistencies and inconsistencies between teachers' beliefs and practices on numeracy outcomes. 


\subsection{Summary}

This chapter has explored literature pertinent to the study. The literature focuses on the main elements derived from the research questions. These elements include teacher beliefs, pedagogical content knowledge, and professional development. Examination of teacher beliefs included discussion of the relationships between beliefs about the nature of mathematics, its teaching, and learning. The pedagogical content knowledge section discussed its importance, especially in regarding teachers' knowledge of teaching. This included recognition of theoretical and cultural perspectives about learning. The exploration of the nature of professional development offered principles for effective professional development for mathematics education. The brief discussion of the implications of classroom practices summarised, synthesised, and evaluated the important arguments in the literature in terms of the approaches or models of teaching and learning of mathematics that can be applied to the Solomon Islands context and therefore to the study's data analysis.

The next chapter describes the research methodology. 


\section{CHAPTER 3 - RESEARCH METHODOLOGY}

We live in an interview society - Denzin \& Lincoln, 2005, p. 642

General methodology includes the processes, principles, and procedures adopted to approach problems and determine solutions (Bodgan \& Taylor, 1975). This chapter describes the study approach, design procedures, and ways used to ensure validity and reliability of the data. The research design section describes the ethical procedures, interview protocol, the participants and the treatment of the data collection procedure.

\subsection{The study approach}

The study adopts a phenomenological method of the interpretive/constructivist paradigm (qualitative approach) (Bogdan \& Biklen, 1992; Creswell, 1998) as this was the methodology best suited to the nature of the research questions and aims. The use of phenomenological approach would allow descriptive and interpretative individual meanings in their multiple experiences to gain reality (McMillan, 2008). The assumption of this study, as opposed to a positivist/postpositivist assumption, is that there are multiple realities, characterised by complex behaviours (McMillan, 2008; Mertens, 2005).

The study aims are consistent with the purpose of qualitative research (Anderson \& Arsenaut, 2002; Denzin \& Lincoln, 2005; Creswell, 1994; McMillan, 2008, Mertens, 2005; Patton, 1987), which is to gain rich narrative descriptions through inductive inquiry that will provide meaningful and contextually based constructions. Qualitative research is exploratory. A qualitative researcher focuses on the social construction, experience of reality, meaning, and the situational constraints that help model the inquiry (Denzin \& 
Lincoln, 2005). Qualitative study, according to Creswell (1994), is defined as “an inquiry process of understanding a social or human problem based on building a complex, holistic picture, formed with words, reporting detailed views of informants, and conducted in a natural setting” (p. 1). In this study, the context is attempting to make sense of teachers' lived experiences, the experiences, knowledge and beliefs teachers have brought with them, and meanings and interpretations attached to these experiences and beliefs.

Exploring teachers' lived experiences is in line with phenomenological methodology and interpretative phenomenological analysis (IPA) (Smith \& Osborn, 2008; Willig, 2003) which are used in this study. IPA involves making sense of or understanding a participant's experiences of the object, event, or phenomenon (Smith \& Osborn, 2008). English and English (1958 as cited in Cohen, Manion, \& Morrison, 2000) broadly defined phenomenology as "a theoretical point of view that advocates the study of direct experience taken at face value; and one which sees behaviour as determined by the phenomena of experience rather than by external, objective and physically described reality" (p. 23). A phenomenological study is a description of individuals' lived experiences regarding a phenomenon (Creswell, 1998).

A phenomenological approach was essential for this study because of the need to listen to and capture teachers' lived experiences. A phenomenological design approach was chosen to explore "situations where variables are unknown and theoretical bases are yet to be formulated” (Walliman, 2001, p. 165). The basis of phenomenology is that each participant has their own experience and the reality or the meaning of that experience can be interpreted in multiple ways (McMillan, 2008). A phenomenological design is therefore appropriate for this study, since there is no available literature to set the ground work in the 
Solomon Islands on primary teachers' beliefs regarding the nature of numeracy teaching and learning, and pedagogical practices.

\subsection{Research design}

The choice of research design and methods depends on the research questions (Anderson \& Arsenault, 2002). This section describes the general plan and processes used for the study. The design framework (Figure 3.1) encapsulates the study focus, the main elements, the study approach and design, the data procedure, and finally the results.

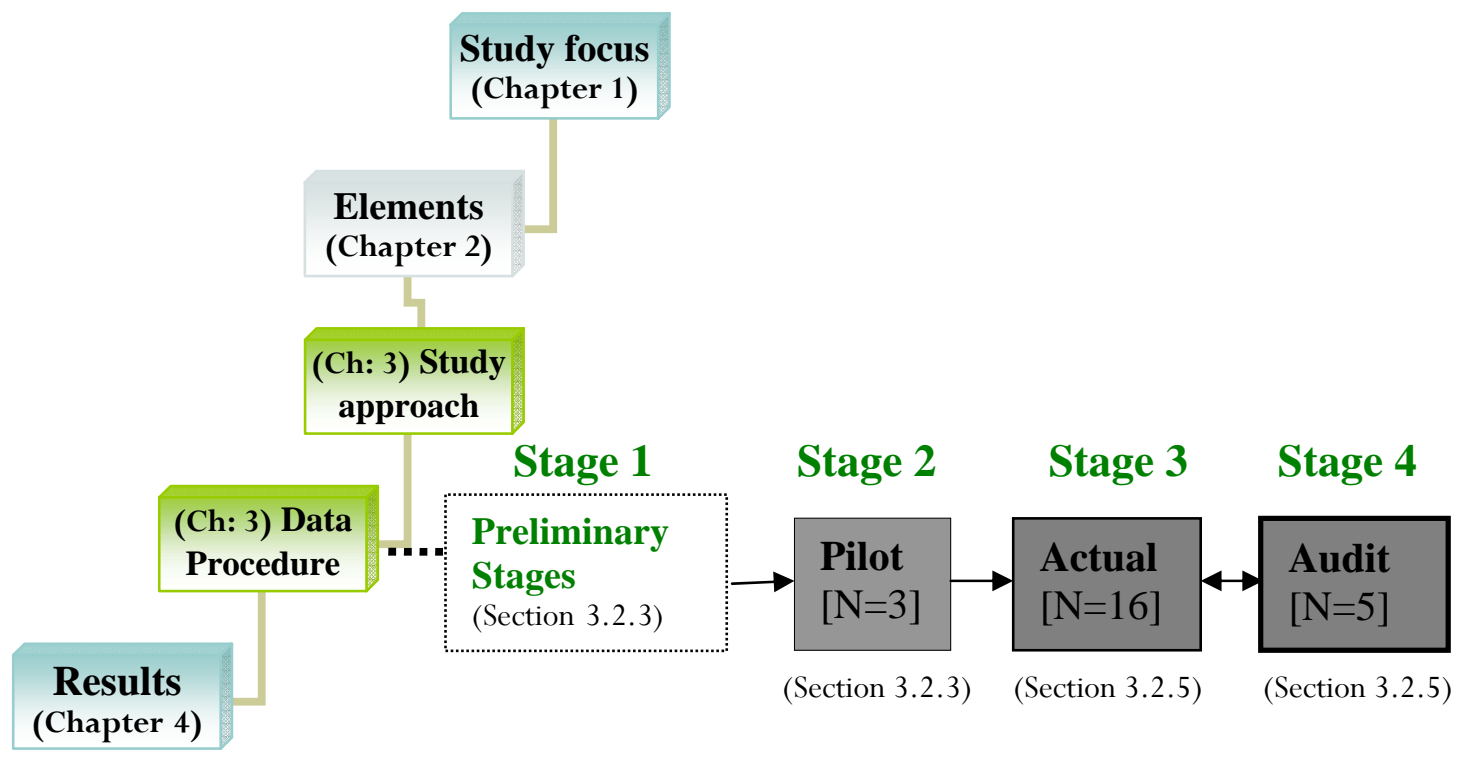

Figure 3. 1: The design framework

The data collection procedure indirectly involved four stages. Stage 1 (explained further in Section 3.2.3) included an informal visit to a primary school and an interview with a colleague from Vanuatu, both carried out in Wellington, New Zealand. The remaining stages were conducted in the Solomon Islands. 


\subsubsection{Ethical procedure}

Ethical consideration is critical (Mertens, 2005; Powell \& Smith, 2006) for any research involving human subjects. This study was approved by the Victoria University of Wellington Human Ethics Committee (Appendix 1), and a research permit to conduct the study was granted in accordance with the Solomon Islands Research Act 1982 (No. 9) (Appendix 2).

The following general procedures were adhered to. Information letters and consent forms (Appendices 3 \& 4) were sent to the following: the Chairman of the Solomon Islands Research Committee (seeking permission to carry out the research project); Solomon Islands Education Secretaries (seeking consent for the participation of their schools); Headmasters/Headmistresses of invited schools (seeking consent about their teachers' participation), and the invited participant teachers themselves.

\subsubsection{The interview protocol}

McMillan (2008) describes that phenomenological studies normally have a single question followed by subquestions to frame the collection of data and the results.

The notion about using Belief Cards is espoused by Lawrence ${ }^{10}$. I was intrigued by the notion of turning belief statements into discussion cards, and this became part of the interview as the introductory activity. The cards discussion engendered the interviewee's participation, and at the same time generated data. The belief statements used in Beswick's (2005) study (Chapter 2) were designed as an instrument to measure beliefs (Teacher

\footnotetext{
${ }^{10}$ Anne Lawrence, from Massey University, College of Education, Palmerston North, New Zealand.
} 
Belief Survey Response). The statements were also recommended for use with primary teachers (Beswick, 2005). In my study, the 16 Belief Cards (Appendix 5) were derived from some of the belief statements used by Beswick (2005) with some minor amendments to suit the study context. The amendments and selection of 16 belief statements were based on beliefs that reflect the constructivist (shaded light blue, see Appendix 5) and the transmission (un-shaded) nature of teaching and learning of mathematics according to Beswick's (2005) interpretation. Also, statements were modified in order that Solomon Islands primary teachers could more easily understand them.

The preference of a semi-structured interview over other methods was because of how close the researcher is in interviews to the participants in face-to-face conversations and that "beliefs cannot be directly observed or measured but must be inferred from what people say...” (Pajares, 1992, p. 314). Phenomenologists normally use in-depth interviews to capture the lived experiences of the participants (Hess-Biber \& Leavy, 2006). Asking questions in a truly open-ended style is crucial for qualitative interviewing and allows the respondent to respond in his or her own words (Bodgan \& Biklen, 1992; Patton, 1987). However, caution is necessary to avoid uncontrolled responses or discussion. Therefore the use of prompts and minimal probes on the key issues that arise during interviewing is necessary to guide and elicit further information.

The research subquestions were used to develop an interview protocol (Appendix 6) with two data collection modes (a Belief Cards exercise and a semi-structured interview). The first part of the interview protocol was the Belief Card exercise which required participants to choose belief cards that best described their beliefs about the nature of mathematics, its teaching, and its learning. Sixteen Belief Cards in random order were displayed for 
interviewees to browse through and decide on regarding the best fit with their own personal beliefs. The second part of the interviews involved the semi-structured questions targeting the teacher's pedagogical content knowledge and professional development experiences.

The interview protocol in its initial form underwent trialling in Stages 1 and 2 of the study (Figure 3.1).

\subsubsection{Preliminary stage: Informal visit, pre-trial interview, and the pilot run}

An informal school visit and a trialling of the interview protocol with a colleague, an experienced mathematics educator from Vanuatu (both convenience samples) were carried out as the first steps of ensuring the data gathering tool was fit for the purpose.

The pre-trialling involved checking the integrity of the interview items, the prompts, timing, styles and ways of questioning, in preparation for the actual pilot run (Figure 3.1, Stage 2). The outcome provided perspectives about valuable views and beliefs of mathematics teaching and learning from the Melanesian context of Vanuatu (e.g., the current teachers' beliefs and practices in Vanuatu that reflect the traditional transmission orientation)

The school visit (arranged through the Faculty of Education, Victoria University of Wellington) involved three classroom observations followed by one-on-one informal conversational interviews with teachers. The aim was to gain first hand experience in conversing with teachers and observing classroom pedagogical practices from another context. The visit broadened my perspective about the kinds of classroom practices (e.g., 
spiral learning, scaffolding, and reflection strategies, monitoring and recording pupils' different learning abilities) regarding numeracy teaching and learning which this study aimed to explore.

The pilot interviews $(\mathrm{N}=3)$, stage 2 were carried out with one teacher from each of the categories of schools (Section 3.2.4). Each pilot interview involved the following: i) dialogue with the participants by providing an overview of the study; ii) gathering of information by interviewing; iii) transcribing the transcripts into narrative text, and iv) a pilot analysis to inform later analysis of likely patterns of responses.

The pilot questions had been pre-trialled in two ways before the actual trial as mentioned above, and the pilot interviews did not change the actual protocol questions further. However, the pilot sensitised the researcher to key data themes and informed the choice of probing questions. For example, the use of prompts sometimes enhanced the fluidity of the interviews.

These preliminary activities set the scene for the research journey. They helped build my confidence in the interview protocol in terms of questioning and the use and fine-tuning of prompts. It allowed me focus deeply on the overall study, and provided opportunities to listen and observe pedagogical strategies.

\subsubsection{Selection of participants}

Since 24 schools indicated their availability, a geographical convenience sampling was used to select schools. In order to carry out maximum variation sampling (McMillan, 2008) I referred to the SISTA 2006 and 2007 results to categorise the schools as: High- 
Performing Schools (HPS), Average-Performing Schools (APS), and Low-Performing Schools (LPS). The SISTA is the only available S.I numeracy achievement data, believed to be the most reliable measure of numeracy achievement in the Solomon Islands according to the MEHRD (MEHRD, 2007). Further considerations included accessibility (easily accessed by public transport), familiarity (between the school and researcher), and the number of schools per category (there were few schools in the HPS category) to choose from.

My aim was to obtain data from teachers of each type of school, although the intention was not to compare results across these categories of schools. McMillan (2008) describes that the value of this type of sampling is that it represents extreme cases which can be informative. The sampling approach of including extreme schools in the sample was intended to improve the validity of the data collected and hence of the results.

Mainly Honiara (S.I’s capital) and two schools under Guadalcanal province were selected for the study. This restriction was done in order to restrict travel and make it possible to collect data in the time available.

The participants $(\mathrm{N}=16)$ were Years 4 and 6 primary school teachers from the three categories of schools. All except two were urban teachers. One HPS school decided to have two of their teachers interviewed at the same time, similar to a focus group interview, which increased the actual participants from 15 to 16. 
A summary of the actual participants' background information is given in Table 3.1. The participants were coded as teacher $\left[\mathrm{T}_{1}\right]$ to teacher $\left[\mathrm{T}_{16}\right]$ arranged according to teachers' experience (number of years they have taught).

Other characteristics such gender, class taught, qualification, and school type were included in Table 3.1 for purposes of comparison and analysis. There were seven female participants out of the total sixteen. Ten of the teachers were teaching Year 6. In terms of qualifications, only two participants had a Degree and a Diploma in Education and the rest obtained their certificates in teaching primary school from the Solomon Islands College of Higher Education. School type mainly refers to public and private schools (Section 1.1.2).

Table 3. 1: Participants' background information (arranged by years of experience)

\begin{tabular}{llllll}
\hline Participants & Gender & \multicolumn{2}{l}{ Year } & Qualification Experience & School Type \\
\hline $\mathrm{T}_{1}$ & $\mathrm{~F}$ & 6 & Certificate & $3 \mathrm{yrs}$ & Province \\
$\mathrm{T}_{2}$ & $\mathrm{M}$ & 5 & Certificate & $4 \mathrm{yrs}$ & Church \\
$\mathrm{T}_{3}$ & $\mathrm{~F}$ & 4 & Certificate & $5 \mathrm{yrs}$ & Public \\
$\mathrm{T}_{4}$ & $\mathrm{~F}$ & 6 & Degree & $5 \mathrm{yrs}$ & Private \\
$\mathrm{T}_{5}$ & $\mathrm{M}$ & 6 & Certificate & $6 \mathrm{yrs}$ & Public \\
$\mathrm{T}_{6}$ & $\mathrm{M}$ & 6 & Certificate & $7 \mathrm{yrs}$ & Province \\
$\mathrm{T}_{7}$ & $\mathrm{~F}$ & 4 & Certificate & $8 \mathrm{yrs}$ & Private \\
$\mathrm{T}_{8}$ & $\mathrm{M}$ & 6 & Certificate & $9 \mathrm{yrs}$ & Public \\
$\mathrm{T}_{9}$ & $\mathrm{M}$ & $5 \& 6$ & Certificate & $10 \mathrm{yrs}$ & Public \\
$\mathrm{T}_{10}$ & $\mathrm{~F}$ & 4 & Certificate & $10 \mathrm{yrs}$ & Public \\
$\mathrm{T}_{11}$ & $\mathrm{M}$ & 6 & Certificate & $11 \mathrm{yrs}$ & Church \\
$\mathrm{T}_{12}$ & $\mathrm{M}$ & 6 & Diploma & $13 \mathrm{yrs}$ & Private \\
$\mathrm{T}_{13}$ & $\mathrm{M}$ & 5 & Certificate & $20 \mathrm{yrs}$ & Public \\
$\mathrm{T}_{14}$ & $\mathrm{~F}$ & 5 & Certificate & $23 \mathrm{yrs}$ & Public \\
$\mathrm{T}_{15}$ & $\mathrm{~F}$ & 6 & Certificate & $30 \mathrm{yrs}$ & Private \\
$\mathrm{T}_{16}$ & $\mathrm{M}$ & 6 & Certificate & $33 \mathrm{yrs}$ & Church \\
\hline
\end{tabular}




\subsubsection{Treatment of data collection procedure}

Qualitative data analysis is an ongoing process (Mertens, 2005). As part of exploratory research, "data may be continuously analysed as they are collected, the analysis giving clues as to the most fruitful area of further data collection and subsequent analysis" (Walliman, 2001, p. 227). Patton (1987) describes ‘analysis’ of qualitative data as bringing order into patterns, categories, and description, and 'interpretation' as applying meaning and connections.

Although the data collection procedure (Figure 3.1) included four stages, only data gained from the last two (Stages 3 and 4) were counted as data since the other stages are regarded as preparatory. An MP3 recorder was the main device used for all audio recordings, followed by transcription and translation of data where necessary.

The one-on-one interviews lasted for 40 to 60 minutes and were structured as follows: The participants were i) informed about the aim of the study and the methodology, ii) given the opportunity to ask questions about the study to enhance their comfort to give honest, open responses, iii) asked for their demographic information, iv) given the Belief Cards exercise, and v) interviewed using the semi-structured interview questions.

All interviews were pre-arranged a week in advance and one to two interviews were held each day. Interview times and venues were determined by the interviewee at their convenience. Nearly all interviews were done at schools either during break times or straight after school. Interviewees were asked to respond either in English or Pidgin languages, whichever they felt comfortable with. Most opted for a combination of both. 
Hence transcriptions were done in both Pidgin and English. Translation to English was carried out by me where necessary for analysis, interpretation, and reporting.

The following procedures were used after the interviews: The interviews were transcribed directly after the interviews, translated from Pidgin to English where appropriate, and an audit check (Mertens, 2005) carried out to help reduce the occurrences of incorrect data (e.g., to eliminate mistakes in transcription) and to help improve interpretation of participants' responses. Five participants were recalled to cross check with their transcribed data to clarify a small number of seemingly ambiguous responses. This was done through phone conversation and appointments.

In terms of the treatment of the data, the analysis involved three stages: descriptive analysis, thematic analysis, and interpretive analysis, consistent with phenomenological methods (Wolcott, 1994) (Chapter 4). The method of IPA applies to these three levels. In this case, for generating meaning it was crucial to understand the content received from the respondents and not necessarily to record measures of frequency (Smith \& Osborn, 2008).

A recursive analysis approach was applied to the transcription data, that is, transcribed data was reread and the audio recordings listened to several times each. In most cases words initially overlooked were added. In addition, field notes were used to note important points and terms that emerged during interviewing and additional discussions after the interviews. These added clarity to the transcribed data and resulted in additional statements and themes. For example, useful comments were made by some participants during our informal discussions after the interviews, which were noted because they were not mentioned during the actual interviews. 
In summary, the descriptive analysis involved summarising responses and emerging patterns from the interview data. The thematic analysis involved interpreting emerging themes, and the interpretative analysis involved explaining the meanings and context of the phenomenon in light of the literature.

\subsection{Ensuring validity and reliability}

Nearly all research reports have some flaws, errors, and weaknesses in the information they provide (Katzer, Cook, \& Crouch, 1998). Qualitative studies are open to criticism in terms of debate over paradigms that differ in their epistemological beliefs; the assumptions in terms of the roles of the researcher towards evidence and quality of the study (Lancy, 2001). For example, qualitative studies often criticised for its methodological issues in terms of the trustworthy of human reports, the criteria to judge the data collection, and its validity and reliability aspects of the data (Patton, 1987).

McMillan (2008) emphasises credibility as the primary criterion for evaluating qualitative studies and defines credibility "as the extent to which the data, data analysis, and conclusions are believable and trustworthy” (p. 296). In this study, several steps were undertaken to ensure results and findings held credibility and trustworthiness.

The use of triangulation is one of the principles of gaining credible qualitative data (McMillan, 2008). In short, triangulation helps to gain credibility (internal validity) and dependability (reliability) of the reported data. Hence, the use of the Belief Cards exercise and the semi-structured interview questions in this study allowed for a methodological 
triangulation $^{11}$, as two methods of data collection were used to provide evidence towards a coherent picture of beliefs, knowledge, and practices. The combined methods helped to build the overall picture of teachers' beliefs, knowledge, and practices. In addition, using the four stages in the data production (Figure 3.1) indirectly helped to triangulate the data through information gathered. Dependability has also been achieved through consistent attempts to avoid my personal bias towards the results and findings, the use of recorder to record data, the auditing process, and the use in reporting of participants' descriptive accounts with their quotations.

Another important aspect of minimising such issues is to clarify at the outset to the participants my status as an Assessment Education Officer. This enhances the potential of fear and lack of candour of interviewees' responses and highlights the possibility that researcher effects (Lee, 1993, cited in Cohen et al., 2000) may have impacted on the study data.

\subsection{Summary}

This chapter described the phenomenological method of the qualitative approach used in this study, outlined the design of the study, and justified study design decisions.

The next chapter describes and analyses the results gained through the Belief Cards exercise and the semi-structured interviews.

11 “... different methods of data collection to provide evidence of corroboration or coherence” (Hall, 2007, p. 3). 


\section{CHAPTER 4 - FINDINGS}

This chapter provides the results and the findings of the study. The three research subquestions framed the collection of data and the analysis and help shape this chapter. The focus areas are teacher beliefs, pedagogical content knowledge, and professional development experiences. The arrangement of the chapter follows three levels of analysis: descriptive analysis of the raw data, a thematic analysis, and lastly the interpretative analysis that discusses the overall findings in this study.

\subsection{Interview data: Descriptive analysis}

This section provides a brief overview of the data transcription analysis as carried out in working towards the initial stage of examining participants' responses for patterns, themes, and standalone issues.

Understanding the meaning of what is transcribed from each respondent is important in trying to capture the essence of the phenomenon and link to relevant theoretical underpinnings (Smith \& Osborn, 2008). Consistent with Smith and Osborn’s (2008) analysis process, looking for initial themes from the transcription data involves two stages: 1) locating interesting and significant statements particularly pertinent to the research question; and 2) developing emerging theme titles from these statements. The latter involved clustering initial themes and deciding on superordinate themes ${ }^{12}$. A template with three columns was developed to record a) emerging theme titles (right-hand column), for b) the selected statements (left-hand column), and c) the middle column held the interview

\footnotetext{
${ }^{12}$ Refers to clusters of themes which come under another theme that represents them (Smith \& Osborn, 2008)
} 
transcription.

Next, the initial selected statements were examined for connections, similarities, differences, meanings, and relationships. This resulted in clustering themes (allowing close interaction with the transcript (Smith \& Osborn, 2008)) that best described the responses. Some theme titles were clustered under superordinate themes and others, from an individual participant’s experiences alone, were recorded as standalone themes.

In the next section, the thematic analysis, the first interpretation of the emerging themes is provided.

\subsection{Thematic analysis}

Thematic analysis involves expanding the themes into narratives based on information the participants have shared. The outcome of this thematic analysis leads towards further superordinate themes and in turn, to the main findings of this study.

Direct quotes and paraphrasing from the transcribed data are used to support the discussion. Direct quotes involving Pidgin are either explained through English or translated into English to facilitate reading. Paraphrasing is always in English.

The thematic analysis is described in relation to the three research subquestions (1) teacher beliefs, (2) teacher pedagogical content knowledge, and (3) professional development. 


\subsubsection{Teacher beliefs}

The results of the Belief cards exercise are summarised in Table 4.1 which indicates the kinds of beliefs that the teacher-participants stated they held about the nature of mathematics, mathematics teaching, and mathematics learning by showing how many teachers chose each card as representative of their own beliefs. The Belief Cards are presented in order of the number of teachers that agreed with each card. Cards chosen by individual teachers are displayed in Table 4.2.

Table 4. 1: Number of teachers who responded to each Belief Card

\begin{tabular}{|c|c|c|}
\hline Rank & Belief Card Statement & $\begin{array}{l}\mathrm{N}=16 ; \\
\text { [partly] }\end{array}$ \\
\hline 1 & $\begin{array}{l}\text { Providing children with interesting problems to investigate in small groups is an } \\
\text { effective way to teach mathematics }\end{array}$ & 15 \\
\hline 2 & $\begin{array}{l}\text { It is important for children to be given opportunities to reflect on and evaluate } \\
\text { their own mathematical understanding }\end{array}$ & 14 \\
\hline 3 & $\begin{array}{l}\text { Children always benefit by discussing their solutions to mathematical problem } \\
\text { with each other }\end{array}$ & $13 ;[1]$ \\
\hline 4 & $\begin{array}{l}\text { Teachers can create, for all children, a non-threatening environment for learning } \\
\text { mathematics }\end{array}$ & 13 \\
\hline 5 & It is important to cover all the topics in the mathematics curriculum & 12 \\
\hline 6 & $\begin{array}{l}\text { A vital task for the teacher is motivating children to solve their own } \\
\text { mathematical problems }\end{array}$ & $11 ;[1]$ \\
\hline 7 & $\begin{array}{l}\text { Ignoring the mathematical ideas that children generate themselves can seriously } \\
\text { limit their learning }\end{array}$ & 11 \\
\hline 8 & $\begin{array}{l}\text { Allowing a child to struggle with a mathematical problem, even a little tension, } \\
\text { can be necessary for learning to occur }\end{array}$ & 10 \\
\hline 9 & $\begin{array}{l}\text { Teachers of mathematics should be fascinated with how children think and } \\
\text { intrigued by alternative ideas }\end{array}$ & 10 \\
\hline 10 & $\begin{array}{l}\text { Listening carefully to the teacher explain a mathematics lesson is the } \\
\text { most effective way to learn mathematics }\end{array}$ & 9; [1] \\
\hline 11 & Children need to link and experience mathematics in a context & 9; [1] \\
\hline 12 & $\begin{array}{l}\text { Effective mathematics teachers enjoy learning and 'doing' } \\
\text { mathematics themselves }\end{array}$ & 8 \\
\hline 13 & $\begin{array}{l}\text { It is not necessary for teachers to understand the sources of children's errors: } \\
\text { follow up instruction will correct their difficulties }\end{array}$ & 4 \\
\hline 14 & $\begin{array}{l}\text { I would feel uncomfortable if a child suggested a solution to a mathematical } \\
\text { problem that I hadn't thought of previously }\end{array}$ & 4 \\
\hline 15 & $\begin{array}{l}\text { If a child's explanation of a mathematical solution doesn't make } \\
\text { sense to the teacher it is best to ignore it }\end{array}$ & 3; [1] \\
\hline 16 & $\begin{array}{l}\text { Telling the children the answer is an efficient way of facilitating their } \\
\text { mathematics learning }\end{array}$ & $2 ;[2]$ \\
\hline
\end{tabular}

Table note:

- [partly] indicates those teachers that expressed ambivalent views about the statements 
- The items in Table 4.1 were ranked in descending order from those most teacherparticipants agreed with to those agreed with least often. For example, 15 teachers agreed with Belief Card ranked \#1, and only two teachers with another two partially agreed with Belief Card ranked \#16. The Belief Cards towards the bottom of the table were those that the majority of the teachers did not agreed with.

What does Table 4.1 indicate? First, the majority of teachers $(>10)$ selected Belief Cards ranked one to nine (1-9) that view mathematics with a problem solving and pupil-centred approach to the teaching and learning of mathematics, including identifying some specific pedagogical strategies (Ranked 3, 4, and 8). From 13 to 15 of the teacher-participants agreed on the following that: 'providing children with interesting problems to investigate in small groups is an effective way to teach mathematics' (Belief Card ranked 1); 'it is important for children to be given opportunities to reflect on and evaluate their own mathematical understanding' (Ranked 2); and 'children always benefit by discussing their solutions to mathematical problem with each other' (Ranked 3). The only exception was the belief that 'it is important to cover all the topics in the mathematics curriculum' (Ranked 5). This belief reflects a content-focused teaching of mathematics that syllabus coverage is important.

About half of the teachers (eight to nine) agreed with Belief Cards ranked 10 to 12 indicating a likely diversity of views and beliefs within individual teachers (can be seen in Table 4.2). Which include, 'listening carefully to the teacher explain a mathematics lesson is the most effective way to learn mathematics' (Ranked 10: teachers agreed- $T_{1}, T_{3}, T_{5}$, $\mathrm{T}_{6}, \mathrm{~T}_{8}, \mathrm{~T}_{9}, \mathrm{~T}_{10}, \mathrm{~T}_{12}, \mathrm{~T}_{15}, \mathrm{~T}_{16}$ ); 'children need to link and experience mathematics in a context' (Ranked 11: teachers agreed- $T_{2}, T_{4}, T_{5}, T_{6}, T_{7}, T_{8}, T_{9}, T_{11}, T_{12}, T_{15}$ ); and 'effective mathematics teachers enjoy learning and 'doing' mathematics themselves' 
(Ranked 12: teachers agreed- $\mathrm{T}_{1}, \mathrm{~T}_{6}, \mathrm{~T}_{7}, \mathrm{~T}_{8}, \mathrm{~T}_{9}, \mathrm{~T}_{11}, \mathrm{~T}_{12}, \mathrm{~T}_{15}$ ). The disparity of individual teachers’ differences about these Belief Cards (Ranked 10 - 12) was inconsistent with the majorities ( $>10$ ) views and beliefs about the nature of mathematics, its teaching, and learning being problem solving and pupil-centred.

One quarter of the teachers agreed with these Belief Cards: 'It is not necessary for teachers to understand the sources of children's errors: follow up instruction will correct their difficulties' (Ranked 13); 'I would feel uncomfortable if a child suggested a solution to a mathematical problem that I hadn't thought of previously' (Ranked 14); 'if a child’s explanation of a mathematical solution doesn't make sense to the teacher it is best to ignore it' (Ranked 15); and 'telling the children the answer is an efficient way of facilitating their mathematics learning' (Ranked 16). However, one teacher [ $\mathrm{T}_{9}$ ] believes number 15 only works in some situations. Only two teachers $\left[T_{3}, T_{16}\right]$ believed that 'telling the children the answer is an efficient way of facilitating their mathematics learning' (Ranked 16), whereas the other two teachers $\left[\mathrm{T}_{4}, \mathrm{~T}_{8}\right]$ partly believed so that it can work both ways. This indicated that the majority of the teachers do not believe providing direct answers to mathematical problems affects mathematics learning more than pupils working out their own solutions. Few teachers opted for these Belief Cards tended to reflect an opposing views and beliefs about the nature of mathematics, teaching, and learning as problem solving and pupil-centred.

Some teachers explained why they choose certain Belief Cards. Some common reasons given were: That the beliefs represent effective mathematics teaching approaches; the approaches develop children's knowledge and skills; they matched their beliefs about teacher learning; where learning occurs; classroom practices; what should be done; what 
kinds of things do not occur in the classroom; and beliefs based on their understanding, experience, and what they see.

The individual teachers' results showed in Table 4.2 indicate some characteristics of beliefs. Individually, they showed patterns of beliefs, for examples, teachers $\left[\mathrm{T}_{6}, \mathrm{~T}_{8}, \mathrm{~T}_{9}\right]$ agreed with almost all of the belief statements provided whereas teacher $\left[\mathrm{T}_{1}\right]$ only agreed with seven, and $\left[\mathrm{T}_{14}\right]$ could only agree with two belief statements (Ranked 3 and 5). It seems teachers between five to ten years of experience chose more cards than those with fewer or many years of experience. There are no obvious relationships in terms of beliefs amongst those who chose only a few and those who choose many. But it appeared in the Table 4.2 that each individual teacher's beliefs and views about mathematics, its teaching, and learning reflected a combination of contemporary-constructivist in nature (problem solving and pupil-centred), and those that showed traditional-transmission orientation (teacher-directed or dominant) as highlighted. For example, teacher $\left[\mathrm{T}_{1}\right]$ showed ten white cells that reflect the constructivist nature of mathematics and showed six light blue cells that reflect the traditional transmission approach of mathematics. The ranking itself almost showed the cards that reflect the traditional transmission towards the bottom and more constructivist in nature towards the top. On the other hand, teacher $\left[\mathrm{T}_{12}\right]$ chooses cards that reflect the constructivist nature of mathematics and also disagreed with cards that reflect the traditional-transmission nature of mathematics by not choosing them (Blank cell). 
Table 4. 2: Teachers individual results of the Belief Cards statements

\begin{tabular}{|l|l|l|l|l|l|l|l|l|l|l|l|l|l|l|l|l|}
\hline Cards & $\mathrm{T}_{1}$ & $\mathrm{~T}_{2}$ & $\mathrm{~T}_{3}$ & $\mathrm{~T}_{4}$ & $\mathrm{~T}_{5}$ & $\mathrm{~T}_{6}$ & $\mathrm{~T}_{7}$ & $\mathrm{~T}_{8}$ & $\mathrm{~T}_{9}$ & $\mathrm{~T}_{10}$ & $\mathrm{~T}_{11}$ & $\mathrm{~T}_{12}$ & $\mathrm{~T}_{13}$ & $\mathrm{~T}_{14}$ & $\mathrm{~T}_{15}$ & $\mathrm{~T}_{16}$ \\
\hline 1 & $\mathrm{y}$ & $\mathrm{y}$ & $\mathrm{y}$ & $\mathrm{y}$ & $\mathrm{y}$ & $\mathrm{y}$ & $\mathrm{y}$ & $\mathrm{y}$ & $\mathrm{y}$ & $\mathrm{y}$ & $\mathrm{y}$ & $\mathrm{y}$ & $\mathrm{y}$ & & $\mathrm{y}$ & $\mathrm{y}$ \\
\hline 2 & $\mathrm{y}$ & $\mathrm{y}$ & $\mathrm{y}$ & $\mathrm{y}$ & $\mathrm{y}$ & $\mathrm{y}$ & $\mathrm{y}$ & $\mathrm{y}$ & $\mathrm{y}$ & & $\mathrm{y}$ & $\mathrm{y}$ & $\mathrm{y}$ & & $\mathrm{y}$ & $\mathrm{y}$ \\
\hline 3 & & $\mathrm{y}$ & $\mathrm{y}$ & $\mathrm{y}$ & $\mathrm{y}$ & $\mathrm{y}$ & $1 / 2$ & $\mathrm{y}$ & $\mathrm{y}$ & & $\mathrm{y}$ & $\mathrm{y}$ & $\mathrm{y}$ & $\mathrm{y}$ & $\mathrm{y}$ & $\mathrm{y}$ \\
\hline 4 & $\mathrm{y}$ & $\mathrm{y}$ & $\mathrm{y}$ & $\mathrm{y}$ & $\mathrm{y}$ & $\mathrm{y}$ & $\mathrm{y}$ & $\mathrm{y}$ & $\mathrm{y}$ & & $\mathrm{y}$ & $\mathrm{y}$ & $\mathrm{y}$ & & $\mathrm{y}$ & \\
\hline 5 & $\mathrm{y}$ & $\mathrm{y}$ & $\mathrm{y}$ & $\mathrm{y}$ & $\mathrm{y}$ & $\mathrm{y}$ & $\mathrm{y}$ & $\mathrm{y}$ & $\mathrm{y}$ & & & & & $\mathrm{y}$ & $\mathrm{y}$ & $\mathrm{y}$ \\
\hline 6 & $\mathrm{y}$ & $\mathrm{y}$ & & $\mathrm{y}$ & $\mathrm{y}$ & $\mathrm{y}$ & $1 / 2$ & $\mathrm{y}$ & $\mathrm{y}$ & $\mathrm{y}$ & & $\mathrm{y}$ & $\mathrm{y}$ & & $\mathrm{y}$ & $\mathrm{y}$ \\
\hline 7 & & $\mathrm{y}$ & $\mathrm{y}$ & $\mathrm{y}$ & $\mathrm{y}$ & $\mathrm{y}$ & & $\mathrm{y}$ & $\mathrm{y}$ & $\mathrm{y}$ & & $\mathrm{y}$ & $\mathrm{y}$ & & $\mathrm{y}$ & \\
\hline 8 & & $\mathrm{y}$ & & $\mathrm{y}$ & $\mathrm{y}$ & $\mathrm{y}$ & & $\mathrm{y}$ & $\mathrm{y}$ & $\mathrm{y}$ & & $\mathrm{y}$ & $\mathrm{y}$ & & & $\mathrm{y}$ \\
\hline 9 & & & & $\mathrm{y}$ & & $\mathrm{y}$ & $\mathrm{y}$ & $\mathrm{y}$ & $\mathrm{y}$ & & $\mathrm{y}$ & $\mathrm{y}$ & $\mathrm{y}$ & & $\mathrm{y}$ & $\mathrm{y}$ \\
\hline 10 & $\mathrm{y}$ & & $\mathrm{y}$ & & $\mathrm{y}$ & $\mathrm{y}$ & & $\mathrm{y}$ & $\mathrm{y}$ & $\mathrm{y}$ & & $\mathrm{y}$ & & & $1 / 2$ & $\mathrm{y}$ \\
\hline 11 & & $\mathrm{y}$ & & $\mathrm{y}$ & $\mathrm{y}$ & $\mathrm{y}$ & $1 / 2$ & $\mathrm{y}$ & $\mathrm{y}$ & & $\mathrm{y}$ & $\mathrm{y}$ & & & $\mathrm{y}$ & \\
\hline 12 & $\mathrm{y}$ & & & & & $\mathrm{y}$ & $\mathrm{y}$ & $\mathrm{y}$ & $\mathrm{y}$ & & $\mathrm{y}$ & $\mathrm{y}$ & & & $\mathrm{y}$ & \\
\hline 13 & & & & $\mathrm{y}$ & & $\mathrm{y}$ & & & $\mathrm{y}$ & & & & $\mathrm{y}$ & & & \\
\hline 14 & & $\mathrm{y}$ & $\mathrm{y}$ & & & & $\mathrm{y}$ & & $\mathrm{y}$ & & & & & & & \\
\hline 15 & & & & $\mathrm{y}$ & & $\mathrm{y}$ & & $\mathrm{y}$ & $1 / 2$ & & & & & & & \\
\hline 16 & & & $\mathrm{y}$ & $1 / 2$ & & & & $1 / 2$ & & & & & & & & $\mathrm{y}$ \\
\hline
\end{tabular}

Table note:

- $\quad$ The same ranking used in Table 4.1 is retained in Table 4.2

Key: $\quad$ - agree with the belief statement

$1 / 2$ : partly agree or believe

Blank cell: not selected and disagreed

Un-shaded cell: showing constructivist in nature by individual teacher choices (by choosing constructivist cards and not choosing)

Shaded light blue: showing traditional-transmission orientation by a teacher's choices

(by choosing transmission cards and not choosing)

In summary, the teachers' reported beliefs based on the Belief Cards exercise about mathematics, mathematics teaching, and mathematics learning showed that:

- The majority of the teachers reported holding problem solving and a pupil-centred view about mathematics (constructivist in nature) (Belief Cards ranked one to nine).

- Although the majority agreed with mathematics as problem solving and pupilcentred in nature, individual teachers had different views when it came to specific teaching and learning approaches. 
- Although fewer teachers held beliefs that reflect the traditional views about mathematics than those beliefs that reflect the constructivist views, nearly all of the teachers had displayed a combination of contemporary-constructivist and traditional-transmission beliefs and views (Table 4.2 shown by teachers with different colours).

Further interpretation of these results follows in section 4.3. Before going into the broad theme of 'pedagogical content knowledge', three lead-on questions in the interview protocol (Appendix 3) also related to teacher beliefs about mathematics, its teaching, and learning, as they were designed to examine: teacher feelings towards mathematics, the teacher's role in the teaching and learning of mathematics, and teacher monitoring of pupils' learning progress in mathematics. The results from these questions are reported next.

\subsubsection{Teachers' feelings towards mathematics}

Finding out about how teachers feel about teaching mathematics is important because as teachers share their thoughts, feelings, attitudes, and experiences about teaching mathematics, they are likely to also reveal their internalised views and beliefs about mathematics in general. In this study teachers expressed mixed feelings about mathematics.

Six of the teachers described teaching mathematics as generally interesting $\left[T_{1}, T_{2}, T_{3}, T_{5}\right.$, $\left.\mathrm{T}_{8}, \mathrm{~T}_{15}\right]$, as part of our life $\left[\mathrm{T}_{15}\right]$, living $\left[\mathrm{T}_{12}\right]$, and difficult at times $\left[\mathrm{T}_{3}\right]$. It was considered interesting but with some difficulties by one teacher $\left[T_{3}\right]$. Teacher $\left[T_{16}\right]$ enjoys the new Nguzu Nguzu maths curriculum because they believe it is more practical than the previous 
curriculum. Another teacher $\left[\mathrm{T}_{13}\right]$ also likes the new Nguzu Nguzu maths curriculum because they view it as involving the processing of learning and contextually based. A quarter of the teachers reported enjoying teaching mathematics $\left[T_{6}, T_{9}, T_{10}, T_{12}\right]$ but at the same time they had some concerns. For example, they considered teaching mathematics only to be enjoyable when you are prepared $\left[T_{9}, T_{10}\right]$, have the required resources, and time. Teacher $\left[\mathrm{T}_{6}\right]$ 's response was “I enjoy mathematics but materials are a problem. Sometimes units are not covered in detail because of a lack of materials” (translation).

Teacher $\left[\mathrm{T}_{8}\right]$ stated: "For primary level, there are other subjects to teach as well. If I only teach maths then I will enjoy it because my belief will be 100 per cent but there are other subjects to teach” (translation).

Teacher $\left[\mathrm{T}_{14}\right]$ stated that she only enjoyed teaching certain topics in mathematics because of her confusion about other topics. Responses also revealed that some teachers only teach the topics they are comfortable with and they skim through or skip the others. Teacher $\left[\mathrm{T}_{7}\right]$ described mathematics as not an easy subject, requiring good knowledge with good explanations. Teacher $\left[\mathrm{T}_{4}\right]$ commented that at first teaching mathematics at the present school was quite scary but as time went by she felt confident, and now she could sometimes even teach mathematics at the secondary school level.

In short, the results show that nearly all of the participating teachers felt teaching mathematics to be interesting, enjoyable, and two teachers did mentioned their support for the new Nguzu Nguzu maths curriculum. However, according to the Belief Cards exercise only half believed that 'effective mathematics teachers enjoy learning and 'doing' mathematics themselves'. 


\subsubsection{Teachers' practice}

\subsubsection{Teachers' primary role in teaching and learning mathematics}

The teachers were asked to describe their primary role when it comes to the teaching and learning of mathematics. Based on the initial clustering of emerging roles and the emerging theme titles, the following three superordinate themes emerged: (1) to provide assistance, (2) to impart knowledge and skills, and (3) to provide guidance (summarised in Table 4.3).

Table 4.3: Teacher's primary role as reported by participants

\begin{tabular}{|l|l|}
\hline Superordinate themes & \multicolumn{1}{c|}{ Teacher's role } \\
\hline Provide assistance & $\begin{array}{l}\text { General assistance } \\
\text { Assistance in solving problems } \\
\text { Provide explanation }\end{array}$ \\
\hline $\begin{array}{l}\text { Impart Knowledge } \\
\text { \& Skills }\end{array}$ & $\begin{array}{l}\text { Extend current knowledge and skills } \\
\text { for further education and life after schooling }\end{array}$ \\
\hline Provide guidance & $\begin{array}{l}\text { To guide learning } \\
\text { Guide pupils' understanding \& activities } \\
\text { To demonstrate or display } \\
\text { Provide hints \& direction } \\
\text { Encourage learning } \\
\text { Develop pupils own mathematical thinking and concepts }\end{array}$ \\
\hline
\end{tabular}

More than half of the teachers stated that their role in the teaching and learning of mathematics was to provide assistance and guidance $\left[T_{3}, T_{4}, T_{5}, T_{8}, T_{9}, T_{11}, T_{12}, T_{14}, T_{15}\right]$. Less than a quarter stressed that their role was to impart knowledge and skills $\left[T_{2}, T_{3}, T_{5}\right]$ and these teachers have comparatively little experience. One third of the teachers believed their role was to guide pupils. There are overlapping roles under these themes, for example, providing assistance in solving problems could mean providing hints and directions and developing pupils' concepts which in turn could mean guiding pupils' understanding about mathematics concepts. 
Other roles stated by individual teachers included the importance of showing good character or attitude, being a role model $\left[\mathrm{T}_{9}, \mathrm{~T}_{11}\right]$ and motivating pupils $\left[\mathrm{T}_{4}\right]$. Teacher $\left[\mathrm{T}_{10}\right]$ stated that their role: "Is to make sure that I teach that particular subject, make sure I explain better to the children, the children must know what to do, make sure no one child is left out, help them out during activities, move around to see who needs help". (translation).

Teachers expressed a number of roles and functions relating to the teaching and learning of mathematics (Table 4.3). These roles are likely to relate to their beliefs about the teaching and learning of mathematics (Section 4.2.1).

\subsubsection{Monitoring pupils' learning progress}

The participants mentioned that they monitor pupils' progress mainly through daily activities, lessons, work, and assessments $\left[T_{2}, T_{3}, T_{4}, T_{8}, T_{12}, T_{14}, T_{15}\right]$, and through knowing the pupils and their responses $\left[\mathrm{T}_{1}, \mathrm{~T}_{6}, \mathrm{~T}_{10}, \mathrm{~T}_{13}\right]$. Some teachers apply grouping pupils as a strategy $\left[T_{4}, T_{6}, T_{7}\right]$. For example, one teacher $\left[T_{6}\right]$ applied a 'seating arrangement' for shy or weaker pupils who normally opted to sit at the back. This ensured that these pupils sat at the front, and received interaction and developed confidence according to the teacher. Another teacher $\left[\mathrm{T}_{9}\right]$ using a 'learning improvement' book: "I used one book called 'learning improvement'. Use it to track down and locate slow learners and I must find out where the root cause is". The teacher reported this strategy worked well to monitor pupils' learning progress.

Using topic or unit tests was most the commonly reported way of monitoring pupils' learning progress $\left[\mathrm{T}_{1}, \mathrm{~T}_{4}, \mathrm{~T}_{12}, \mathrm{~T}_{13}, \mathrm{~T}_{15}, \mathrm{~T}_{16}\right]$, although, one teacher $\left[\mathrm{T}_{10}\right]$ stated that, "I don't see students' weaknesses in tests but through observing my students doing their work" 
(translation). Other monitoring methods mentioned by teachers include Nguzu Nguzu Check Up pages $\left[\mathrm{T}_{5}, \mathrm{~T}_{9}\right]$, observation $\left[\mathrm{T}_{1}, \mathrm{~T}_{4}\right]$, homework $\left[\mathrm{T}_{12}\right]$, and mental calculations $\left[\mathrm{T}_{5}\right]$

The results indicate that the study teachers use wide range of formative and summative tasks to monitor their pupils’ progress and hence their numeracy outcomes. Some teachers used more than one method of monitoring their pupils’ learning progress as reported.

\subsubsection{Teacher pedagogical content knowledge}

The results of the investigation of teacher pedagogical content knowledge were gathered under three broad themes: (1) knowledge of content, (2) knowledge of curriculum, and (3) knowledge of teaching mathematics (Section 2.2)

\subsubsection{Knowledge of content}

Knowledge of content involves broad and specific content in the Nguzu Nguzu maths curriculum. Teachers were asked to share their experiences and their understanding of the difficulty of some strands or units in the Nguzu Nguzu mathematics curriculum to examine their subject content knowledge. Probing questions were also asked which included topic preference of teachers and pupils, and the content areas which pupils found most difficult.

\section{i) Difficulties teachers faced with the current Nguzu Nguzu content}

Although teachers did not specifically describe their weaknesses and strengths in the current curriculum content (strands/topics), they stressed a number of important conditions for success with the new curriculum and discussed the content of the current Nguzu Nguzu curriculum and the previous curriculum (HBJ). 
Some of the important conditions expressed by teachers to avoid misconceptions and misunderstanding in teaching the current curriculum were: teachers having good knowledge and understanding of mathematics $\left[T_{2}, T_{5}\right]$; teachers knowing the mathematics vocabulary very well in order for the pupils to understand, especially when it comes to written work $\left[\mathrm{T}_{15}\right]$; early preparation to avoid misunderstanding by teachers $\left[\mathrm{T}_{9}\right]$; training in constructivist teaching strategies $\left[\mathrm{T}_{9}\right]$; and teachers having the ability and confidence to be effective in their approaches to handle any curriculum $\left[\mathrm{T}_{5}\right]$. This same teacher mentioned that "staka teachers long side long mathematics garem less knowledge, even College givim less knowledge”, meaning that most primary school teachers have inadequate knowledge in mathematics and to some extent rely on what they were taught in their own secondary education; resulting in shallow content knowledge. One teacher $\left[\mathrm{T}_{6}\right]$ states that "somefala units hem more advance, some simple or no gud me nao me no understandem units ia". Here the teacher mentioned that some maths units are quite advanced for him, and this may be due to his lack of advanced theoretical understanding of some mathematical concepts covered by the curriculum.

In addition, most participating teachers reported they appreciated the new Nguzu Nguzu curriculum, although a few teachers were concerned about its content, format, and approaches. Some teachers from Honiara public schools made the following comments about the new Nguzu Nguzu mathematics curriculum: “The Nguzu Nguzu maths is quite difficult to teach compared to HBJ. Class 3 Nguzu Nguzu is okay but class 4 is a bit complicated. Teachers need good reading; maybe because I didn't attend the Nguzu Nguzu training. Only two teachers from this school attended the training” ${ }^{\left[T_{3}\right]}$ (translation). "The Nguzu Nguzu format is a bit hard for me compared with the old previous curriculum” $\left[\mathrm{T}_{14}\right]$ (translation). 
Teacher $\left[\mathrm{T}_{3}\right]$ expressed her difficulties with the Nguzu Nguzu maths curriculum and attributes this to her lack of training for the Nguzu Nguzu. She $\left[\mathrm{T}_{3}\right]$ believed that the old curriculum was better because that is how she was taught during her schooling days and it was easy for her. Teacher $\left[\mathrm{T}_{14}\right]$ has been teaching for the last twenty-three years. For this reason she had mastered the old curriculum format and so she reported that adapting to this new Nguzu Nguzu curriculum was a challenge for her. This is an example of how teacher beliefs and practices are influenced by how they themselves have been taught or trained.

In general, about 50 per cent of teachers placed a strong emphasis on having adequate knowledge and understanding of the subject in order to teach mathematics effectively. Although the teachers did not spell out directly which particular topics were difficult in mathematics, they felt that they had insufficient content knowledge and understanding in some of the topics. Similarly, they felt the need for effective teaching strategies and timely preparation was important.

\section{ii) Pupils' difficulties with mathematics}

This discussion of pupils' difficulties is based on teachers' descriptions. Nearly all teachers reported pupil difficulties in some topic areas. The teachers' perceptions of pupils' difficulties included consideration of concepts, working with numbers, and mathematical application (Box 4.1). 


\section{Box 4.1: Teachers' perceptions on pupils' areas of difficulties}

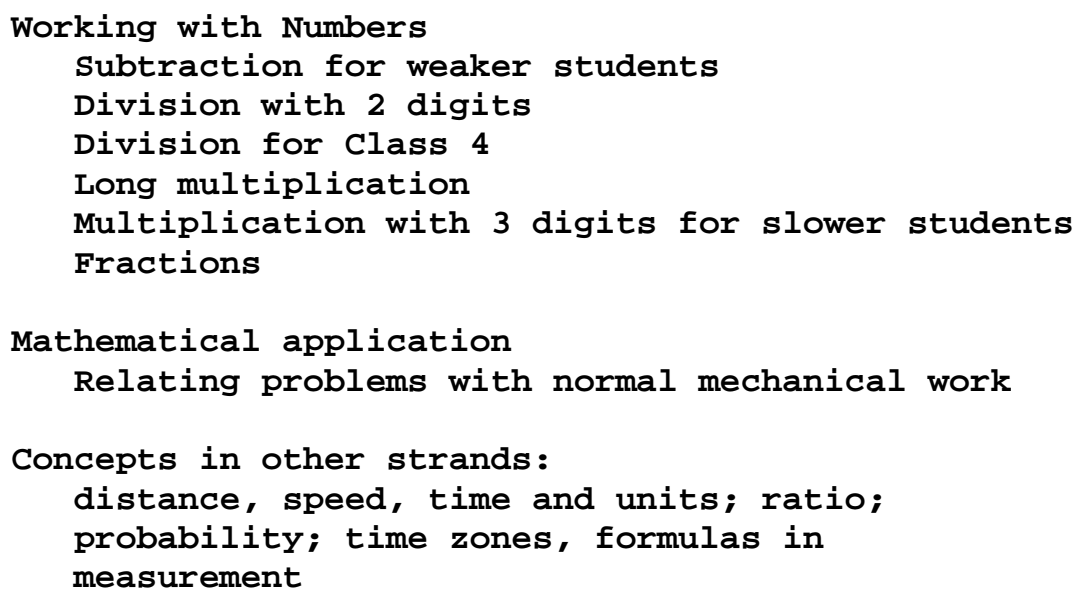

According to teachers, not all pupils share similar areas of difficulties. They reported that the weaker pupils in maths have much more difficulty than others in understanding some of the basic mathematical concepts, for example, working with numbers involving division with two digits or long multiplication.

In my opinion, some concepts listed in Box 4.1 may be quite abstract for the pupils. For example, concepts involving ratio, probability, or measurement may be problematic. As one teacher $\left[\mathrm{T}_{5}\right]$ puts it, "teachers nao mas learn more and not to depend on text books, teachers should develop their own approaches”. In other words, he is trying to discourage teacher text-book dependency and encourage teachers to have in-depth understanding in order to develop their own teaching approaches.

One teacher $\left[\mathrm{T}_{15}\right]$ described that pupils were put off when they attempted mathematical problems involving words and comprehension in her upper classes:

“One big problem me findem long maths long upper grade is relating problems with normal mechanical work. Me save talem that olketa pikinini ia, if givim mechanical work they can 
do it alright, but as should as words hem come withim olketa throw off na, so hem meanim the comprehension part na olketa findem problem long hem".

The same teacher $\left[T_{15}\right]$ added that she found pupils are fine when using mathematical formulae but have problems when it comes to mathematics applications.

Teacher $\left[T_{1}\right]$ stated that many pupils did not show interest in mathematics and her belief was that they could do better if they showed more interest.

Teachers in general agreed that in average pupils lack basic numerical knowledge and skills when they reach the upper classes. This was of grave concern to the majority of the teachers in public schools, and a few of the teachers from private schools. Teacher $\left[\mathrm{T}_{13}\right]$ stated believing that better preparation in lower classes would help alleviate some of the pupils' misconceptions or difficulties faced in the upper classes.

The difficulties pupils faced were reported as being mainly relating to conceptual understanding and application.

\subsubsection{Knowledge of curriculum}

This section describes how teachers reported identifying effective curriculum materials and resources ${ }^{13}$ to support their teaching. Participants were asked if they faced challenges regarding selecting materials. Most participants responded in terms of the availability of resources. Half of the participants were satisfied with what is currently available, whereas the other half claimed there were insufficient resources.

${ }^{13}$ Resources included text books, equipment, and all other support materials for classroom mathematics activities. 


\section{Sufficient resources}

Teachers who felt there were sufficient resources were content with the current resources/materials provided by both schools and the Curriculum Development Centre. However, teachers $\left[T_{4}, T_{7}\right]$ from private schools pointed out that although resources and materials were available or could be made available; “mefala resources hem stap, mefala nomoa no save usim" $\left[\mathrm{T}_{7}\right]$, it is their lack of creativity that impinged on their use. Another teacher $\left[T_{16}\right]$ mentioned that he sometimes adds his own materials to complement what is available at school.

The majority of teachers claiming sufficient resources were in the private schools, such as church schools. As one church run school teacher remarked, "long here mefala no garem problem, school save providem everything, mefala just to submit nomoa olketa things mefala needim, but long other public schools hem nao problem, school sometimes no garem money fo those materials you need" $\left[\mathrm{T}_{2}\right]$. The teacher is comparing how easy it is for them to get materials they need in their school in contrast to public schools where financial support can be difficult.

\section{Insufficient resources}

Most of the teachers who felt about insufficient resources were predominantly from the public schools. The majority of the schools in Honiara are public schools. These teachers expressed a lack of materials from general to specific equipment $\left[T_{1}, T_{3}, T_{5}, T_{6}, T_{10}, T_{12}, T_{13}\right.$, $\left.\mathrm{T}_{14}\right]$. These teachers expressed their feelings about the lack of resources along with a lack of positive response from their supervisors (headmasters/principals) about this situation. One teacher stated that the normal excuse given for is the lack of money to purchase materials. 
Some of the teachers' responses about insufficient resources were:

"Time no enough resources bae samfala time side lo toktok nomoa lo oketa pikinini but pikinini need for lukim resources you usim ia so most of the time mifala duim blackboard waka nomoa ia" $\left[\mathrm{T}_{3}\right]$. (Translated- when there are not enough resources, sometimes only verbal teaching but pupils need to see the resources that are going to be used and most of the times resort to blackboard teaching.)

"Units long angle cos me no garem nao protractor for measuring" [ $\left.\mathrm{T}_{6}\right]$. (Translatedlack of protractor to actually measure angles.)

"Most time mefala usim nomoa books ia (Teachers guide, students bk) and no garem extra resource for support. In terms of equipment, mefala no garem measuring cylinder, scale, so sometimes mefala skip over nomoa, cos time mefala ask school no garem money" $\left[\mathrm{T}_{10}\right]$. (Translated: Most times we use books (the Teacher's Guide and Students' books) because there are no extra resources to support. In terms of equipment, we do not have measuring cylinder, scale, therefore sometimes we skip those units since the school has no money to purchase these materials.)

"Mifala lo hia challenge ia nomoa is that mifala no garem samfala extra apparatus like weight and capacity mifala no garem what for showm lo hem, mass, mifala no garem so the hardest thing now is mi teach without those. So mi go pickim nomoa oketa tin wea garem labels finish na ia, this one mass blo hem olsem ia weight blo hem olsem ia capacity blo hem olsem hem nomoa but if any extra apparatus for mifala garem lo school moa na, sorry, nomoa" $\left[\mathrm{T}_{12}\right]$. (Translated: We do not have extra apparatus to show for weights, capacity, and mass. That is the hardest thing to teach without these. Therefore, what I did is using 'tin' foods that have labels on them showing their mass or weight and capacity.)

The challenges discussed by teachers included the lack of specific apparatus such as measuring equipment. As a result, teachers reported that teaching is mostly done verbally and on the blackboard without practical activities to support teaching.

Another teacher described that, "First year me garem that problem, time me kam long second year, me improve, me findem ways although materials hem scarce. Me save feel guilty if 
resources/materials not available esp. for long samfala units” $\left[\mathrm{T}_{5}\right]$. This teacher mentioned that the first year of teaching was a challenge because of insufficient materials required for certain units, but in following years things started to improve as he explored alternative ways of doing things. He mentioned having a guilty conscience if resources were not available for particular units and pupils were not able to experience the real thing.

\subsubsection{Knowledge of teaching}

Teachers' knowledge of teaching was captured through their discussions of their best lessons, teaching styles and strategies, and their accounts of their pupils' preferred teaching methods.

\section{i) Representations of best practice}

Teachers were asked to describe one of the best lessons they had given recently. It was hoped that these lesson descriptions would indicate the kinds of practices teachers carried out. Teachers provided a range of lessons from different topics and some indicated lesson strategies (Box 4.2) selected for one of two reasons: the teacher feeling satisfied with the lesson outcome or had observed that the pupils enjoyed the lesson. Their account for these lessons follows next.

More than a quarter of the teachers identified a fraction lesson as their best lesson. Teaching fractions includes range of units and teachers have identified certain units within the strand of fractions from the Nguzu Nguzu Mathematics curriculum. For example, teacher $\left[\mathrm{T}_{16}\right]$ commented that the lesson about 'conversion of fractions' was one of the best. Teacher $\left[\mathrm{T}_{11}\right]$ identified 'division of fraction' was his best. The list continued for other lessons as listed (Box 4.2). 
Box 4.2: Teachers' best lessons

Fractions (T2, T3, T9, T11, T16)

Finding circumference (T12)

Angles and volumes (T9)

Multiplication (T5)

Money relating to real context (T10)

Negative and positive (T14)

Mixed operations of numbers (T1)

Time: everybody's business (T13)

Finding out per cent discount (T15)

Lesson strategies: lesson recapping and reflecting (T4)

: encouraging feed-forward from pupils (T9)

The following comments were made about the teachers' best lessons:

"Fraction hem gud becos hem bara clear na and everything lo there na ia, you demonstrate like you drawm picture and if you writim digit or number for shadim then ba oketa save follom then draw then shade. Students oketa interest and oketa fast for finish time mi givim waka lo blackboard. Oketa garem interest lo hem fo duim so time mi givim oketa extra waka ba oketa duim na" $\left[\mathrm{T}_{3}\right]$. (The teacher reported that the pupils were interested in doing fractions after they had seen several demonstrations and the pupils could work by themselves either shading pictures or drawing, and they can do blackboard tasks very quickly.)

"Best topic mi save enjoyem na fractions Fractions na mi bara enjoyem. You teachem fraction, you convertim fraction into decimal fraction the percentage oketa ia, mekem mi enjoyem, then putim go lo oketa pikinin oketa easy fo duim na, putim lo fraction, percentage and decimal fraction" $\left[\mathrm{T}_{16}\right]$. (This particular teacher enjoys doing conversion of fractions into decimals or percentage and the pupils find it easy.)

"Finding circumference, one fala best lesson mi teachem this year and every single pikinini lo class ia oketa tekem very fast, within one day. Using pie as 3.14 and finding circumference and radius blo hem, mi no usim diameter mi usim radius. Radius ia for oketa findem as pie times $r$ times 2 but mi no go further to find areas mi only concentrate nomoa lo circumference. Whole class 6 ia ... hem nomoa ia. You givim lo oketa for answerem lo two minites ia. The best one mi meetim na ia and hao mi teach kam too.this one na best lesson ia, one day nomoa, next day mi givim oketa flow,cos ba oketa seleva ask 'teacher what is 
pie?'mi se 3.14 finish oketa save na becos formulae ia mi givim clear lo oketa" [ $\left.\mathrm{T}_{12}\right]$. (This lesson is about finding circumference and radius of a circle using its formula. Pupils found it quite easy using the formula and could finish off very quickly.)

“Mi work wetimna oketa top students ia, wea oketa bara stay alone stay quiet and work by themselves, mi just recap nomoa wetim previous lessons ia and mifala reflect for few minuites and then oketa say that oketa bae waka seleva, so mi just roam around and lukim hao na oketa work, so tuday na best lesson mi teachem" [ $\left.\mathrm{T}_{4}\right]$. (The teacher's best lesson was when pupils were working quietly themselves, and the teacher was just there to recap the previous lessons and reflect for few minutes.)

"Last year, me barava satisfy, about money, me providem staka things, like cards, by end of lesson most kids getem nao want mefala try fot duim. Relate money to shops, games" $\left[\mathrm{T}_{10}\right]$. (The teacher used games and a variety of teaching aids related to money, and the pupils easily understood what they were doing.)

Another teacher mentioned the topic areas of fractions, angles and volume; however, reported his best lesson was when he received good feed-forward from his pupils [ $\left.\mathrm{T}_{9}\right]$.

"Side long mixed operation of numbers. Everyone interest long hem, me no save whether hem simple or nomoa" [ $\left.\mathrm{T}_{1}\right]$. (Translated- Everyone is interested in mixed operation of numbers, I do not know whether [mixed operations] is that simple or not.)

"Finding out per cent on discount, something on sale and if 20 per cent discount how much $u$ will spend. B'cos olketa save relatim go long real context" $\left[\mathrm{T}_{15}\right]$. (When finding out selling prices from a discounted percentage because pupils managed to relate this to a real situation.)

The comments made by teachers portrayed a number of emphases in terms of the teaching and learning of mathematics, for example, some teachers' emphasis on speed and the use of formulas or algorithms as judgments for a 'good' lesson. Pupils working fast to complete a given task and the use of formulas or algorithms more than on conceptual underpinnings (e.g., in the example of circumference) were considered as success by some 
teachers. The description indicates that pupils in some teachers' classes may be led to believe mathematics is as easy as putting numbers in a formula and coming up with an answer.

There were some important lesson strategies used by some teachers. For example, the notion about lesson recapping and reflection are essential for teachers and pupils [ $\left.\mathrm{T}_{4}\right]$. In my view, this is an important strategy to gauge what pupils have done or learned. Similarly, the strategy involving getting feed-forward from the pupils $\left[\mathrm{T}_{9}\right]$ is another important example of reflection in teaching and learning. The lesson involving money where pupils were able to relate it to real life experiences was another useful example of effective practice. These strategies as applied in variety of lessons described by few teachers are consistent with practices described in the literature as effective mathematics teaching practices, for example, the inquiry-oriented approach (Stipek et al., 2001), the convergent process (An et al., 2004) or the ZPD approach (Haylock \& Thangata, 2007; Reid, 2005).

\section{ii) Teaching styles and strategies used in mathematics}

Teachers were asked to describe the teaching styles or strategies they had employed in mathematics teaching and learning. More importantly, the study sought their knowledge and understanding of learning theories, considered a vital ingredient to enable the kinds of teaching strategies or techniques needed to enhance pupils’ learning (Haylock \& Thangata, 2007; Reid, 2005). A probing question was used to ask about their knowledge and understanding about any learning theories they may have come across as trainee teachers. 
Teachers reported a number of teaching styles or strategies (Box 4.3). Some teacherparticipants indicated using more than one teaching style or strategy. Some teachers may only have indicated a single style or strategy, although they may use more than one.

\begin{tabular}{l} 
Box 4.3: Reported teaching styles and strategies \\
Working in Groups ( $\mathrm{T} 1, \mathrm{~T} 2, \mathrm{~T} 3, \mathrm{~T} 5, \mathrm{~T} 6, \mathrm{~T} 8, \mathrm{~T} 9, \mathrm{~T} 10, \mathrm{~T} 11, \mathrm{~T} 12, \mathrm{~T} 14)$ \\
Hands on activities (T7, T15) \\
Learning independently (T12) \\
Outdoor teaching ( T12) \\
Night classes (T12) \\
Chalkboard (T1) \\
Homework (T1) \\
Self discovery (T2) \\
\hline
\end{tabular}

Consistent with the Nguzu Nguzu curriculum (Section 1.1.3), working in groups is the most common teaching approach teachers reported (11 teachers). When it comes to group work, more than one strategy can be applied as described by some teachers: "Lo mi, mi save duim na group work lo class becos class ia crowded tumas ia and hem crowded tumas so even if you duim group work ba group hem big but ba hem cuttem down noise and oketa pikinini save consentrate time duim group. But time you just teach general olsem ia bae noise ia narawei na ia” $\left[\mathrm{T}_{3}\right]$. The above Class 4 teacher claimed that although she applied group work, the groups were still large in number because of overcrowding. However, she found that group work helped to reduce the level of noise coming from the pupils, unlike her normal teaching, when she reports the class to be very noisy. It appeared that pupils may not be concentrating during normal teaching and that they may prefer to work with a group of their peers.

Another Class 6 teacher claimed group work as his favourite approach:

"Mi favourem na group work, they discuss, time oketa discuss they learn from each other ia so hem best that lo topic hem hard for oketa duim together becos learning, ba you save that they learn from themselves ia, becos time oketa depend lo you olowei, no any thing hem 
waka ia, heti blo oketa no waka stret na ia becos oketa olsem folom nomoa footstep blo you olowei. Waswei oketa, oketa no garem any saying? Livim oketa for oketa learn independently and time oketa learn from each other tingting blo oketa, oketa sharem na ia wea sometimes oketa for folom you ia that one hide behind brain blo oketa ia, oketa no talem, hem hard, aya time you putim oketa lo group you lukim oketa showm na ia” [ $\left.\mathrm{T}_{12}\right]$.

This teacher favours group work because he sees it as an opportunity for the pupils to discuss among themselves and in that way, learn from each other. He believes that when pupils depend entirely on the teacher, nothing seems to work out because they just follow what the teacher says and one cannot fully know what is going on in their brains. In order for them to express their own understanding, he believes it is better to allow them to work by themselves and become independent learners in groups.

The same teacher reported using two other teaching styles: outdoor classroom teaching and night classes. He mentioned that he recently tried out teaching outside the classroom. Outside the classroom they had applied a questioning and answering type of teaching strategy where pupils formed a circle around him and had open discussion on any mathematics topics. He found this strategy more satisfying for pupils and for himself than the conventional classroom setting. The night classes were held for pupils who did not understand certain topics. His night classes normally ran from 7 pm to 9 pm. He found these groups of pupils worked much better at night than during normal class times.

Teacher $\left[\mathrm{T}_{5}\right]$ similarly reported using group work for mathematical discussions with close supervision and encouraging communication and at the same time monitored the weaker pupils. This teacher often used pupils to demonstrate in front of the class as part of their group work. Likewise, Teacher $\left[\mathrm{T}_{11}\right]$ mentioned “two heads are better than one' as a 
strategy for those pupils who cannot work alone. He encouraged pupils to work with someone and sometimes formed them into groups where different problems were given to solve. He further mentioned that groups sometimes had leaders and he would allow groups to critique each other. He allowed the groups to identify their own mistakes or errors.

Teacher $\left[\mathrm{T}_{6}\right]$ stated that, "time kids hem boring and sleep, me duim somefala funny things for motivating olketa more or if pikinini hem hungry me sendem olketa home nomoa. But group work nao me lukim olsem hem gud”. Although this teacher sees group work as better than other teaching approaches, he said children sometimes feel bored, sleepy, and even hungry, so then he tries to motivate the pupils using funny jokes, and if they were hungry he would send them home. Similarly, teacher $\left[\mathrm{T}_{4}\right]$ also reported using group work to motivate pupils. This was organised through games and was treated like a race or competition between the groups. Pupils were interested with the games and quite often would ask for it $\left[\mathrm{T}_{4}\right]$. This teacher $\left[\mathrm{T}_{4}\right]$ was from a high performing school.

Teacher $\left[\mathrm{T}_{2}\right]$ reported applying a child-centred approach where pupils discover their own learning. The teacher found out that in his experience, when he explained things on the blackboard or directly to the pupils, they would quite often forget or not understand what he said; however, if the pupils themselves discovered the mathematics ideas for themselves, he felt they remembered and understood things better.

There are some participant teachers who prefer grouping pupils by ability. Others $\left[\mathrm{T}_{10}\right]$ did not believe in separating pupils in that way. She mentioned that it is important for the weaker ones to learn from the faster ones, and thus it is important to mix abilities together in mixed groups. At the same time she did not want the weaker pupils to feel that they 
were weaker. These two approaches both have their own advantages and disadvantages. For example, as she mentioned, separating the weaker ones could psychologically affect them in terms of alienation and inferiority.

Other teachers reported using teaching approaches based on what they believed pupils enjoyed or were interested in. For example, for lower classes, they stated children would prefer more hands on activities rather than the traditional blackboard teaching, and children generally liked using materials $\left[\mathrm{T}_{7}, \mathrm{~T}_{15}\right]$. On the other hand, only one teacher $\left[\mathrm{T}_{1}\right]$, apart from organising group work or activities, also reported continuing to use the chalkboard style of teaching, mental calculation, and giving out homework.

All in all, the teachers reported using a variety of styles, approaches, and strategies in their delivering of mathematics.

The following paragraphs explore teacher background knowledge and understanding of some of the important theories about learning and development (e.g., the constructivist and socio-cultural perspectives). These theoretical perspectives are believed to have helped set the platform for teachers' understanding of how children learn, and the teaching strategies needed for effective learning. The results show two scenarios for teachers: 1) those that have some knowledge and surface understanding of learning theories and 2) those that lack knowledge or basic understanding of any learning theories.

Teachers in their everyday classroom work might have come across in one way or the other some basic principles consistent with learning theories form the literature (Section 2.2.1) without realising their theoretical underpinnings. As mentioned in one or two examples above, teachers have used strategies that support constructivist views about the 
teaching and learning of mathematics. For example, the child-centred approach using group work as a strategy helps pupils to participate, engage, and discover knowledge for themselves.

Almost half of the participants described that they have come across some learning theories while undertaking their teacher training at the college. These teachers concluded that they have surface knowledge about learning theories but lack in-depth understanding. On the one hand, teacher $\left[\mathrm{T}_{11}\right]$ claimed that she had remembered writing an assignment on child development at the college and that made her vividly remember about how children grow up.

A quarter of the participants felt that they had no idea about any learning theories. When asked about constructivist-based teaching, they reported having no idea about what constructivism is. One teacher $\left[\mathrm{T}_{1}\right]$ mentioned that she could not remember anything from her teacher's college study.

\section{iii) Teachers' perceptions of pupils' preferred teaching methods}

Pupils' preferences refer to teaching methods teachers reported that their pupils appear to have enjoyed. They are important to consider in relation to teachers identifying pupils’ learning preferences which help their informed pedagogical choices.

A quarter of the teachers interviewed seemed not to have noticed any methods their pupils liked or have enjoyed. They observed that their pupils seem to accept whatever teaching methods they present. "It was a bit hard for students to tell me which method they like but then I told them to tell me about my way of teaching" $\left[\mathrm{T}_{6}\right]$ (Translation). 
Three-quarters of the teachers, however, said they did observe their pupils’ preference for certain types of teaching and learning. They observed this in a number of ways. For example, one teacher $\left[\mathrm{T}_{3}\right]$ observed that pupils preferred using the pupils' resource book for doing their work rather than the work that teacher put on the blackboard and they would ask to use the resource books. Two teachers $\left[\mathrm{T}_{10}, \mathrm{~T}_{11}\right]$ mentioned that most of their pupils enjoyed working with their peers and in groups. Another teacher $\left[\mathrm{T}_{4}\right]$ described that her pupils preferred having a game where they would challenge each other in groups before/after the lesson. Teacher $\left[\mathrm{T}_{1}\right]$ found her pupils liked to take work home and bring it the next day, like homework. Teacher $\left[\mathrm{T}_{7}\right]$ noted that her pupils often liked having options provided, especially for calculations that had alternative ways of being done and pupils would choose. Teacher [15] mentioned that her pupils enjoyed nearly everything she provided. Teacher $\left[\mathrm{T}_{2}\right]$ stated that only fast learners normally opened up and shared what they like.

Overall the analysis provided in this section on PCK (Section 4.2.3) indicates that the study teachers had mixed reactions towards the current Nguzu Nguzu maths curriculum, and they believe they must have good knowledge and understanding of mathematics in order to handle any curriculum. In terms of knowledge of curriculum materials, teachers were divided according to schools that have sufficient resources and those with insufficient resources. Lastly, knowledge of teaching (Section 4.2.3.3) seems to show some similarities between teachers' methods of teaching and their perceptions of pupils' preferences, especially in the areas of working in groups and giving out homework. It appears that there are teachers who prefer to practise a traditional or transmission model of teaching to constructivist approaches, despite their child-centred views about mathematics teaching and learning reflected in their stated beliefs (Table 4.1, Section 4.2.1). 


\section{2.4 Professional development (PD)}

In order to explore how and what form of professional support teachers have undertaken for mathematics teaching and learning, and what kind of support teachers would like to have, teacher-participants were asked whether they have attended any form of professional development activities for mathematics. The data showed there were two categories of teachers: those that had received some form of professional development support and those who had not. These are summarised in Figure 4.1.

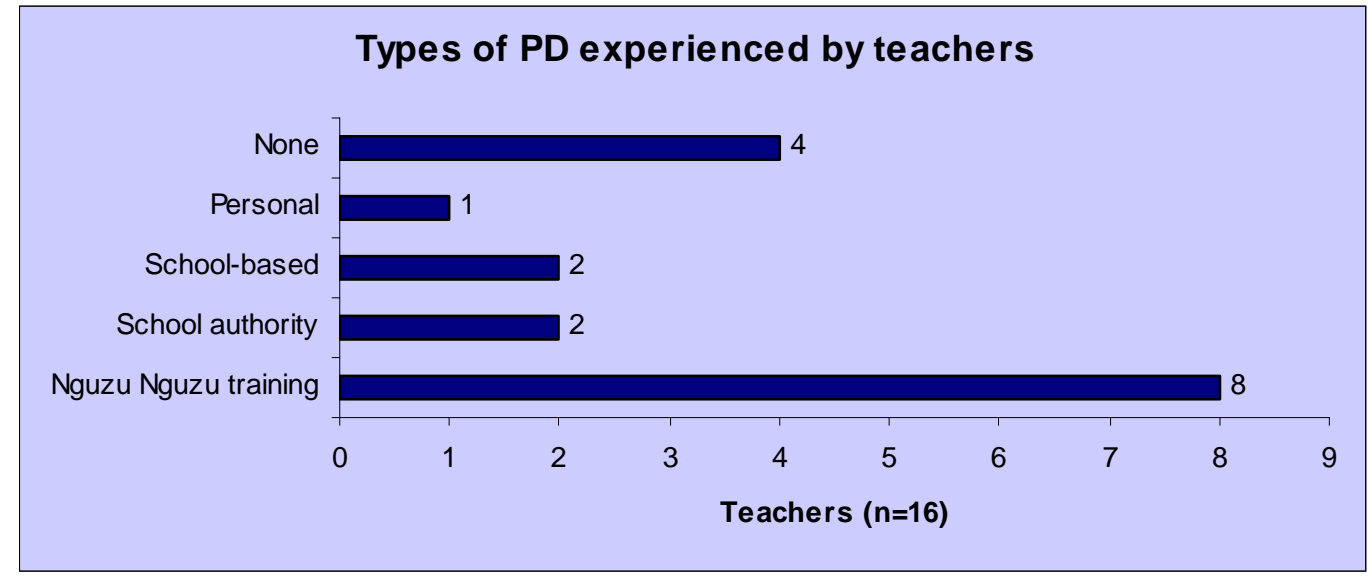

Figure 4.1: Types of PD experienced by teachers

\subsubsection{Teachers with some PD support}

Half of the participating teachers $\left[T_{4}, T_{8}, T_{9}, T_{11}, T_{12}, T_{13}, T_{14}, T_{16}\right]$ stated that they had participated in the Nguzu Nguzu mathematics training workshop when it was first introduced from the Curriculum Development Centre (Section 1.1.3). Most of the teachers who had attended the Nguzu Nguzu mathematics induction training stated that apart from Nguzu Nguzu there had been no other form of mathematics PD provided for them. 
Two of the teachers $\left[T_{2}, T_{16}\right]$ stated that their church authority often organised PD for teachers during school holidays and another two teachers $\left[\mathrm{T}_{7}, \mathrm{~T}_{15}\right]$ described PD they had received school-based PD. One described that through their church authority they have a sister school from Australia which normally conducts PD training once a year on one subject area. They had mathematics a year before the study and science the previous year. This teacher $\left[\mathrm{T}_{2}\right]$ claimed that the training provided by their sister school was very useful, especially for him. The short term PD training reminded him of some of the things he had forgotten since college and he had also discovered some of his difficulties in teaching, and this has made him become energetic in his teaching once more.

Two teachers from one private school described that they normally had school-based PD organised by the school. These two teachers mentioned that they have very good leadership from their supervisor, who monitors teachers’ work. This had greatly improved their work $\left[\mathrm{T}_{7}\right]$, compared to when they first taught at public schools where she reported that she felt teachers did whatever they wanted and there was no monitoring of teachers' work.

Teacher $\left[\mathrm{T}_{5}\right]$ explained that he did his own personal development by exploring literature about effective teaching strategies and working with a mentor. He found this to be effective in broadening his approach to teaching. For example, the mentor taught him how to calculate standard deviations, an important assessment tool.

\subsubsection{Teachers without PD support}

These include a quarter of them $\left[T_{1}, T_{3}, T_{6}, T_{10}\right]$ who did not experience any form of PD training, and about 50 per cent of the teachers reported without Nguzu Nguzu training 
(Fig. 4.1). Apart from the Nguzu Nguzu mathematics training workshops, 75 per cent of the teachers claimed lacking of ongoing mathematics PD support.

There is a difference noted also between school types in terms of PD activities. Four out of seven teachers $\left[T_{2}, T_{7}, T_{15}, T_{16}\right]$ from the private run schools had organised professional support as reported, whereas none from the public schools.

\subsubsection{Professional support for mathematics teachers}

Teachers were asked to indicate what kinds of professional development support they need for their mathematics teaching. Teachers came up with a number of general areas of professional development support rather than specific areas. The majority (75 per cent) of the teachers stated the need for ongoing PD support, rather than one-off workshops. Some of the teachers also highlighted the need for the local teacher training institution to accommodate Nguzu Nguzu training.

Teacher $\left[\mathrm{T}_{1}\right]$ who has not undertaken Nguzu Nguzu training would like to see more training in Nguzu Nguzu provided for all teachers. Other teachers $\left[\mathrm{T}_{8}, \mathrm{~T}_{10}, \mathrm{~T}_{14}\right]$ would like to undergo refresher programmes on Nguzu Nguzu mathematics. Teacher $\left[\mathrm{T}_{3}\right]$ would like

to attend training or workshops on specific skills in mathematics. Teacher $\left[\mathrm{T}_{4}\right]$ believed that:

"Each term olketa principals or headmasters should duim professional development within in school blo hem seleva. If mi go principal lo any primary school, mi like duim that one ia. Mi likem, oketa lukim that school based na hem more effective than you go attendim onefala external workshop, you kam back every thing hem nomoa too”. (This teacher is recommending headmasters/principals to take leading roles in organising PD within school during holidays rather than having staff attend external workshops which they feel are often fruitless) 
Teacher $\left[\mathrm{T}_{11}\right]$ was also supportive of developing school-based programmes that cater for teachers in their particular school, such as teachers exchanging ideas or their experiences of teaching other classes. Teacher $\left[\mathrm{T}_{5}\right]$ was also supportive of having PD programmes in place during school holidays, and for teachers who are interested in certain areas $\left[\mathrm{T}_{6}\right]$. Teacher $\left[\mathrm{T}_{9}\right]$ wanted mathematics refresher programmes and $\mathrm{PD}$ in other areas such as motivation and effective ways of teaching mathematics. Teacher $\left[\mathrm{T}_{12}\right]$ would like PD on classroom 'evaluation', ‘achievement', and 'performance’ issues, and as well as Nguzu Nguzu to become part of the teacher's college curriculum.

Training issues relating to the Nguzu Nguzu mathematics curriculum also became apparent as not all teachers had received training in how to use the new Nguzu Nguzu curriculum. Overall, there was overwhelming support from the study teachers for some form of relevant PD to become integral to teaching in the S.I.

\subsubsection{Open question}

Teachers were asked if they wanted to share anything further about what we had discussed so far. Only two teachers responded. Because of the low response to this question, I asked another general question based on their experience of factors that might affect the development of children's numeracy.

Teachers provided a number of factors. One quarter of the teachers agreed that setting a good foundation for early numeracy at lower classes is essential. Another quarter mentioned home support for numeracy from parents and including family background (in terms of education) is important. Two teachers emphasised that teachers play an important

role in developing children's numeracy. In addition, individual teachers reported the 
following positively impact on numeracy outcomes: motivation for teachers; numeracy being linked to literacy; the need for extra classes or helpers for slow learners; and that the school administration has a role in ensuring numeracy is fully developed. The following were reported to negatively affect pupils’ numeracy outcomes such as: outside school distracters; varying conditions and privileges between education authorities (e.g., private education authorities provide accommodation and some allowances for their teachers).

These results indicate that the study teachers believe that achieving better numeracy outcomes is not only the job of the teacher, but others also bear responsibility (such as parents, school administration, school authorities).

In summary, the thematic analysis has described the emerging themes from the interview data into a narrative. It helps to provide a descriptive account of teachers' reported beliefs, knowledge, and practices based on their experiences, and lead us to the main findings of the study. The overall study results are summarised below.

\subsubsection{Summary}

In terms of beliefs:

- The majority of the teachers viewed the nature of teaching mathematics as involving problem solving and being pupil-centred.

- Although the majority of the teachers agreed with mathematics, its teaching, and learning as problem solving and pupil-centred in nature, when identifying specific pedagogic strategies about teaching and learning of mathematics that support these views, individual teachers held different beliefs and views. One in every two teachers held different views when it came to specific teaching and learning 
approaches that reflect problem solving and pupil-centredness in the following areas (as indicative in the Belief Cards statements):

i) mathematics can be learned effectively by listening carefully to the teacher's explanation,

ii) pupils need to experience and link mathematics to real life context other than text book or blackboard experience, and

iii) the passion and enjoyment teachers experience with learning and doing mathematics.

- Almost all teachers shared beliefs and views that reflect both the contemporaryconstructivist and traditional-transmission orientations about mathematics, its teaching, and learning.

In terms of knowledge:

- Almost 50 per cent of study teachers claimed that their current mathematical knowledge and understanding is insufficient, and

- One in every two teachers claimed to have surface knowledge regarding theoretical perspectives about learning, and a quarter of the teachers claimed to have no knowledge of learning theories such as constructivism.

In terms of practices:

- Constructivist teaching strategies and styles were reported, however, it appeared some of the teaching approaches reported reflect a traditional-transmission orientation, for example, the emphasis on speed and formulas in mathematics which counter pupils’ meaningful learning.

- About one in every two teachers reported inadequate teaching resources to be a common problem among public schools, and two reported lack of effective use of available materials.

In terms of professional development: 
- Seventy-five per cent of the teachers claimed that there is a need for ongoing teacher professional development for mathematics.

- The most commonly experienced professional support provided for teachers was the Nguzu Nguzu training workshops (one in every two study teachers participated).

- Four out of seven private school teachers received school-based professional support from their schools.

These overall findings are discussed in Section 4.3.

\subsection{Interpretive analysis}

This section includes discussion of the findings, their relationship to literature and my own reflections and recommendations.

\section{1) Teacher beliefs}

The literature discussed in Section 2.1 indicates that researching teacher beliefs can help pave the way forward for classroom teaching and learning improvement. Studies have shown that teacher beliefs affect teaching and learning. Literature shows that teachers' beliefs about the nature of mathematics are likely to influence their teaching practice and the way pupils learn mathematics or vice versa, and classroom practices may shape teachers’ beliefs. Some beliefs are strongly held and sometimes we practice what we do not believe (Edward \& Mercer, 1987). However, it is also possible that teachers' beliefs may not be transferred into practice for a number of reasons. Studies have found inconsistency between teacher beliefs and practice (for e.g., Cooney, 1985; Ernest, 1989; Shield, 1999) and similar differences between teachers beliefs and their reported practices were found from the results of the Belief Cards exercise in this study. 
In revisiting the results of the Belief Cards exercise (Table 4.1) first, the majority of the teachers $(>10)$ who picked Belief Cards ranked numbered one to nine reflect a problem solving view of mathematics (Ernest, 1989), with pupil-centred views of mathematics teaching and learning and with specific pedagogic strategies (Ranked 3, 4, and 8). These beliefs are consistent with the implications of inquiry-based teaching and learning that reflects a problem solving view of mathematics and a facilitator model of teaching mathematics. The only exception is the belief that 'it is important to cover all the topics in the mathematics curriculum' (Ranked 5). This belief is consistent with mathematics teaching as content-focused (Kuhs \& Balls, 1986). This could be related to the examination-driven education system in the Solomon Islands, with teachers feeling it is important to cover all the topics, but not necessarily to ensure that pupils all understand the topics.

However, when it came to specific pedagogic strategies (Ranked 10-12) that reflect problem solving and pupil-centred approaches, only about 50 per cent of the teachers agreed. This indicates that there is some degree of disparity among individual teachers on these three beliefs and this also inconsistent with the majority viewing mathematics as problem solving and pupil centred (Ranked 1-9).

The indication that only a quarter of the teachers believe in Belief Cards ranked 13 to 16 shows that the majority of the teachers believe that they have a role in understanding pupils’ errors (Ranked 13); that they accept pupils alternative solutions (Ranked 14); that they accept pupils alternative explanation (Ranked 15); and that provide direct answers to mathematical problems seriously affect mathematics learning (Ranked 16). 
The likely interpretations of individual disparity and somewhat inconsistent beliefs and views described above are first that Belief Card ranked 10 shows that the teachers view teaching and learning differently. That is, one in every two teachers believes mathematics is best learned by teacher-directed or teacher-dominant modes, although the majority of the teachers view the teaching and learning of mathematics as pupil-centred. This belief leans toward an instrumentalist view about mathematics, following an instructor-based model of teaching with an emphasis on skill mastery and pupils as passive learners (Ernest, 1989). However, one of the teachers $\left[\mathrm{T}_{2}\right]$ consistent with Askew et al. (1997b) disagreed with this belief explaining that pupils tend to understanding teaching better when they discover mathematics ideas for themselves rather than through teacher-directed teaching.

Whilst the majority of teachers held a problem solving view of the nature of mathematics, only half agreed on the value of children linking mathematics to their experiences and personal contexts (Ranked 11). The Nguzu Nguzu Teacher’s Guide (Section 1.1.3) overtly emphasises the importance of contextual teaching and application, and making mathematics relevant. Teachers generally also highlighted the challenges and difficulties when it comes to reflecting mathematical applications in their teaching. This belief statement is very important for teachers to contemplate to enhance pupils' learning (Nickson, 2004).

The difference of opinion on Belief Card ranked 12 is in contrast with what the majority of teachers stated regarding teaching mathematics as an interesting and enjoyable activity (Section 4.2.1.1). Perhaps a reason for the difference could lie in the differences between teaching of mathematics and actually doing mathematics. As one of the participants [ $\left.\mathrm{T}_{8}\right]$ pointed out, it is quite difficult for him to enjoy teaching mathematics while at the same 
time there are other subjects to teach at the primary level. A similar situation was found by Bakalevu (2009) in Fiji who mentioned that a good number of women primary teachers had found mathematics to be their weak subject since high school days, and therefore were reluctant to teach it.

In addition, regarding Belief Card ranked 6, that is, 'a vital task for the teacher is motivating children to solve their own mathematical problem', this study found that only two-thirds of the teachers agreed. Beswick (2005) on the other hand, found the same belief statement ranked at the top by secondary mathematics teachers in Tasmania, Australia. They believed that motivating pupils is very important. However, one-third of the primary teachers in this study did not indicate they felt motivation important. Although, these two studies are different in focus and context, this may indicate the teachers held traditional (teacher-centred) beliefs of understanding mathematics. This is where teachers become transmitters of static knowledge, rules, or right answers (Stipek et al., 2001), and less time is given to motivate pupils to discover mathematics. Matang's (1998) research in Papua New Guinea suggests that teachers there need to move away from being the transmitter of knowledge to being a facilitator. This is regarded as an inquiry-oriented or constructivist approach. This is where motivation is important to encourage pupils to solve mathematical problems, unlike in a traditional teaching and learning environment where the teacher is in control.

In this context, the consistent views on Belief Cards (Ranked 1-9) and the individual inconsistencies on specific Belief Cards (Ranked 10, 11, and 12) demonstrate that teachers possess conflicting beliefs and views about how they perceive mathematics to be and how they practise mathematics. Theoretically, we can argue that the current teachers' beliefs 
about mathematics can be viewed as moving along the Instrumental (an instructor model) - Platonist (an explainer model) - Problem-solving (a facilitator model) continuum (Ernest, 1989). Simply put, they appear to simultaneously view mathematics with a traditional-transmission orientation and with a contemporary-constructivist orientation (Barkatsas \& Malone, 2005). This view of mathematics is consistent with the nature of teaching and learning as classroom-focused, content-focused or learner-focused (Kuhs \& Balls, 1986), with a combination of emphases. In practice, Cai et al. (2009) support that teacher beliefs often have changeable combinations along the continuum of instrumentalist and Platonist views. The teachers in this study appear to move forth and back between the continuums and therefore have inconsistent views about specific effective practices in mathematics. As a result, teaching becomes either a divergent process (learning by knowing) or a convergent process (learning as understanding) (An et al., 2004). These inconsistent beliefs and practices may threaten pupils' numeracy development due to low teacher emphasis on teaching strategies that link mathematics to real life situations, experiences, motivation, and enthusiasm of doing mathematics exhibited by teachers.

The disparity and inconsistent views among teachers about beliefs and practices above may be linked to a number of factors, for example teachers' own past school experiences that have a cumulative effect on teachers' beliefs and classroom practices (Barkatsas-Tasos \& Malone, 2005; Raymond, 1997); the influence of the current education system in terms of curriculum, assessment, (Ernest, 1989); teacher pedagogical content knowledge (An et al., 2004); and current unfavourable terms and conditions for teachers (Malasa, 2007). It is therefore invaluable to explore teachers' beliefs about mathematics further and how their beliefs match their actual practices because this will allow further understanding of how the inconsistencies described above play out in the classroom. PD strategies can then be 
developed targeting teachers’ specific differences and inconsistencies between beliefs and practices.

\section{2) Teacher reported practices and knowledge}

Pedagogical content knowledge is about understanding teaching and learning (An et al., 2004) and about teachers having sound content knowledge (Ball, Thames, \& Phelps, 2008; Elbaz, 1983; Shulman, 1985). This study explored pedagogical content knowledge. The overall results have revealed effective practices being reported by teachers but also some potential concerns.

It is imperative to note some of the effective classroom practices described by individual teachers. Undoubtedly, these invaluable practices are likely to enhance learning and achieve numeracy understanding. The results showed teachers report using a wide range of teaching styles, strategies, and approaches in mathematics for different purposes. The most common reported practice was grouping pupils into mixed ability groups. Some teacherparticipants cautioned against the non-effective use of group work. They felt group work must be done under teacher supervision because of the tendency of pupils to play instead of doing what they were asked to do. However, it appeared from the teachers' reports that group activities were an effective way for pupils to construct their own knowledge with the teacher merely acting as a facilitator or guide. Apart from group work, other teaching approaches and strategies described in the literature as effective (e.g., Nickson, 2004; Wink \& Putney, 2002; Windschitl, 2002) included reflection and the used of real life examples. 
Lesson recapping and reflection was described by one teacher $\left[\mathrm{T}_{4}\right]$. This is very important in finding out what has been covered or learned (Windschitl, 2002), as it allows pupils to communicate what they have learned (Wink \& Putney, 2002). In the preliminary stages of this study (Section 3.2.3) one of the teachers interviewed also described the use of 'reflection' as a part of ‘maintenance', a learning strategy she employed in finishing off a lesson. The use of 'feedback' as considered by another teacher-participant or feed-forward from pupils is another useful strategy. Feedback should be seen as a two-way process between a facilitator and a learner (Wink \& Putney, 2002), and these comments indicate a constructivist approach to teaching and learning of mathematics.

Another effective lesson strategy reported was portraying real-life examples of mathematics. This is very important in mathematics (Nickson, 2004). One example would be the lesson about money which one teacher $\left[\mathrm{T}_{15}\right]$ believed was her best lesson because of how pupils related money to real life situations. Pupils had the opportunity to use money for buying, selling, or finding out profits and discounts, and the lesson was not based on books or the blackboard. Most pupils experience money daily, and thus it is important to plan and design such lessons/activities based on the pupils' experiences. Contextual application is important and is very much part of learning and teachers are there for facilitation and coordination (Wink \& Putney, 2002). One of the important aims of the Nguzu Nguzu mathematics curriculum (Section 1.1.3) is making mathematics real to the local context. This is one of the implications of a constructivist approach to the effective learning of mathematics, to mathematise, and therefore for pupils to experience mathematics in a context (Nickson, 2004). 
Other effective practices were also found in the data. These were: outdoor classroom teaching, pupils experiencing learning as not only occurring in the classroom; having extra classes for weaker pupils; introducing games along with activities to motivate pupils; and the notion of monitoring pupils' learning progress using records such as a 'learning improvement book’ (Section 4.2.2.1).

However, some of the lessons described by the teachers depend on their effectiveness. Some processes teachers described may have a negative impact on pupils’ learning. For instance, the emphasis on speed where pupils complete given tasks 'very fast' is being regarded as 'best' by some of the teachers. Walls's (2003) study in New Zealand found a similar result of teachers emphasising speed in mathematics learning. Walls cautioned about this emphasis, believing it could result in pupils' alienation, marginalisation and impoverished learning.

Another emphasis found in the results was the use of formulae, where pupils successfully memorise formulae without understanding their meanings. Literature suggests more effective learning occurs when formulae, rules, and facts are understood by pupils (An et al., 2004; Ernest, 1989). Children will not only learning by knowing but will develop better understanding (An et al., 2004). The used of materials, different representations and contexts are some common effective practices in mathematics (Clarke \& Clarke, 2004, as cited in Anthony \& Walshaw, 2007).

Apart from the effective practices reported, almost half of the teachers themselves emphasised the need to have adequate knowledge and sound understandings of topics in mathematics. They felt that their current content knowledge was insufficient (Section 
4.2.3.1). There are concepts and applications in the Nguzu Nguzu mathematics that need sound knowledge and understanding in order to deliver effective classroom instruction. The QCEC and AISQ (2004) in Australia warn that lack of content knowledge and confidence can limit teachers' ability to engage children in learning activities. Some of the participants discussed their fears of having inadequate basic and fundamental conceptual understanding in mathematics.

In addition to subject content knowledge, the results showed that majority of the teachers lack basic knowledge and sound understanding of learning theories (Section 4.2.3.3), useful in understanding how children learn, develop and interact with the environment (Haylock \& Thangata, 2007). One of the dilemmas in creating constructivism in the classroom (Section 2.2.1) is based on its conceptual understanding (Windschitl, 2002). Similar perspectives were also found by Walani (2009) about secondary teachers in the Solomon Islands. Walani's study suggests that classroom teachers need to have better theoretical understanding of social constructivism and meta-cognition in order for them to become effective mediators of learning.

Although most of these theories can be argued as westernised, some of the principles can be seen as relevant across different contextual and cultural settings, for example the sociocultural perspectives on cultural practices and tools (McChesney, 2009). McChesney (2009) views learning theories not as things that occur only overseas or in universities but as things that teachers do in their everyday preparation towards classroom teaching. Teachers also create their own personal learning theories (McChesney, 2009; Sylva \& Lunt, 1992). However, the essence of this is that teachers ought to understand how their pupils learn (Haylock \& Thangata, 2007; Reid, 2005) and therefore it is pertinent for 
teachers to have a grounding in some learning theories including cultural learning styles/preference as described in the literature (Averill et al., 2009; Reid, 2005; Thaman, 1992; Wink \& Putney, 2002). To add, schools in urban centres such as in Honiara are beginning to experience multiethnic classrooms, and challenging teachers in terms of knowing individual pupils' backgrounds and learning preferences. A quarter of the teacher-participants in this study somewhat did not know their pupils’ learning preferences (Section 4.2.3.3). Thus, some teachers' lack of knowledge and understanding of the theoretical perspectives and cultural perspectives about learning and development may contribute towards deficiencies in their pedagogical approaches towards achieving better numeracy outcomes.

Teachers also raised the fact that pupils find conceptual understanding and application in mathematics difficult. For example, one teacher claimed that pupils were normally put off by the comprehension part of solving a problem. The same teacher believed that teachers ought to know the mathematics vocabulary well in order to explain and simplify problems. The teachers expressed that most pupils found it challenging when equations were translated into word problems. The difficulties of language in learning mathematics have been highlighted in the literature (Section 2.2.1.2). Mathematics has its own vocabulary which is sometimes used in specific but different ways from conversational English language, for example, one of the teachers in the preliminary stage of the study (Section 3.2.3) mentioned that children are sometimes confused by the word 'divide' but are more comfortable using the word 'sharing' when relating to mathematical division. In the Solomon Islands, the English language is a third or fourth language for pupils and 
teachers. The interpretation of Mathematical English ${ }^{14}$ can be a barrier to the understanding of mathematical concepts and meanings (Bakalevu, 1999; Clarkson, 1998). This was the case also found in multiethnic societies such as Papua New Guinea, where learning difficulties in mathematics were attributed to the use of the English language (Clarkson, 1998). Nonetheless, Liebeck (1990) mentions that the exercises children do must be simplified and children should be able to verbalise what they have done.

Another likely scenario for pupils having problems with basic conceptual understanding and application as reported in this study may be due to limited activities/lessons that link to real life mathematics (Section 4.2.3.3). This could be linked to the need for teachers to have adequate knowledge and basic understanding, in order to be creative and simplify abstract mathematical concepts to the level where pupils will understand or have experienced (Liebeck, 1990). Some of these concepts could be learned through hands-on manipulative activities; however, seven out of eight public school teachers in the study have claimed having insufficient equipment/apparatus to carry out such lessons. As a result, learning occurs through verbal explanation and blackboard work or, in one case, it was reported that lessons were skipped. The trend of skipping important lessons as described could be detrimental to pupils’ learning, and result in disengagement of learning where pupils are deprived the opportunity to learn new knowledge and skills.

The pupils' difficulties with conceptual understanding and the application of mathematics as reported showed that difficulties are mainly in topics involving other skills and some basic arithmetic operations (Box 4.1, Section 4.2.3.1). The Figure 1.2 and Box 4.1 display some similarities in the areas pupils have difficulty within mathematics. For example, Box

\footnotetext{
${ }^{14}$ Bakalevu (1999) used this term to describe the English of mathematics.
} 
4.1 showed pupils found fractions and measurement difficult similar to Figure 1.2. Despite this, some teachers mentioned fractions as being one of their best lessons. We do not expect Year 4 pupils to perform well in skills other then being numerate and use the basic four operations, however, even at Year 6, similar trends were noticed (SISTA 2 Report, 2007).

The causes of disparity among pupils’ performance in different content areas is unknown, while common sense and wider literature tells us that in terms of difficulty level, other strands can be difficult and complex compared with using the basic four arithmetic operations. At the primary level other content areas should be presented in ways that generate pupils' interest, intrinsic satisfaction, and creativity to motivate pupils, making them want to learn (Reid, 2005). The teaching of mathematics should become more contextual in nature so that children can make meanings out of it (Nickson, 2004).

Most Year 5 and 6 teachers mentioned that generally they found their pupils' level of numeracy lagging behind expected levels by a year or two when pupils entered upper classes. This affirms the SISTA 1 and 2 baseline results established since 2004 which indicate one in every three pupils is achieving below the expected level for Year 4, and one in every two pupils for Year 6 (Figure 1.1 \& Table 1.1). Teachers believe that successive preparation from lower classes would help remediate some of the pupils' misconceptions and difficulties before they get to the upper classes $\left[\mathrm{T}_{12}\right]$. It is sometimes the misconceptions at the early learning stage that cause a lack of understanding about abstract mathematical concepts as pupils progress (Nickson, 2004). 
In short, pedagogical content knowledge is an essential component of teaching and learning. Exploring teacher's content knowledge, curriculum knowledge and teaching helps us to understand teachers better. The experiences shared by teachers provide a stocktake on current instructional practices and challenges they have lived with. The information provided will enable educators and decision makers to rethink, redirect, and create better avenues for improve learning and numeracy outcomes in the S.I.

\section{3) Professional development support in mathematics}

Professional support for teachers is very important as it develops teachers for the betterment of teaching and learning in schools (Earl, 2007) and it brings about changes in classroom practices, beliefs, and attitudes (Guskey, 1986). The results showed teacherparticipants have received varying levels of PD support from different sources.

Patterns that emerged from the results included that:

- About 75 per cent of the participants received some form of PD support mainly through the Nguzu Nguzu training workshops (almost 50 per cent), school-based (25 per cent), and one teacher (through a mentor).

- About one in every two teachers did not attend or received trainings under the Nguzu Nguzu training programmes.

- Mostly only private schools provided some form of PD for their teachers.

- Seventy-five per cent of the teachers claimed the need for ongoing PD support.

Based on the above statements and the results, there is a need for i) ongoing PD support and ii) effective training programmes. In terms of ongoing PD support, the majority of the teachers expressed that they would like to see some form of ongoing PD support rather than a one-off workshops. They felt that this is an area that has been neglected for too long by responsible authorities. The ongoing PD support can be based on teachers' needs and 
thus it is better that teachers themselves are involved in identifying their professional needs and issues (Clark, 1994, cited in QCEC \& AISQ, 2004; Hawley \& Valli, 1999). On the other hand, it is encouraging to know that private schools are providing some form of support for their teachers (as reported by study teachers) by organising school-based activities or through sister school relationships.

Why only half of the teacher-participants received Nguzu Nguzu training since its inception needs further investigation. Some teachers would like to see the inclusion of some part of the Nguzu Nguzu training programme in the National Teacher Institution provider. This could support the notion of sustaining the Nguzu Nguzu programme, especially for trainee teachers. Any curriculum innovations need to be incorporated in teacher training institutions and in-servicing of teachers (Benson, 1993). One participant described that during his time at the college they were trained on the Nguzu Nguzu English curriculum, and this has made him confident in the field but not the Nguzu Nguzu mathematics curriculum. In terms of in-service training, the result shows that not all teachers are trained with the Nguzu Nguzu mathematics curriculum as intended by the MEHRD.

The Nguzu Nguzu induction trainings can be regarded as insufficient because one in every two teacher-participants was not able to attend any Nguzu Nguzu related training. Thus schools and authorities may need to organise their ongoing PD activities based on their teachers' needs, in the way that some of the private schools have done. On the other hand, PD support is not only important when introducing a new curriculum like the Nguzu Nguzu curriculum, but experienced teachers claimed that from time to time they need to be 
kept aware of effective teaching approaches and strategies, and on how to monitor and evaluate their teaching and pupils’ learning (Section 4.2.4.3).

One of the principles of PD in mathematics is to allow teachers to identify the issues (Clarke, 1994, cited in QCEC \& AISQ, 2004; Hawley \& Valli, 1999). This could be an effective approach to adopt to further investigate some of the issues discussed in this study. Likewise, approaches such as those driven by pupils’ performance (Hawley \& Valli, 1999) are also an important PD approach. There is no easy strategy for PD activities; they depend on the needs and learning gaps identified, and other factors like financial restriction and teacher motivation.

\subsection{Summary}

To summarise, this chapter provided the processes involved in the initial data analysis (the descriptive analysis), which then led on to the thematic analysis and descriptive accounts of the data and the overall results. The overall findings in terms of teacher beliefs, practices and knowledge, and professional development were discussed under the interpretive analysis (Section 4.3). The interpretive analysis helps to interpret the superordinate analysis themes, their meanings, and link the results to relevant theoretical perspectives.

The next chapter provides the summarisation of the study, including recapitulation of the aim of the study and the main research question. 


\section{CHAPTER 5 - CONCLUSION}

The study has achieved its aim (Chapter 1) and goal through illuminating some crucial factors about numeracy teaching and learning in the Solomon Islands by exploring primary school teachers' beliefs, knowledge, practices, and professional learning activities. Following the results of the SISTA, stakeholders questioned the quality and effectiveness of teaching and learning in schools. Because of the lack of information about how primary school teachers structure classroom teaching and learning in the Solomon Islands, this study was designed to focus on teacher beliefs, their pedagogical content knowledge, and professional development experiences. Teachers have invaluable information to share about their beliefs, knowledge, and experiences regarding numeracy practices because they are responsible for pupils’ learning. A phenomenological method of a qualitative research approach was adopted through administering the Belief Cards exercise and the semistructured interview questions with sixteen teacher-participants.

This chapter provides the overall summary of the study. It draws conclusions from the findings and provides alternative explanations for the findings. It examines the study limitations. Implications of the study in terms of teachers, teacher education, and the Ministry of Education are discussed (Section 5.3). The final section (Section 5.4) provides recommendations for changes in organisation, procedures, practices, behaviour, professional practices, and further research. A brief summary concludes the chapter. 


\subsection{Summary of the main findings}

The main research question in this study (Section 1.3) was broken down into three subquestions.

\section{i) What beliefs do teachers hold about the nature of mathematics, its teaching, and its learning?}

- The findings showed the majority of the teachers reported holding problem solving and pupil-centred beliefs and views about mathematics, its teaching, and learning. These views reflect the inquiry-based and contemporary-constructivist teaching and learning of mathematics.

- When it comes to identifying specific pedagogical strategies that reflect the problem solving and pupil-centred nature of mathematics, teachers held differing views. About half of the teacher-participants had agreed on these specific areas: i) mathematics can be learned effectively by listening carefully to the teacher's explanation, (this portrays pupils as passive listeners and receptors of knowledge, and the teacher as transmitter and the explainer of knowledge), ii) pupils need to experience and link mathematics to real life context other than text book or blackboard experience, and iii) the passion and enjoyment teachers experience with learning and doing mathematics.

- The disparities of teachers' beliefs and views on specific pedagogic strategies showed inconsistencies, with the majority viewing mathematics, its teaching, and learning as problem solving and pupil-centred in nature. These results suggest that disparities and inconsistencies between teacher beliefs and practices may exist in S.I mathematics teaching more widely than solely within the study group. 
- Nearly all teachers had showed beliefs and views that reflect a combination of contemporary-constructivist in nature and traditional-transmission orientations (Table 4.2).

ii) What are teachers' beliefs about their pedagogical content knowledge and how it links to numeracy outcomes?

- About 50 per cent of teacher-participants claimed insufficient content knowledge and theoretical perspectives about learning.

- Teacher-reported practices support both constructivist and traditional-transmission toward teaching strategies and approaches. These teaching strategies and approaches were affected by inadequate teaching resources as claimed by one in every two teacher-participants. Teachers reported that the lack of specific mathematics resources can lead to skipping lessons and topics, which most likely will result in learning gaps.

iii) To what extent have teachers experienced numeracy professional learning and development? And what are teachers' views on professional development in numeracy teaching?

- A quarter of the teacher-participants did not experience any form of PD for numeracy/mathematics (Fig. 4.1).

- The only commonly reported professional training provided for the teachers was when the Nguzu Nguzu mathematics curriculum was introduced, in which about one in every two teacher-participants had participated.

- Seventy-five per cent of the teacher-participants claimed the need for ongoing teacher professional development for mathematics. 
Overall, the beliefs, knowledge, and reported practices could be attributed to a number of factors. For instances, it could be to do with each teacher's belief system formed by beliefs, attitudes, and values (Pajares, 1992) and the way they hold their beliefs (Green, 1971). Some of these teaching practices and beliefs are shaped by the way they have been taught or been trained, and they believe and value these past experiences (Barkatsas-Tasos \& Malone, 2005; Raymond, 1997). They can be influenced by the current education system which is heavily exam-oriented (Elley, 2001; Ernest, 1989). They can be also attributed to the following areas as shown in the study results, such as disparity of resources among school types (Section 4.2.3.2), not all teachers being inducted with the Nguzu Nguzu training programmes (Fig. 4.1), lack or limited knowledge of theoretical perspectives about learning (Section 4.2.3.3, ii), and the fact that teachers emphasised the need to have adequate knowledge, skills and understanding of the subject matter (pedagogical content knowledge, section 4.2.3.1).

\subsection{Limitation of the study}

Qualitative studies are sometimes criticised in terms of generalisability or how representative or transferable the findings are (Bodgan \& Taylor, 1975; Denzin \& Lincoln, 1995). However, the intention of qualitative studies is to interpret the findings for the unique setting rather than to create generalisations (Merriam, 1988, cited in Creswell, 1994). McMillan (2008, p. 298) mentions that "generalisability is often weak in qualitative studies because the purpose of the research is to increase an understanding of a phenomenon, not to represent a larger population”. In light of these issues, the limitations of the findings of the study are most likely to be linked to the data collection methods, 
which include: the Belief Cards exercise and the interviews; researcher effects, and issues of generalisability and transferability of the results.

First, the Belief Cards exercise could be made more informative by allowing more time for the respondents to explain and justify their choices. In addition, participants could be asked to choose only a limited number of cards to allow more discussion of their choices. In this study, the teacher-participants had identified cards that suit their beliefs and views but were not pressed to explain the reasons for their choices.

The second issue regarding limitations of the study involved the semi-structured part of the interview protocol. Although strong efforts were made to ensure participants knew the importance that their responses were honest and open, concerns always existed in interviewing that depth, richness, and scope of the data truly represented the phenomenon being explored (Cohen, et al., 2000). However to maximise the representativeness of the data, the study adopted methodological triangulation (Section 3.3). In addition to the issue about credible responses, what is known as 'interviewer effects' or researcher effects can become potential sources of bias (Lee, 1993, cited in Cohen et al., 2000). My status as an Education Officer could have influenced teachers' responses as there may have been things the teachers felt inappropriate to discuss in fear of repercussions. This was minimised through thorough explanation of the purpose of my study and why I have chosen teachers as the subject; that exploring and understanding what the teachers have experienced is paramount. As teachers they have something to share about their beliefs and practices which are important to capture. They were being told as well through their consent information sheet and form (Appendices 3 and 4) about the data collected from them is solely for study purpose and will be discarded after the completion of the study. 
Third, how generalisable and transferable the results and findings are to other settings in the S.I is uncertain. The study participants are predominantly urban teachers, the results might be different in rural schools in the provinces. Rural teachers might have different views about mathematics, about its teaching, and its learning. Teacher pedagogical content knowledge could reflect cultural influences to a greater extent. However, in an attempt to sample schools as similar as possible to rural schools in an urban setting, teachers teaching on the outskirts of Honiara were included to represent provincial schools. The teacherparticipants represented a mixture of socio-cultural backgrounds, ethnicity, and they were from different provinces. In addition, most have previously served in the provinces before coming to Honiara schools. Indirectly, the views they expressed could also shared by other teachers. However, in further studies space triangulation for the purposes of exploring or investigating other schools or teachers (Cohen et al., 2000) could be applied to one or more rural schools in the provinces to corroborate the results. Representative sampling using questionnaires for teachers in the provinces could also be employed to maximise confidence in transferability (external validity).

Classroom observation would be useful in further studies to examine teachers' actual practices. This will validate teachers' reported beliefs and reported practices in this study. It will also help to observe the kinds of teaching resources available at schools.

\subsection{Implications}

There are issues found in the study that have some wider implications in the Solomon Island education system in general. There were some issues that peculiar to certain 
individual contexts. Based on the findings, there are a range of implications for teachers, teacher education, and the Solomon Islands Ministry of Education.

\subsubsection{Implications for teachers}

One could ascertain the results in this study that individual teacher's differences and inconsistency beliefs/views about mathematics could affect the actual teaching and pupils’ learning outcomes. The teacher is very much in control of learning and any differing teaching beliefs, knowledge, and practices could show either pupils are learning by 'knowing' or learning by 'understanding'. Teachers are often satisfied once pupils know the basic facts and skills (learning as knowing) compared with teachers making sure pupils comprehend knowledge and able to apply the concepts and skills (An et al., 2004). Based on the results, the kinds of classroom pedagogy likely reflect a combination of teachercentred and pupil-centred approaches. Beswick’s (2005) study found that if teachers do not have problem-solving views of mathematics then pupils are likely to learn mathematics uncharacteristic of constructivist principles. This means teachers are likely to espouse the transmission approaches to teaching and learning in the classroom. Teachers in this study inclined towards constructivist nature of mathematics but were having individual conflicting beliefs and views on pedagogical strategies, which are likely to have classroom implications in terms of how they teach and design classroom activities.

The inadequate specific mathematics resources (as reported) have implications on the way teachers design and execute their lessons. One of the consequences of this is the skipping of lessons and topics as reported, which most likely results in learning gaps. This indicates creativity and improvisation by teachers is important to reflect the reality of mathematics 
in classrooms. But creativity and improvisation are also likely dependent on the extent of pedagogical content knowledge (An et al., 2004). The reported insufficient content knowledge by teachers is likely to have implications for effective classroom mathematics teaching and learning (Bliss, Askew, \& Macrae, 1996; Groves et al., 2004; Kyriacou, 2005; McDonough \& Clarke, 2003; QCEC \& AISQ, 2004; Son, 2006; Stylianides \& Stylianides, 2006).

The implications of study findings of inconsistencies between teachers' beliefs, knowledge, and reported practices may contribute to affect pupils' learning and hence the overall numeracy development.

\subsubsection{Implications for teacher education}

In this study, about half of the teacher-participants claimed inadequate mathematical content knowledge, lack of understanding of theoretical perspectives about learning, and the lack of Nguzu Nguzu trainings, all of which have implications for teacher education providers and PD.

Content knowledge and teaching methodology are crucial for all primary teachers, including trainees. It is important that teacher education providers ensure that primary trainee teachers have the necessary basic pedagogical content knowledge (An et al., 2004) in order to handle the primary mathematics curriculum effectively as teachers lacking content knowledge and teaching practices negatively affect the development of children's numeracy (Groves et al., 2004; Son, 2006; The Profiling High Numeracy Achievement Project Team, 2004). In addition, it is important to introduce trainee teachers to theoretical learning perspectives such as the socio-cultural and constructivist views (Haylock \& 
Thangata, 2007; McChesney, 2009; Reid, 2005; Windschitl, 2002). Beswick (2005) found that some teachers have a limited understanding of constructivism. A similar situation was found in this study. Some teachers claimed that they have come across these learning theories but did not understand them well. This could help explain the different views of teacher-participants about teaching and learning strategies between traditionaltransmission approach and the principles of constructivism. This has implications for teacher education and professional learning providers (Richardson, 2003, cited in Beswick, 2005).

The study findings also indicate a need to accommodate Nguzu Nguzu training within teacher training because doing so would help trainee teachers to have confidence with teaching the Nguzu Nguzu curriculum. The incorporation of Nguzu Nguzu training would help ease the gaps created in the post training programmes and its sustainability, since the results showed not all teachers have had PD including the Nguzu Nguzu curriculum.

Therefore the issues found in the results in terms of pedagogical content knowledge, learning theories (including socio-cultural perspectives), and Nguzu Nguzu mathematics training have strong implications for initial and ongoing teacher education.

\subsubsection{Implications for Ministry of Education}

What can the S.I Ministry of Education or the government offer based on the results? I believe one essential area the Ministry can provide is professional development support and resources to support teaching and learning. 
The findings showed that teachers need professional support specific to their needs. The results also showed that private schools are better resourced than public or provincial schools. It was found that different school authorities provide their teachers with some form of PD support, for example church schools as described in the results (Section 4.2.3.1). However, the bigger portion of teacher-participants lacking any form of PD comes from the public schools. If this is the situation in Honiara then I believe rural and provincial based teachers would also have grave concerns about PD needs because they have similar contexts to public schools. I believe the Ministry has an organisational role through its education authorities, schools, and Ministerial departments to help create such avenues for specific teacher ongoing professional development.

In addition to PD support, the findings also indicate that not all teacher-participants were trained with the Nguzu Nguzu mathematics curriculum as intended for. This is something the Ministry of Education through its department responsible needs to investigate further.

In terms of school resources, the Ministry through the Curriculum Development Centre and other external supports have furnished schools with equipment and materials. However, not all schools received these. As a result schools continue to experience insufficient resources for specific lessons and activities. The results indicate this has affected pupils' learning and some lessons offer limited opportunities for pupils to discover mathematical ideas or explore learning. The Ministry can have a role through its education authorities to encourage schools to have all the necessary learning equipment or apparatus for learning. 


\subsection{Recommendations}

Based on the study findings, recommendations follow concerning changes in organisational procedures and practices, and professional development. Ideas for further research are suggested.

In terms of organisational procedures and practices:

1) An effective and sustainable in-service training programme is vital to avoid teachers missing training (e.g, the Nguzu Nguzu training workshops or any related future training).

2) There should be a strong collaboration between Curriculum Development and the Teacher Training Institution regarding national curriculum innovations (as the case of Nugu Nguzu curriculum) because the teachers being trained are the implementers of the curriculum. It is important that student teachers are able to demonstrate strategies consistent with the latest curriculum resources while on teaching practice.

3) Schools must be resourced to support teaching and learning to avoid skipping mathematical content.

4) Approaches to pedagogy should encompass 'learning by understanding' as well as ‘learning by knowing’

5) Teachers should be supported to ensure their problem solving views about mathematics are able to be reflected in the pedagogical practices and approaches. 
In terms of teacher professional development:

6) A survey should be undertaken by education authorities to ascertain teacher professional learning needs in primary mathematics teaching and learning. Such a survey should include specific content areas, teaching methodologies, and theoretical perspectives (constructivist \& socio-cultural perspectives) that are known to support learning.

Further research into the following would help extend the understanding gained from this study:

7) What are S.I rural-based teachers', pre-service, and secondary teachers' beliefs, knowledge, and practices about numeracy teaching, and learning?

8) What are the causes of disparity of teacher beliefs and actual practices in the Solomon Islands?

9) What are the classroom-based factors that negatively/positively affect the development of children's numeracy in the Solomon Islands?

\subsection{Summary}

The teacher-participants have expressed their beliefs, pedagogical content knowledge, and professional development experiences about mathematics, its teaching, and learning in the Solomon Islands. I hope the findings of this study provide a stimulus in the Solomon Islands education system to look critically at teachers’ beliefs, knowledge, practices, and professional development for numeracy learning. It is hoped that this study may provoke a way forward for achieving better teaching and learning of numeracy, and to work towards 
enhancing the quality of education in general in the Solomon Islands and achieving an increasingly numerate society. 


\section{REFERENCES}

Ackermann, E. (1996). Perspective-Taking and object construction: Two keys to learning. In Y. Kafai \& M. Resnick (Eds.), Constructionism in practice:

Designing, thinking, and learning in a digital world. New Jersey: Lawrence Erlbaum Associates, Publishers.

Ajzen, I., \& Fishbein, M. (1980). Understanding attitudes and predicting social behaviour. Englewood Cliffs, NJ: Prentice-Hall.

An, S., Kulm, G., \& Wu, Z. (2004). The pedagogical content knowledge of middle school, mathematics teachers in China and the U.S. Journal of Mathematics Teacher Education, 17, 145-172.

An, S., Kulm, G., Wu, Z., Ma, F. \& Wang, L. (October, 2002). A comparative study of mathematics teachers' beliefs and their impact on the teaching practice between the U.S and China. Invited paper presented at the International Conference on Mathematics Instruction, Hong Kong.

Anderson, G., \& Arsenault, N. (2002). Fundamentals of educational research ( $2^{\text {nd }}$ ed.). London: RoutledgeFalmer.

Anthony, G., \& Walshaw, M. (2007). Effective pedagogy in mathematics/Pangarau: Best evidence synthesis iteration. Wellington: Ministry of Education.

Askew, M., Brown, M., Rhodes, V., Wiliam, D., \& Johnson, D. (1997a). Effective teachers of numeracy: Final report. London: Kings College.

Askew, M., Brown, M., Rhodes, V., Wiliam, D., \& Johnson, D. (1997b). The contribution of professional development to effectiveness in the teaching of numeracy. Teacher Education, 1(3), 335-356.

Averill, R., Anderson, D., Easton, H., Te Maro, P., Smith, D., \& Hynds, A. (2009). Culturally responsive teaching of mathematics: Three models from linked studies. Journal for Research in Mathematics Education, 40(2), 157-186.

Averill, R., Maro, P. T., Taiwhati, M., \& Anderson, D. (2009). Culturally responsive mathematics teaching: A bicultural model. In R. Averill \& R. Harvey (Eds.), Teaching secondary school mathematics and statistics: Evidence-based practice (Vol. 2, pp. 2746). Wellington: NZCER PRESS.

Bakalevu, S. (1999). The language factor in mathematics education. Directions: Journal of Educational Studies, 21(2), 59-68. 
Bakalevu, S. (2009). Engendering culturally responsive teaching. In K. Sanga \& K. H. Thaman (Eds.), Re-thinking Education Curriculum in the Pacific: Challenges and Prospects. Wellington: He Parekereke Institute for Research and Development in Maori and Pacific Education, Victoria University.

Ball, D. L., Thames, M. H., \& Phelps, G. (2008). Content knowledge for teaching: What makes it special? Journal of Teacher Education, 59(5), 389-407.

Banks, J. A. (2001). Approaches to multicultural curriculum reform. In J. A. Banks \& C. A. M. Banks (Eds.), Multicultural education: Issues \& perspectives (4th ed., pp. 225-246). New York: John Wiley \& Sons.

Barkatsas-Tasos, A., \& Malone, J. (2005). A typology of mathematics teachers' beliefs about teaching and learning mathematics and instructional practices. Mathematics Education Research Journal, 17(2), 69-90.

Barry, B., Booker, G., Perry, B., \& Siemon, D. (n.d.). HBJ mathematics. Sydney: Harcourt Brace Jovanich Publisher.

Benson, C. (1993). Curriculum development and teacher education. In C. Benson (Ed.), Pacific curriculum network (Vol. 2, pp. 21-22). Suva: Department of Education and Psychology and the Institute of Education, the University of the South Pacific.

Beswick, K. (2005). The beliefs/practice connection in broadly defined contexts. Mathematics Education Research Journal, 17(2), 39-68.

Beswick, K. (2006). The importance of mathematics teachers' beliefs. The Australian Mathematics Teacher, 62(4), 17-22.

Bliss, J., Askew, M., \& Macrae, S. (1996). Effective teaching and learning: Scaffolding revisited. Oxford Review of Education, 22(1), 37-61.

Bogdan, R., \& Biklen, S. (1992). Qualitative research for education. Boston: Allyn and Bacon.

Bogdan, R., \& Taylor, S. J. (1975). Introduction to qualitative research methods. New York: A Wiley-Interscience Publication.

Borko, H., \& Putnam, R. (1996). Learning to teach. In R. Calfee \& D. Berliner (Eds.), Handbook of educational psychology (pp. 673-708). New York: Macmillan.

Boz, N. (2008). Turkish pre-service mathematics teachers' beliefs about mathematics teaching. Australian Journal of Teacher Education, 33(5), 66-80.

Burton, L. (1993). The constructivist classroom. Perth: Mathematics, Science \& Technology Centre, Edith Cowan University. 
Cai, J., Perry, B., Wong, N.Y., \& Wang, T. (2009). What is effective teaching? In J. Cai, G. Kaiser, B. Perry \& N.-Y. Wong (Eds.), Effective mathematics teaching from teachers' perspectives: National and cross-national studies (pp. 1-36). Rotterdam: Sense Publishers.

Catherwood, V. (2007). Solomon Islands National Education Action Plan 2007-2009. Wellington: Vince Catherwood \& Associates Ltd.

Clarkson, P. C. (1998). Mathematics and language: Culture and Implementation. Directions: Journal of Educational Studies, 20(1), 58-73.

Cobb, P. (2005). Where is the mind? A coordination of sociocultural and cognitive constructivist perspective. In C. T. Fosnot (Ed.), Constructivism: Theory, perspectives, and practice (2nd ed.). New York: Teachers College Press.

Cohen, L., Manion, L., \& Morrison, K. (2000). Research methods in education. (5 ${ }^{\text {th }}$ ed.). London: Routledge.

Cooney, T. J. (1985). A beginning teacher's view of problem solving. Journal for Research in Mathematics Education, 16(5), 324-326.

Cooney, T. J., \& Shealy, B. E. (1997). On understanding the structure of teachers' beliefs and their relationship to change. In E. Fennema \& B. Nelson (Eds.), Mathematics teachers in transmission (pp. 87-109). Mahwah, N.J.: Lawrence Erlbaum

Creswell, J. W. (1994). Research design: Qualitative \& quantitative approaches. London: SAGE Publications.

Creswell, J. W. (1998). Qualitative inquiry and research design: Choosing among five traditions. Thousand Oaks: SAGE Publications.

Cummings, J. A. (2005). Foreword. In R. Brown-Chidsey (Ed.), Assessment for intervention: A problem-solving approach (pp. xi-xiv). New York: The Guilford Press.

Curriculum Development Centre. (2005). Nguzu Nguzu Mathematics Teacher’s Guide. Standard 5, Book 1. Honiara: The Curriculum Development Centre, Ministry of Education and Human Recourses Development.

Denzin, N. K., \& Lincoln, Y. S. (1995). The handbook of qualitative research. London: SAGE Publications.

Denzin, N. K., \& Lincoln, Y. S. (2005). Introduction: The discipline and practice of qualitative research. In N. K. Denzin \& Y. S. Lincoln (Eds.), The Sage handbook of qualitative research (3rd ed.). Thousand Oaks: SAGE Publications.

Dougiamas, M. (1998). A journey into constructivism. Retrieved July 1, 2008, from htt://go.webassistant.com 
Earl, L. (2007). Forewords. In H. Timperley, A. Wilson, H. Barrar \& I. Fung (Eds.), Teacher professional learning and development: Best evidence synthesis iteration (pp. vii-ix). Wellington: Ministry of Education.

Education Act. (1978). The statues of the Solomon Islands, No. 26.

Education Queensland, Queensland Catholic Education Commission (QCEC) \& Association of Independent School of Queensland (AISQ). (2004). Teachers enhancing numeracy. Retrieved February 11, 2009, from http://www.dest.gov.au

Edward, D, \& Mercer, N. (1987). Common knowledge. The development of understanding in the classroom. London: Methuen.

EFA Global Monitoring Report. (2006). Summary: Literacy for life. Paris: UNESCO.

Elbaz, F. (1983). Teacher thinking: A study of practical knowledge. London: Croom Helm.

Elley, W. (2001). Examinations and assessment in the Solomon Islands. Draft Report. Honiara: NESU, July.

Ernest, P. (1989). The impact of beliefs on the teaching of mathematics. In P. Ernest (Ed.), Mathematics teaching: The state of art (pp. 249-254). New York: The Falmer Press.

Even, R., \& Tirosh, D. (1995). Subject-matter knowledge and knowledge about students as sources of teacher presentations of the subject-matter. Educational Studies in Mathematics, 29, 1-20.

Fang, Z. (1996). A review of research on teacher beliefs and practices. Educational Research, 38(1), 47-65.

Fosnot, C. T. (Ed.). (2005). Constructivism: Theory, perspectives, and practice (2nd ed.). New York: Teachers College Press.

Fosnot, C. T., \& Dolk, M. (2005). "Mathematics” or mathematizing”?. In C. T. Fosnot (Ed.), Constructivism: Theory, perspectives, and practice (2nd ed.). New York: Teachers College Press.

Fosnot, C. T., \& Perry, R. S. (2005). Constructivism: A psychological theory of learning. In C. T. Fosnot (Ed.), Constructivism: Theory, perspectives, and practice (2nd ed.). New York: Teachers College Press.

Green, T. F. (1971). The activities of teaching. New York: McGraw-Hall.

Groves, S., Mosley, J., \& Forgasz, H. (2004). Primary numeracy: A review of Australian research. Australian Primary Mathematics Classroom, 9(4), 10-13.

Guskey, T. R. (1986). Staff development and the process of teacher change. Educational Researcher, 15(5), 5-12. 
Hall, C. (2007). Evaluation as a method of educational enquiry. Wellington: Victoria University of Wellington, School of Education (class handout).

Hattie, J. (2002). "What are the attributes of excellent teachers?” In B. Webber (ed.), Teachers make a difference: what is the research evidence? (Proceedings of the New Zealand Association of Research in Education conference), pp. 3-26. Wellington: NZARE.

Hawley, W. D., \& Valli, L. (1999). The essentials of effective professional development. In L. Darling-Hammond \& G. Sykes (Eds.), Teaching as the learning profession (pp. 127-150). San Francisco: Jossey-Bass.

Haylock, D., \& Thangata, F. (2007). Key concepts in teaching primary mathematics. Los Angeles: SAGE Publications.

Hess-Biber, S. N., \& Leavy, P. (2006). The practice of qualitative research. Thousand Oaks: Sage Publications.

Hoyles, C. (1992). Mathematics teaching and mathematics teachers: A meta-case study. For the Learning of Mathematics, 12(3), 32-44.

Katzer, J., Cook, K. H., \& Crouch, W. W. (1998). Evaluating information: A guide for users of social science research ( $4^{\text {th }}$ ed.).New York: McGraw Hill.

Kuhs, T. M., \& Ball, D. L. (1986). Approaches to teaching mathematics: Mapping the domains of knowledge, skills and dispositions. East Lansing, MI: Center on Teacher Education, Michigan State University.

Kyriacou, C. (2005). The impact of daily mathematics lessons in England on pupil confidence and competence in early mathematics: A systematic review. British Journal of Educational Studies, 53(2), 168-186.

Lancy, D. F. (2001). Studying children and schools: Qualitative research traditions. Illinois: Waveland Press, Inc.

Liebeck, P. (1990). How children learn mathematics. London: Penguin Group.

Malasa, D. P. (2007). Effective school leadership: An exploration of issues inhibiting the effectiveness of school leadership in Solomon Islands' secondary school. Unpublished master's thesis, University of Waikato, Hamilton.

Marau, D. (2007, November 23). Solomon Islands faces literacy crisis. Solomon Star.

Matang, R. (1998). The role of ethnomathematics and reflective learning in mathematics education in Papua New Guinea. Directions: Journal of Educational Studies, 20(2), 22-29. 
McChesney, J. (2009). How do students learn maths? Theorising about learning. In R. Averill \& R. Harvey (Eds.), Teaching secondary school mathematics and statistics: Evidence-based practice (Vol. 1, pp. 67-78). Wellington: NZCER PRESS.

McDonough, A., \& Clarke, D. (2003). Describing the practice of effective teachers of mathematics in the early years. Paper presented at the Proceedings of the 27th Conference of the International Group for the Psychology of Mathematics Education held jointly with the $25^{\text {th }}$ PME-NA conference, Honolulu, Hawaii. (ED501025).

McMillan, J. H. (2008). Educational research: Fundamentals for the consumer (5th ed.). Boston: Pearson Education Inc.

MEHRD (Ministry of Education and Human Recourses Development) (S.I). (2007). Education Strategic Framework 2007-2015. Honiara: Author.

Mertens, D. M. (2005). Research methods in education and psychology: Intergrading diversity with quantitative \& qualitative approaches (2nd ed.). London: SAGE Publications.

Ministry of Education (S.I). (2001). Primary mathematics syllabus: standards one to six. Honiara: Curriculum Development Centre.

National Examination and Standards Unit (S.I). (2007). Annual report. Honiara: Author.

Nickson, M. (1989). What is multicultural mathematics? In P. Ernest (Ed.), Mathematics teaching: The state of art (pp. 236-240). New York: The Falmer Press.

Nickson, M. (2004). Teaching and learning mathematics: A guide to recent research and its applications. London: Continuum.

Ninnes, P. (1992). Solomon Islands students' perceptions of appropriate behaviours for success in schooling. Retrieved May 28, 2009, from http://www.directions.usp.ac

Nisbet, S., \& Warren, E. (2000). Primary school teachers' beliefs relating to mathematics, teaching and assessing mathematics and factors that influence these beliefs. Mathematics Teacher Education and Development, 2, 34-47.

Pehkonen, E., \& Pietila, A. (2003, 28 February - 3 March). On relationships between beliefs and knowledge in mathematics education. Paper presented at the Proceedings of the Third Conference of the European Society for Research in Mathematics Education, Bellaria, Italia.

Pajares, M. F. (1992). Teachers’ beliefs and educational research: Cleaning up a messy construct. Review of Educational Research, 62(3), 307-332.

Patton, M. Q. (1987). How to use qualitative methods in evaluation. London: Sage Publications. 
Phillips, G. W. (2007). Chance favors the prepared mind: Mathematics and science indicators for comparing states and nations. Washington DC: American Institute for Research.

Powell, M. A., \& Smith, A. B. (2006). Ethical guidelines for research with children: A review of current research ethnics documentation in New Zealand, from http://www.rsnz.org.helicon.vuw.ac.nz

Puamau, P. (2007). A literate and numerate society: introducing the book. In P. Puamua \& F. Pene (Eds.), The basics of learning: Literacy and numeracy in the Pacific (pp. xivxxii). Suva: Institute of Education University of the South Pacific.

Putnam, R. (1992). Teaching mathematics for understanding: Discussing case studies fo four fifth-grade teachers. Elementary School Journal, 93(2), 213-228.

Raymond, A. M. (1997). Inconsistency between a beginning elementary school teacher's mathematics beliefs and teaching practice. Journal for Research in Mathematics Education, 28(5), 550-576.

Reid, G. (2005). Learning styles and inclusion. London: Paul Chapman Publishing.

Sanga, K. (2009). Curriculum as process: Essential phases and features of Ausae pedagogy. In K. Sanga \& K. H. Thaman (Eds.), Re-thinking education curricula in the Pacific: Challenges and prospects. Wellington: He Parekereke Institute for Research and Development in Maori and Pacific Education, Victoria University.

Sanga, K., \& Thaman, K. H. (Eds.). (2009). Re-thinking education curricula in the Pacific: Challenges and prospects. Wellington: He Parekereke Institute for Research and Development in Maori and Pacific Education, Victoria University.

Sanders, A. G. (1989). Kamasu perceptions of learning: traditional training and formal schooling. Papua New Guinea Journal of Education, 25(2), 29-39.

Shield, M. (1999). The conflict between teachers' beliefs and classroom practices. In J.M. Truran \& K.M. Truran (Eds.), Making the difference: Proceedings of the $22^{\text {nd }}$ Annual Conference of the Mathematics Education Research Group of Australasia (pp. 439445). Adelaide: MERGA.

Shulman, L. (1985). On teaching problem solving and solving the problems of teaching. In E. Silver (Ed.), Teaching and learning mathematical problem solving: Multiple research perspectives (pp. 439-450). Hillsdale, NJ: Lawrence Erlbaum Associates.

Shulman, L. S. (1986). 'Those who understand: Knowledge growth in teaching’. Educational Researcher, 15(2), 4-14.

Shulman, L. (1987). Knowledge and teaching: Foundation of the new reform. Harvard Educational Review, 57(1), 1-22. 
Sikua, D. D. (2002). The decentralisation of education in a developing country: A case of community high schools in the Solomon Islands. Unpublished doctorial thesis, University of Waikato, Hamilton.

SISTA 1 Report. (2006). Setting literacy and numeracy baseline standards in the Solomon Islands: A report on the monitoring of literacy and numeracy achievements at the end of year 4. Suva: South Pacific Board for Educational Assessment.

SISTA 2 Report. (2007). Setting literacy and numeracy baseline standards in the Solomon Islands: A report on the monitoring of literacy and numeracy achievements at the end of year 6. Suva: South Pacific Board for Educational Assessment.

Smith, J. A., \& Osborn, M. (2008). Interpretative phenomenological analysis. In J. A. Smith (Ed.), Qualitative psychology: A practical guide to research methods (2nd ed.). Los Angeles: SAGE Publications.

Smith, R. W. (2001). Professional development organisation and primary mathematics teachers: Exploring connections with beliefs and practice. Unpublished doctorial thesis, Monash University, Melbourne.

Solomon Islands Government, MEHRD. (2005). Digest of education statistics. Honiara: Planning, Research and Co-ordination Unit, MEHRD.

Solomon Islands National Statistics Office. (2006). Census and surveys. Honiara: National Statistics Office.

Son, J. W. (2006). Investigating preservice teachers' understanding and strategies on a student's errors of reflective symmetry. Paper presented at the proceedings of the 30th Conference of the International Group for the Psychology of Mathematics Education, Charles University, Prague.

Stipek, D. J., Givvin, K. B., Salmon, J. M., \& MacGyvers, V. L. (2001). Teachers’ beliefs and practices related to mathematics instruction. Teaching and Teacher Education, 17, 213-226.

Stylianides, A. J., \& Stlianides, G. J. (2006). Content knowledge for mathematics teaching: The case of reasoning and proving. Paper presented at the proceedings of the 30th Conference of the International Group for the Psychology of Mathematics Education, Charles University, Prague.

Sylva, K., \& Lunt, I. (1992). The school years: learning. In their Child development: a first course. Oxford: Blackwell.

Thaman, K. H. (1992, June 8). Looking towards the source: a consideration of cultural context in teacher education. Address given at the Institute of Education/School of Humanities Forward Planning Meeting, University of the South Pacific, Suva. 
Thaman, K. H. (2002). Towards cultural democracy in Pacific education: An imperative for the 21st century. In F. Pene, A. M. Taufe'ulungaki \& C. Benson (Eds.), Tree of opportunity: Re-thinking Pacific education (pp. 22-30). Suva: The University of the South Pacific, Institute of Education.

Thaman, K. H. (2009). Introduction: The need to re-think Pacific curriculum. In K. Sanga \& K. H. Thaman (Eds.), Re-thinking education curriculum in the Pacific: Challenges and prospects. Wellington: He Parekereke Institute for Research and Development in Maori and Pacific Education, Victoria University.

The Profiling High Numeracy Achievement Project Team. (2004). Profiling high numeracy achievement. Australian Primary Mathematics Classroom, 9(4), 35-38.

Thompson, A. G. (1992). Teachers' beliefs and conceptions: A synthesis of the research. In D.A. Grouws (Ed.), Handbook of research on mathematics teaching and learning (pp. 127-146). New York: MacMillan.

Timperley, H., Wilson, A., Barrar, H., \& Fung, I. (2007). Teacher professional learning and development: Best evidence synthesis iteration. Wellington: Ministry of Education.

Treadaway, J. (2003, September 23-25). Education for what? revisited. Paper presented at the SICHE conference, Panatina, Honiara, S.I.

Vine, K., \& Ordonez, V. (2000). A Synthesis Report of Education for All 2000 Assessment for the Asia-Pacific Region. Bangkok: UNESCO

Walani, D. N. (2009). An investigation into classroom teachers' perceptions of the value of assessment for formative purposes in secondary school in Solomon Islands. Unpublished master's thesis, University of Waikato, Hamilton.

Walliman, N. (2001). Your research project: a step-by-step guide for the first-time researcher. London: SAGE Publications.

Walls, F. (2003). Sociomathematical worlds: The social world of children's mathematical learning in the middle primary years. Unpublished doctorial thesis, Victoria University of Wellington, Wellington.

Willig, C. (2003). Introducing qualitative research in psychology. Buckingham: Open University Press

Willis, S. (1998). Which numeracy? Unicorn, 24(2), 32-42.

Wilson, M. S., \& Cooney, T. J. (2002). Mathematics teacher change and development. In G. C. Leder, E. Pehkonen \& G. Torner (Eds.), Beliefs: A hidden variable in mathematics education (pp. 127-147). Dordrecht: Kluwer. 
Windschitl, M. (2002). Framing constructivism in practice as the negotiation of dilemmas: An analysis of the conceptual, pedagogical, cultural, and political challenges facing teachers. Review of Educational Research, 72(2), 131-175.

Wink, J., \& Putney, L. (2002). A vision of Vygotsky. Boston: Allyn and Bacon.

Withers, G. (1992). Pacific Islands Literacy Levels. Suva: SPBEA.

Wolcott, H. F. (1994). Transforming qualitative data: Descriptive, analysis and interpretation. London: SAGE Publications. 


\section{APPENDICES}

\section{Appendix 1: Ethics Approval}

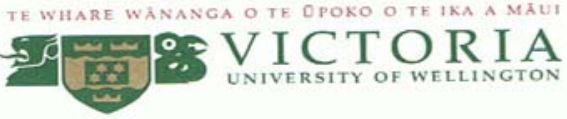

$8^{\text {th }}$ July 2009

Adrian Alamu

Master of Education Student - EDUC588

Victoria University of Wellington Faculty of Education

$\mathrm{C} /$ - School of Education Policy and Implementation

Donald Street

Wellington

Dear Adrian

\section{RE: Ethics application SEPI/2009/31: RM 16663}

I am pleased to advise you that your ethics application 'MEd EDUC588 -Teacher's beliefs, pedagogical content knowledge, and reported practices regarding numeracy teaching in the Solomon Islands' with the requested amendments, has been approved by the Victoria University of Wellington Faculty of Education Ethics Committee. Please note that the approval for your research to commence is from the date of this letter.

Good luck with your research.

Yours Sincerely

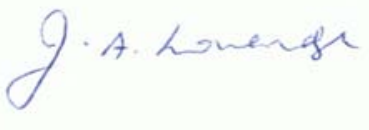

Dr Judith Loveridge

Co-Convener

Victoria University of Wellington Faculty of Education Ethics Committee 


\section{THE RESEARCH ACT 1982 \\ (No. 9 of 1982)}

\section{RESEARCH PERMIT}

Permission is hereby given to:

1. Name: Adrian Alamu

2. Country: Solomon Islands

3. To undertake research in (subjects): Exploring Primary Teachers' beliefs, knowledge, and practices regarding numeracy outcomes in the Solomon Islands.

4. Ward(s): Honiara

5. Province(s):

6. Conditions:

a. To undertake research only in the subject areas specified in 3 above.

b. To undertake research only in the ward(s) and Province(s) specified in 4 and 5 above.

c. To observe with respect at all times local customs and the way of life of people in the area in which the research work is carried out.

d. You must not, at any time, take part in any political or missionary activities or local disputes.

e. You must leave 4 copies of your final research report in English with the Solomon Islands Government Ministry responsible for research at your own expense.

f. A research fee of $S B D 300.00$ and deposit sum of $S B D 200.00$ must be paid in full or the Research Permit will be cancelled. (See sec. 3 Subject. 7 of the Research Act).

g. This permit is valid until $\underline{31 / 07 / 09}$ provided all conditions are adhered to.

$\mathrm{h}$. No live species of plants and animals may be taken out of the country without approval from relevant authorities.

i. A failure to observe the above conditions will result in automatic cancellation of this permit and the forfeit of your deposit.
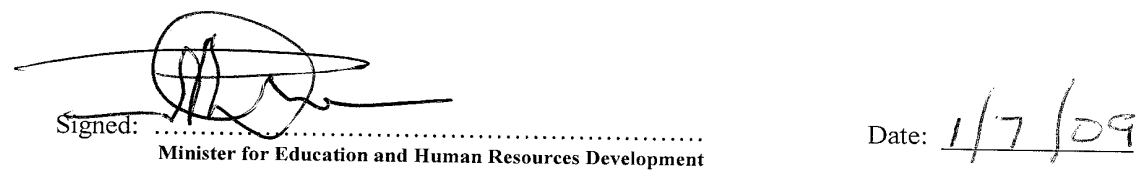


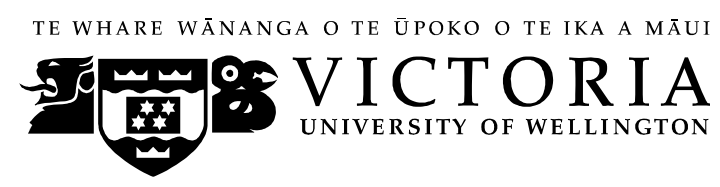

\section{PARTICIPANTS’ INFORMATION SHEET AND CONSENT FORM}

Teacher Beliefs, Pedagogical Content Knowledge, and Reported Practices regarding Numeracy teaching in the Solomon Islands

Dear Sir/Madam,

I am a Solomon Islander studying at Victoria University of Wellington, New Zealand. As part of my study towards a Master's Degree in Education, I wish to do research in areas of teaching and learning mathematics/numeracy and would like to invite Years 4 to Year 6 primary school teachers to participate in a one-on-one interview. Teachers have the right to accept or decline the invitation. This research has been assessed and approved by Victoria University College of Education Ethics Committee.

The purpose of my study is to explore teachers' beliefs, knowledge, and practices regarding numeracy outcomes. The outcome of this study will not only fulfil my purpose for qualification but is likely to provide vital information for the educators in areas such as policy direction, planning and designing appropriate professional learning needs for the teachers. It will also add to the subject literature on the context of the Solomon Islands teaching and learning mathematics/numeracy.

The primary data collection method for this research project is by interview. Since teachers will be involved, it is a requirement of Victoria University that due consideration to ethical principles and standards are adhered to. Therefore consent is sought for your participation in this study. Your participation includes that: your name/identity or personal background information provided will be treated as confidential and anonymous; your responses will be collected as aggregated data and could be used for quotation or reported as narratives. you have the right not to answer any interview questions; you have the right to verify or check the interview notes; you have a right to ask me for feedback on the results; you have the right to withdraw from the study up until the data analysis and if you choose to withdraw, any data collected from you will not be used in the study. The interview data gathered will be solely use for study purposes and will be safely stored in my personal external computer drive. At the conclusion of the study all interview data and interview materials will be destroyed.

The final results of this study will be published as thesis and can be accessed at the following places. This includes deposits of the thesis at the libraries of Victoria University 
of Wellington, University of the South Pacific campus, Honiara, and Ministry of Education, Honiara or through academic journals.

If you agree to this request I would appreciate it very much if you would sign and date the consent form attached. I would be most happy to conduct this interview at a time that suits you the best.

I am happy to answer any further queries regarding this proposed research project or my supervisors can be contacted should you need additional clarifications at the following addresses.

Robin Averill: School of Education Policy and Implementation, Victoria University of Wellington, New Zealand

Email: Robin.Averill@vuw.ac.nz

ph: (644) 4639714

Roger Harvey: School of Education Policy and Implementation, Victoria University of Wellington, New Zealand

Email: roger.harvey@vuw.ac.nz

ph: (644) 4639673

Thank you.

Yours faithfully,

Adrian Alamu (Researcher)

School of Education Policy and Implementation, Victoria University of Wellington, PO Box 17310, Karori, Wellington, New Zealand

Email: adrianalamu@gmail.com 


\section{Appendix 4: Participants' Consent Form}

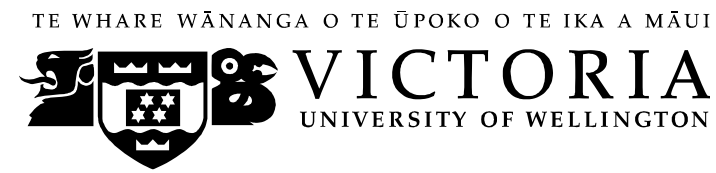

\section{INTERVIEWEE'S CONSENT FORM}

\section{One-on-one interview}

Teacher Beliefs, Pedagogical Content Knowledge, and Reported Practices regarding Numeracy teaching in the Solomon Islands

\section{Consent to participate in the research}

I understand that the study will involve my contribution as providing accurate information based on my beliefs, knowledge, practices and experience regarding teaching mathematics/numeracy.

Furthermore, I understand that:

I have been given sufficient information and have understood the purpose of the research project.

My name/identity or personal background information would be treated as confidential and anonymous.

My interview responses will be collected as aggregated data and could be used for quotations or reported as narratives.

I have the right not to answer any interview questions.

I have the right to check or verify my interview transcriptions.

I have the right to ask for feedback on the results.

I have the right to withdraw from the study.

The data collected will be solely use for study purposes.

The data collected will be safely stored and all interview data and interview materials will destroyed at the conclusion of the study.

I agree to participate in this research project.

Name:

Signature:

Date: 


\begin{tabular}{|c|c|}
\hline $\begin{array}{l}\text { A vital task for the teacher is motivating } \\
\text { children to solve their own } \\
\text { mathematical problems }\end{array}$ & $\begin{array}{l}\text { It is important for children to be given } \\
\text { opportunities to reflect on and evaluate } \\
\text { their own mathematical understanding }\end{array}$ \\
\hline $\begin{array}{l}\text { Ignoring the mathematical ideas that } \\
\text { children generate themselves can } \\
\text { seriously limit their learning }\end{array}$ & $\begin{array}{l}\text { Effective mathematics teachers enjoy } \\
\text { learning and 'doing' mathematics } \\
\text { themselves }\end{array}$ \\
\hline $\begin{array}{l}\text { Providing children with interesting } \\
\text { problems to investigate in small groups } \\
\text { is an effective way to teach mathematics }\end{array}$ & $\begin{array}{l}\text { Teachers of mathematics should be } \\
\text { fascinated with how children think and } \\
\text { intrigued by alternative ideas }\end{array}$ \\
\hline $\begin{array}{l}\text { Allowing a child to struggle with a } \\
\text { mathematical problem, even a little } \\
\text { tension, can be necessary for learning to } \\
\text { occur }\end{array}$ & $\begin{array}{l}\text { Children always benefit by discussing } \\
\text { their solutions to mathematical problems } \\
\text { with each other }\end{array}$ \\
\hline $\begin{array}{c}\text { Teachers can create, for all children, a } \\
\text { non-threatening environment for } \\
\text { learning mathematics }\end{array}$ & $\begin{array}{l}\text { Children need to link and experience } \\
\text { mathematics in a context }\end{array}$ \\
\hline $\begin{array}{l}\text { I would feel uncomfortable if a child } \\
\text { suggested a solution to a mathematical } \\
\text { problem that I hadn't thought of } \\
\text { previously }\end{array}$ & $\begin{array}{l}\text { It is not necessary for teachers to } \\
\text { understand the source of children's } \\
\text { errors: follow up instruction will correct } \\
\text { their difficulties }\end{array}$ \\
\hline $\begin{array}{l}\text { Listening carefully to the teacher } \\
\text { explain a mathematics lesson is the most } \\
\text { effective way to learn mathematics }\end{array}$ & $\begin{array}{l}\text { It is important to cover all the topics in } \\
\text { the mathematics curriculum }\end{array}$ \\
\hline $\begin{array}{l}\text { If a child's explanation of a } \\
\text { mathematical solution doesn't make } \\
\text { sense to the teacher it is best to ignore it }\end{array}$ & $\begin{array}{l}\text { Telling the children the answer is an } \\
\text { efficient way of facilitating their } \\
\text { mathematics learning }\end{array}$ \\
\hline
\end{tabular}

Shaded Belief Cards: reflect the traditional-transmission orientation; Non-shaded: reflects the constructivist in nature 


\section{INTERVIEW INFORMATION}

Teacher Beliefs, Knowledge, and Practices regarding

Numeracy teaching in the Solomon Islands

\section{Interviewer: Adrian Alamu: Postgraduate student, Victoria University of Wellington, New Zealand}

Interviewee (Code):

Please note that your responses will be solely used for the study purposes. You will remain anonymous and non traceable. Information provided will be kept confidential and discarded upon the completion of the study. You also have the right to withdraw from participating in or answering any interview questions

Thank you for your willingness and time

\section{SECTION 1: Background Information}

Date:

Location:

School:

Qualification:
Time :

Gender:

Grade/Class/Year

Experience:

(Years) 


\section{PART ONE: DISPLAY OF BELIEF CARDS}

The participant will be asked to pick belief cards that best describe his/her beliefs. Then the participant will be asked to explain the belief cards he/she has picked. Probing questions will be followed to further elicit beliefs regarding teaching and learning mathematics.

PART TWO: OPEN-END QUESTIONS

1) Describe how do you feel about teaching mathematics?

Probing: enjoy/interest/difficult, and why

2) How do you describe your primary role in teaching and learning of mathematics? Prompts: your role as a teacher in general

3) How do you monitor your students’ progress in learning mathematics?

Probing: identify pupils' at risk

How do you know that learning occurs/taking place

\section{SECTION 3: $\quad$ Pedagogical Content Knowledge}

\section{Knowledge of Content}

4) Is there any particular strand or topic in the mathematics curriculum that is quite difficult to understand or difficult to teach? Explain why.

Probing: subject content knowledge; difficult to teach, topic preferences or pupils finding it a bit abstract.

\section{Knowledge of Curriculum}

5) Are there challenges and limitations when it comes to selecting your materials to teach?

Are curriculum goals and objectives clear to you? You understand the prescribed curricula. Supporting materials, resources 


\section{Knowledge of Teaching}

6) Can you describe the best lesson you have given this year? And please explain why?

7) Have you used any teaching styles/strategies or approaches? If yes/no, please describe.

Probing: learning theories during training

8) Is there any particular teaching method your students enjoyed/like the most? Pupils learning preferences - lead on to identify learning styles

Pupils' learning strategies or tactics of learning

Styles vs strategies

\section{SECTION 4: $\quad$ Professional Development Experiences}

9) Have you attended any professional development activities for maths teaching? If yes, in what areas, and how would you describe the professional development activities?

Probing: The important things that you learned or gained, and did you manage to apply what you learned or are there challenges you faced in implementing?

10) Please indicate what professional development support you would like to support your mathematics teaching.

Probing: When, how often

Is there anything else you wish to tell me or add on from what we have covered so far or that I didn't ask you about? If not then in your experience and observation what would be some key factors you believe affecting numeracy. 